International Scientific-Technical and Production Journal

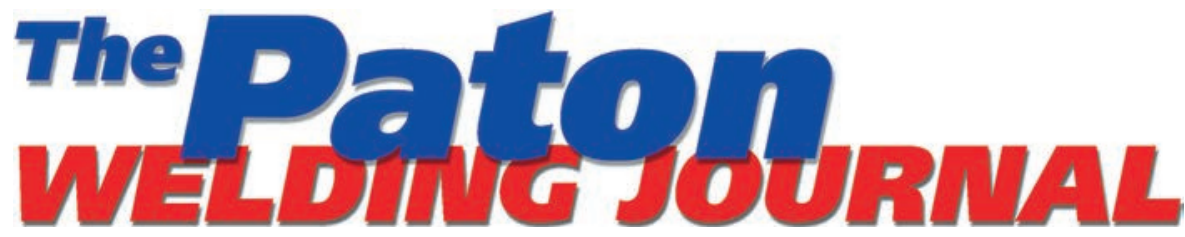

\section{EDITORIAL BOARD \\ Editor-in-Chief B.E. Paton}

Scientists of PWI, Kyiv S.I. Kuchuk-Yatsenko (vice-chief ed.), V.N. Lipodaev (vice-chief ed.)

Yu.S. Borisov, G.M. Grigorenko A.T. Zelnichenko, V.V. Knysh,

I.V. Krivtsun, Yu.N. Lankin, L.M. Lobanov, V.D. Poznyakov, I.A. Ryabtsev, K.A. Yushchenko

Scientists of Ukrainian Universities V.V. Dmitrik, NTU «KhPI», Kharkov V.V. Kvasnitsky, NTUU «KPI», Kyiv E.P. Chvertko, NTUU «KPI», Kyiv

Foreign Scientists

N.P. Alyoshin

N.E. Bauman MSTU, Moscow, Russia Guan Qiao

Beijing Aeronautical Institute, China M. Zinigrad

Ariel University, Israel V.I. Lysak

Volgograd STU, Russia Ya. Pilarczyk

Welding Institute, Gliwice, Poland U. Reisgen

Welding and Joining Institute, Aachen, Germany G.A. Turichin

St. Petersburg SPU, Russia

Founders

E.O. Paton Electric Welding Institute, NASU

International Association «Welding» Publisher

International Association «Welding» Translators

A.A. Fomin, O.S. Kurochko, I.N. Kutianova Editor

N.G. Khomenko

Electron galley

D.I. Sereda, T.Yu. Snegiryova Address

E.O. Paton Electric Welding Institute, International Association «Welding» 11 Kazimir Malevich Str. (former Bozhenko Str.), 03150, Kyiv, Ukraine

Tel.: (38044) 20060 16, 2008277

Fax: (38044) 20082 77, 2008145

E-mail: journal@paton.kiev.ua

www.patonpublishinghouse.com

State Registration Certificate

KV 4790 of 09.01 .2001

ISSN 0957-798X

DOI: http://dx.doi.org/10.15407/tpwj Subscriptions

$\$ 384,12$ issues per year

air postage and packaging included. Back issues available.

All rights reserved.

This publication and each of the articles contained herein are protected by copyright

Permission to reproduce material contained in this

journal must be obtained in writing from the Publisher.

\section{CONTENTS}

\section{SCIENTIFIC AND TECHNICAL}

Nesterenkov V.M., Matviichuk V.A., Rusynik M.O., Yanko T.B. and

Dmitrenko A.E. Microstructure of VT20 titanium alloys produced by the method of layer-by-layer electron beam fusion using domestic powder materials

Makhnenko O.V., Kostin V.A., Zhukov V.V. and Kostenevich E.S.

Effect of cooling cycle of welding on structure-phase composition of 15Kh2NMFA steel

Zhang YP, Dong CL, Wang YQ, Hou B, Yu C, Fang WP and Xu WH.

High cycle fatigue property of electron beam welded thick section of

Ti-6Al-4V plates

Borisov Yu.S., Borisova A.L., Tsymbalista T.V., Kaporik N.I. and

Vasilkovskaya M.A. Heat-resistant thermal sprayed coatings based

on FeAICr intermetallide with $\mathrm{CeO}_{2}$ additives

Peremitko V.V., Kolomoets I.V. and Sukhomlin V.I. Effect of preliminary application of alloying powders on the structure and hardness of

deposited metal

\section{INDUSTRIAL}

Mazur A.A., Makovetskaya O.K., Pustovojt S.V. and Petruk V.S.

Economic and statistical review of the world and regional markets of welding materials

Moltasov A.V. and Klochkov I.N. Calculation of the radius of transition of the weld to base metal of aluminium alloy welded joints

Kuskov Yu.M., Biktagirov F.K. and Fesenko M.A. Effect of tellurium on microstructure of low-alloy cast iron deposited by electroslag method in current-carrying mold

Makhlin N.M. and Buryak V.Yu. Drives of mechanisms of automatic machines for orbital TIG welding of metal pipeline butt joints in NPP power units

CALENDAR OF SEPTEMBER 53 


\title{
MICROSTRUCTURE OF VT20 TITANIUM ALLOYS PRODUCED BY THE METHOD OF LAYER-BY-LAYER ELECTRON BEAM FUSION USING DOMESTIC POWDER MATERIALS
}

\author{
V.M. NESTERENKOV ${ }^{1}$, V.A. MATVIICHUK ${ }^{1}$, M.O. RUSYNIK ${ }^{1}$, T.B. YANKO ${ }^{2}$ and A.E. DMITRENKO ${ }^{3}$ \\ ${ }^{1}$ E.O. Paton Electric Welding Institute of the NAS of Ukraine \\ 11 Kazymyr Malevych Str., 03150, Kyiv, Ukraine. E-mail: office@paton.kiev.ua \\ ${ }^{2} \mathrm{PJSC}$ «Titanium Institute» \\ 180 Soborny Prosp., 69035, Ukraine. E-mail: titanlab3@ukr.net \\ ${ }^{3}$ NSC «Kharkov Institute of Physics and Technology» \\ 1 Akademicheskaya Str., 61108, Kharkov, Ukraine. E-mail: dmitrenko@kipt.kharkov.ua
}

\begin{abstract}
Samples of products of domestic nonspherical powders of VT-20 titanium alloy were produced by the method of electron beam 3D fusion. Microstructure of deposited metal is pore-free, finely dispersed and uniform over the entire surface of the section. It is acicular $\alpha^{\prime}$-phase of titanium with a small content of $\beta$-phase. Sample microhardness is from $H V 3960$ to $H V 4150 \mathrm{MPa}$. Uniform distribution of alloying elements and decreased content of aluminium due to its volatility in deposition was noted. Presence of insignificant porosity and increased roughness on part edges was detected. The methods of their elimination were obtained. 10 Ref., 1 Table, 11 Figures.
\end{abstract}

Ke y w o rds : additive technologies, titanium alloy, electron beam, surfacing, structure, microhardness

Innovative technologies of layer-by-layer manufacturing of products by rapid prototyping open up new possibilities for producing parts of the specified shape and structure with predictable properties. The process of manufacturing products by such a method with application of the electron beam is relatively new, but it has already successfully demonstrated great prospects for its application in industry for producing a wide range of parts and assemblies. It is based on layer-by-layer fusion of metal powder in vacuum by the electron beam. This approach features a rapid transition to manufacturing 3D products directly from the CAD system with the capability of application of a wide range of metals and alloys, including refractory and reactive metals [1].

All the currently available commercial developments belong to foreign companies. Application of prototyping technologies and machines in Ukraine involves their purchasing abroad and subsequent considerable expenses for acquiring the required materials which are a consumable and expensive component of this technology.

However, consumable materials, applied in these units, namely titanium alloy powders, have several disadvantages. These include the mismatch between powder materials composition and a large number of alloys certified for Ukrainian enterprises, as well as absence of domestic commercial technologies for manufacturing them. Thus, there is the problem of im- port substitution and raw material supply for additive manufacturing.

An urgent task is development of units based on electron beam processes with application of domestic powder materials, which will be certified and targeted for introduction in domestic enterprises.

These technologies are highly attractive for manufacturing complex parts, applied in aircraft and turbine construction. In recent years there has been a steady trend for introduction of additive technologies in the leading domestic companies. For domestic machine-building enterprises (SC PA «Yuzhmash», OJSC «Motor Sich», GP SPCG «Zorya»-«Mashproekt», SC LRW «Motor») the problems of manufacturing products with application of powder materials from titanium alloys are urgent, as a large number of gas turbine engine elements are produced from these alloys.

Development of new solutions in titanium powder manufacture should not be ignored, that will allow lowering the cost of raw materials. The developed technology of producing titanium alloy powders by the principle of hydration-dehydration (HDH processes) of a sintered semi-finished product can be regarded as one of such solutions [2].

The problem of producing a product from VT20 titanium alloy with application of additive electron beam technologies by the method of layer-by-layer fusion was solved in this work. 


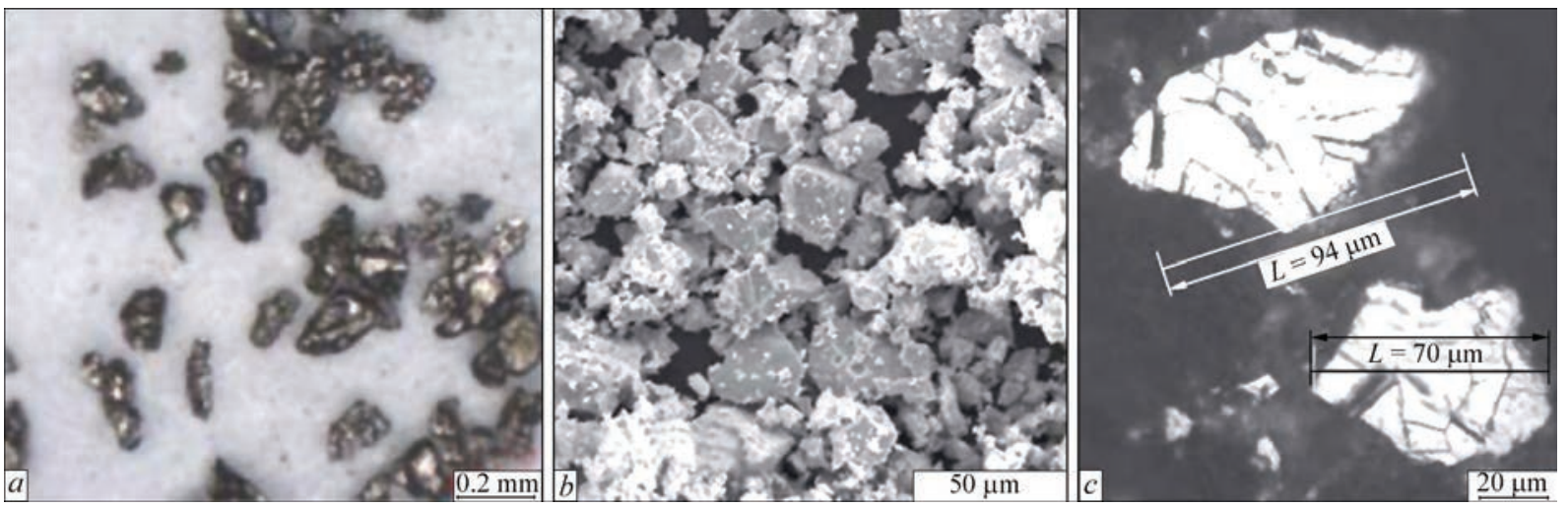

Figure 1. Appearance $(a)$ and microstructure $(b, c)$ of HDH VT20 powders with 60 to $140 \mu \mathrm{m}$ particle size

Chemical composition of used VT20 powder

\begin{tabular}{|c|c|c|c|c|c|c|}
\hline \multicolumn{3}{|c|}{ Alloying element content, not more than, wt.\% } & \multicolumn{3}{c|}{ Impurity content, not more than, wt.\% } \\
\hline $\mathrm{Zr}$ & $\mathrm{Mo}$ & $\mathrm{V}$ & $\mathrm{Al}$ & $\mathrm{N}$ & $\mathrm{H}$ & $\mathrm{O}$ \\
\hline $1.5-2.5$ & $0.5-2.0$ & $0.8-2.5$ & $5.5-7.0$ & 0.05 & 0.015 & 0.15 \\
\hline
\end{tabular}

Materials and equipment. Nonspherical powder of VT20 titanium produced by domestic «Ti Technology» Company was used for producing product samples. The powder was Ti-Mo-Al-V-Zr alloy with granules of a nonspherical shape and cast microstructure of particles (Figure 1). Selection of an alloy of this system is due to the fact that it is characterized by good anticorrosion, heat-resistant and mechanical properties. VT20 alloy is used for manufacturing parts, also aviation parts, capable of operating for a long time at up to $500{ }^{\circ} \mathrm{C}$ temperature.

The powder was produced by the method of thermochemical embrittlement by hydrogen (hydration-dehydration method, HDH) of a sintered billet of VT20 alloy. A fraction with particles size from 60 up to $140 \mu \mathrm{m}$ was selected for investigations. Chemical composition of the used material is given in the Table.

Fusion operations were performed in equipment for 3D printing, based on a small-sized electron beam welding unit of SV-212M type with $60 \mathrm{kV} / 60 \mathrm{~kW}$ pulsed power source; electron beam gun ELA-60 and application package for controlling $3 \mathrm{D}$ printing process.

Equipment and software were developed at PWI. The general view of the equipment is shown in Figure 2.

The unit consists of small-sized vacuum chamber 1 with the mechanisms of powder feed and distribution, movement of the item, electron beam gun 2, high-voltage power source 4 and control system 3 . Electron beam gun 2 is fixedly mounted on the top wall of the vacuum chamber. The unit vacuum system provides up to $10^{-4} \mathrm{~mm} \mathrm{Hg}$ vacuum level in the chamber. Industrial computer, monitor, control blocks of high-voltage source and vacuum system are mounted in control cabinets 3 . High-voltage source 4 provides adjustable voltage of up to $60 \mathrm{kV}$ and beam current of up to $1000 \mathrm{~mA}$.

The process of electron beam fusion takes place in vacuum chamber 1 (Figure 3). Metal powder is fed in bulk to work table 9 from hoppers 3. Rack 4, moving along table 9 , forms on the surface of pallet 7 a layer of powder of preset depth. In the initial position, the pallet is on top of shaft 8 . The focused electron beam formed by EBG 2, melts the power surface by a preset trajectory. Thus, in keeping with the algorithm, the item contours and its layer are formed. Then pallet 7 is lowered by the specified distance and the next powder layer is deposited. The process is repeated. Item 6 is grown layer-by-layer. At the end of the production cycle, the part is taken out of the vacuum chamber, cleaned from unmolten powder 5 and machined.

Equipment control block diagram is given in Figure 4 . To form the melting zone, we used computer-controlled programmable controller Siemens SIMATIC WinAC. The electron beam is deflected along axes $X, Y$ and creates a melting zone of the specified shape. The fusion process is performed by

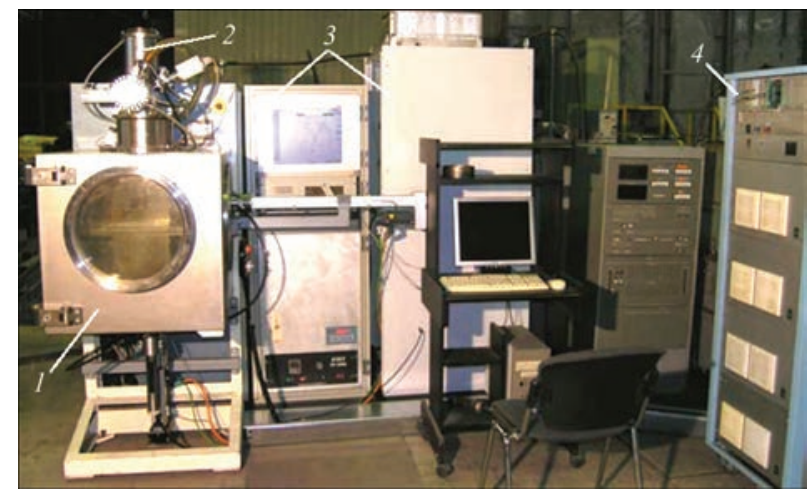

Figure 2. Equipment for electron beam 3D printing (for description of $1-4$ see the text) 


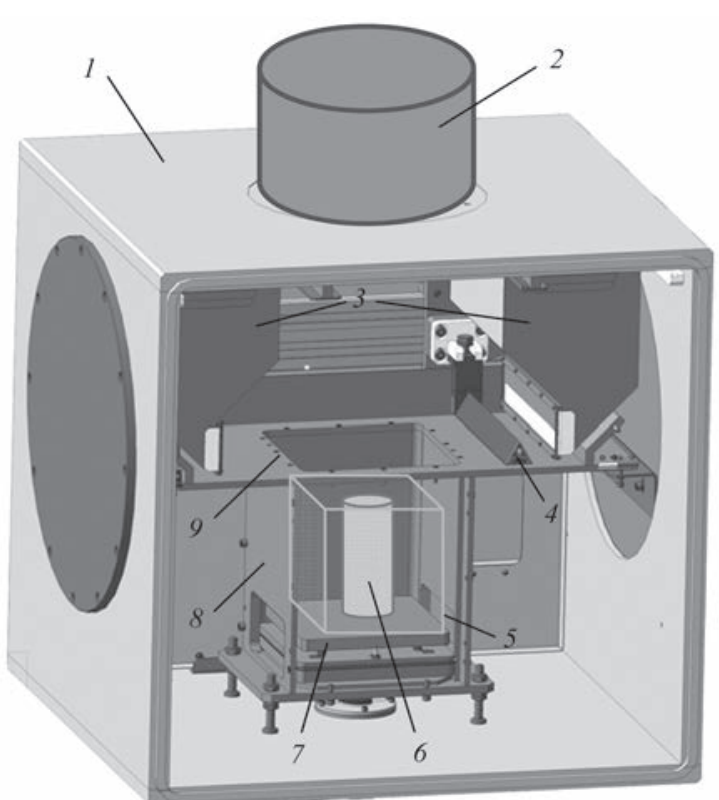

Figure 3. Scheme of a unit for additive manufacturing with application of metal powder materials (for description of 1-9 see the text)

the program in keeping with the computer model of the product and with preset technological modes. The objects of control are beam current $I_{w}$, focusing current $I_{\mathrm{f}}$, beam deflection along axes $X$ and $Y$, as well as depth of powder layer ( $Z$ axis).

The product sample in the form of a hollow cylinder was grown layer-by-layer in a vacuum chamber at vacuum level of $1 \cdot 10^{-4} \mathrm{~mm} \mathrm{Hg}$. Each deposited powder layer was preheated under the impact of a defocused electron beam, followed by its melting by the electron beam. The electron beam was moved along Archimedean spiral from larger to smaller diameter. When fusion was over, the next powder layer was deposited. Thus, the product was grown layer by layer. The depth of each powder layer was equal to $300 \mu \mathrm{m}$. When the production cycle was over, the product was cooled in vacuum for $18 \mathrm{~h}$.

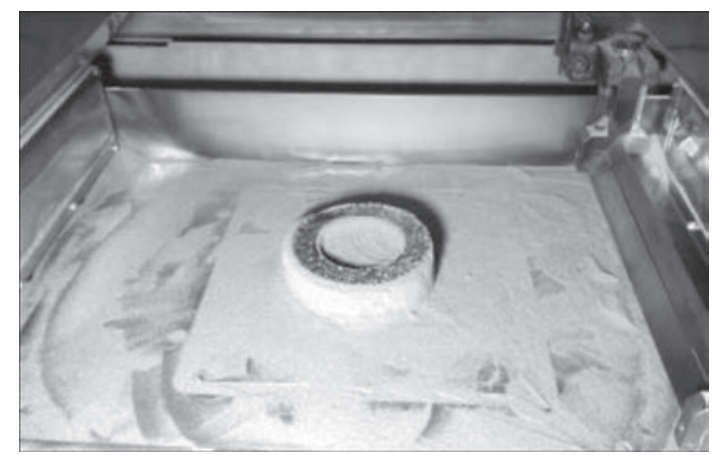

Figure 5. Product in vacuum chamber of 3D printer

The photo of the item located in the vacuum chamber of 3D printer, is given in Figure 5, the produced sample is shown in Figure 6. Geometrical dimensions of the item are as follows: outer diameter of $85 \mathrm{~mm}$, inner diameter of $55 \mathrm{~mm}$, height of $35 \mathrm{~mm}$.

The obtained sample was prepared for further metallographic examination of the features of structure formation along and across the fusion axes. Microstructure was studied in the metallographic optical microscope Neohpot-32 at different magnifications. Hardness of phase components was measured in microhardness meter M-400 of LECO Company, the load was $0.3 \mathrm{~N}$ with application time of $10 \mathrm{~s}$. Microstructure image was obtained using Olympus C-500 camera. The structure and chemical composition of the samples were studied by scanning electron microscopy and energy-dispersive microanalysis, using scanning electron microscope JSM 7001F with accelerating voltage of $20 \mathrm{kV}$. Observation of the structure was conducted both in secondary electron mode (SEI), and in back-scattered electron mode (COMPO), forming a contrast of the composite image. The composition was analyzed using INCA PentalFET $\times 3$ detector and Oxford Instruments INCA 4.11 program. 99.99 \% purity cobalt standard was used for calibration of quantitative analysis. Investigations in the mapping mode

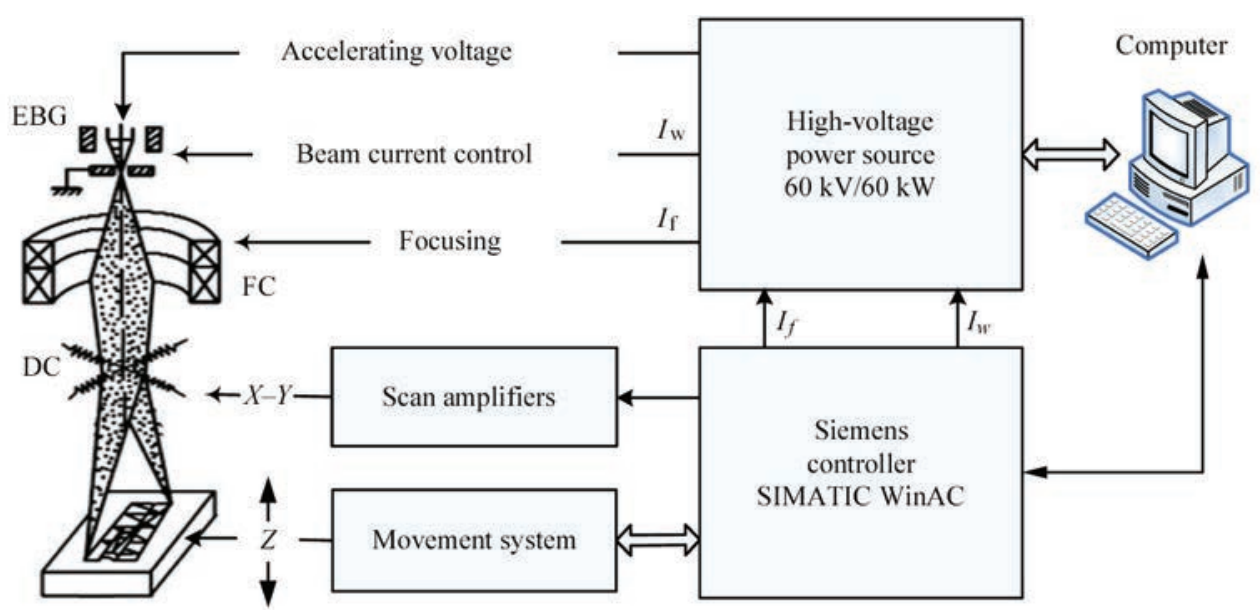

Figure 4. Block diagram of control of equipment for additive electron beam fusion: EBG — electron beam gun; FC — EBG focusing coil; DC - EBG deflecting coil (for description of other parameters see the text) 

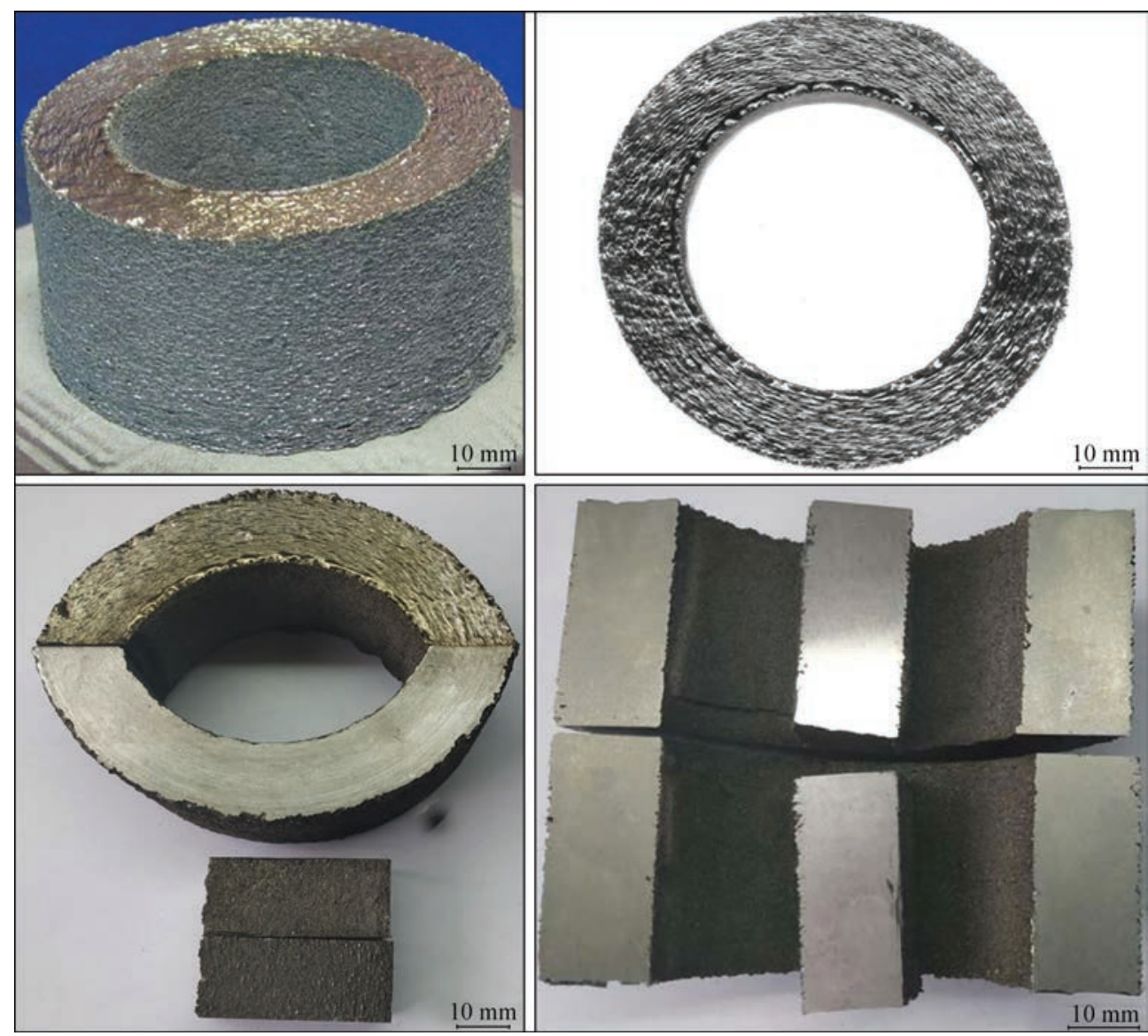

Figure 6. Sample made by the method of 3D printing

were conducted in order to determine the degree of distribution of the alloy main elements.

Results and discussion. In order to study deposited metal properties, transverse cuts were made and macrosections were prepared, one of which is given in Figure 7.

Analysis of transverse sections reveals the produced dense cast structure of the deposited metal. On the whole, formation defects are absent. Individual lacks-of-fusion are found closer to the side surfaces, which are indicative of the need to correct the technological process of melting of the product edge layers. Such defects can be eliminated by preforming the product outer and inner contours with their subsequent melting and filling of intercontour space with cast metal at scanning of the electron beam.

Chemical composition of the product was studied by X-ray spectral microanalysis (XSMA) - method of determination of substance composition by analysis of the characteristic X-ray radiation. Investigation results are given in Figures 9 and 10. The studied object was exposed to the impact of the electron beam which generated $\mathrm{X}$-ray radiation. The sample was bombarded by high-energy electrons, which resulted in emission of X-ray radiation from its surface. Analysis of characteristic X-ray radiation was used to determine, which elements and in what quantitative proportions are included into product composition. Higher element content corresponds to more intensive colour (Figure 9), or presence of peaks on the intensity curve along the line or area of scanning (Figure 10).

$\mathrm{X}$-ray spectral microanalysis (Figure 9) confirms that the alloying elements are uniformly distributed.

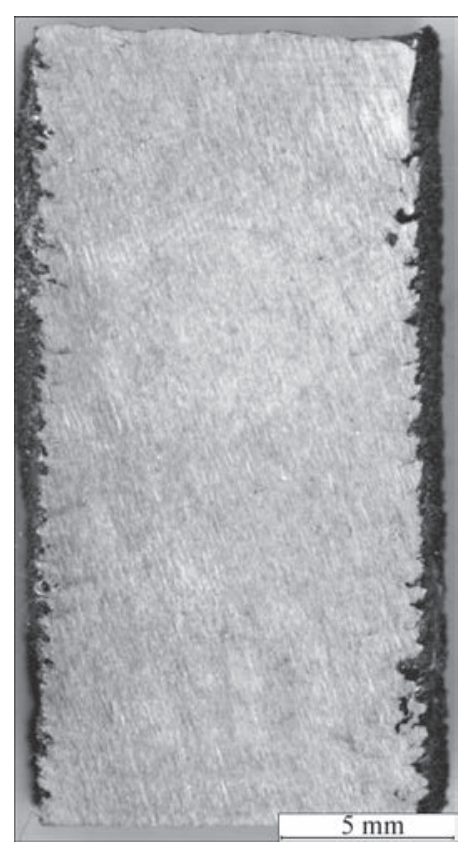

Figure 7. Transverse macrosection of a product from titanium alloy VT20 


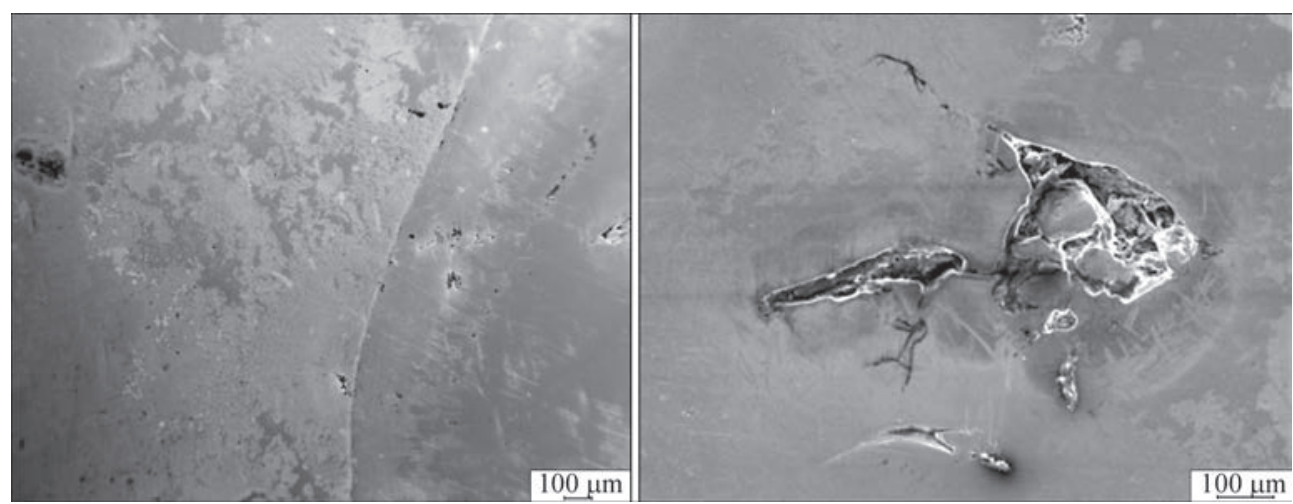

Figure 8. Defects on the surface of sample cross-section
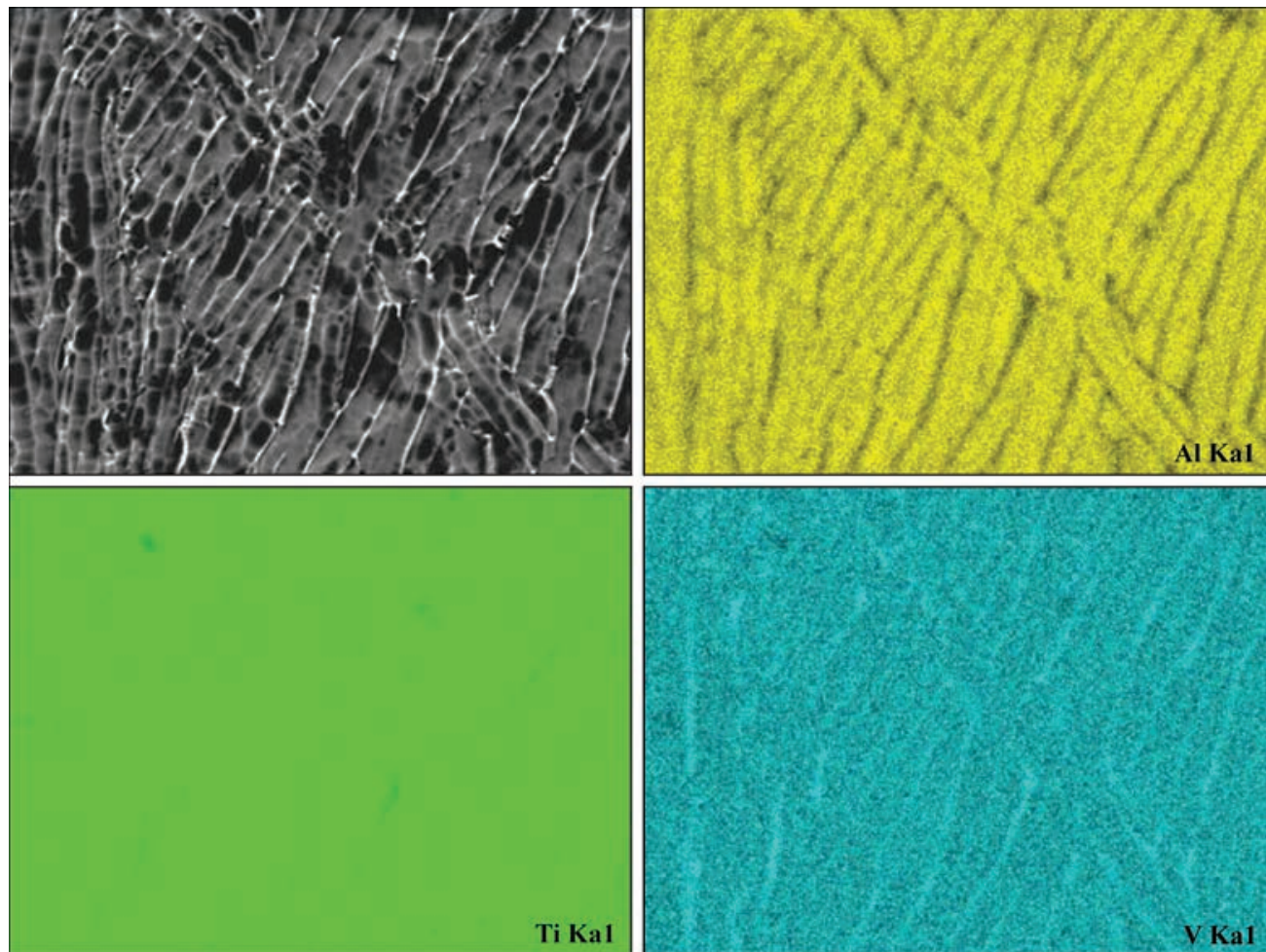

Figure 9. X-ray spectral microanalysis of distribution of titanium, aluminium and vanadium in the sample (top left is the electronic image)

Moreover, vanadium has a higher concentration along the boundaries of $\alpha$-phase grains that is characteristic for titanium alloys of this alloying system.

However, as shown by EDX-analysis - method of energy-dispersive X-ray spectroscopy (Figure 10), aluminium content somewhat differs from the limits, specified by GOST 19807-91 «Wrought titanium and titanium alloys. Grades», as well as from values given in the Table. The deviation is, most probably, associated with higher volatility of aluminium vapours under the conditions of fusion in high vacuum.

In order to eliminate this drawback, it is necessary to maintain aluminium content on a higher level in the initial material - titanium alloy powders. Percentage excess of aluminium content in the initial charge should be selected empirically, depending on alloy type. On the whole, deposited metal microstructure is finely dispersed and uniform over the entire surface of the section, and consists of crystallites, elongated in the direction of heat removal.

Deposit structure in the crystallite body consists mainly of an acicular $\alpha^{\prime}$-phase (oversaturated solid solution of substitution of alloying elements in $\alpha$-titanium) and small quantity of $\beta$-phase (Figure 11).

Grain boundaries are clean without inclusions. The melted-through parts of the sample are poreless, that is indicative of complete melting through of the powder layer during 3D printing.

Metal hardness in all the sections did not differ significantly and was within the range from HV 3960 MPa up to HV 4150 MPa.

Thus, performed research showed that the developed technology of additive electron beam fusion allows producing complex-shaped products from non- 

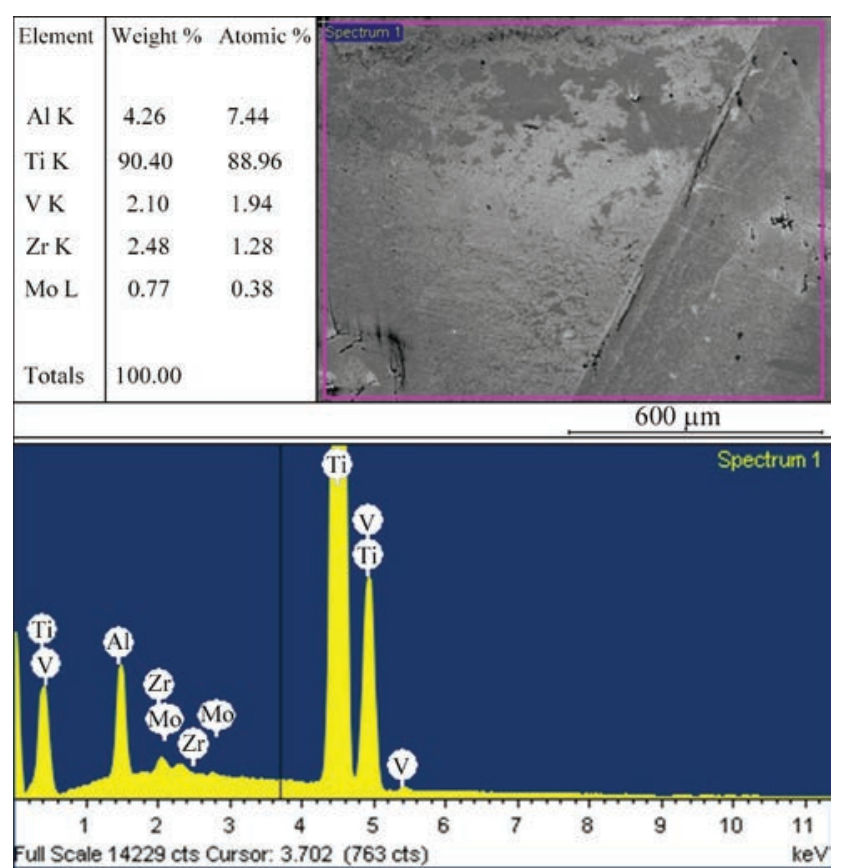

Figure 10. Elemental EDX-analysis of the sample

spherical powders of titanium alloys VT-2, having cavities specified in the drawings.

\section{Conclusions}

1. Additive electron beam fusion of products of the specified shape from nonspherical powders of titanium alloys was performed.

2. Reliable operation of the equipment is shown that confirmed the correctness of the taken design solutions.

3. Samples with good formation of deposited metal cast structure and homogeneous chemical composition were obtained.

4. Drawbacks, associated with the modes of fusion of powder combinations, were revealed.

5. The need to increase aluminium content in the initial raw material was defined, in order to compensate for its evacuation into the vacuum system.

6. Directions of further studies and improvements of additive electron beam technologies were determined.

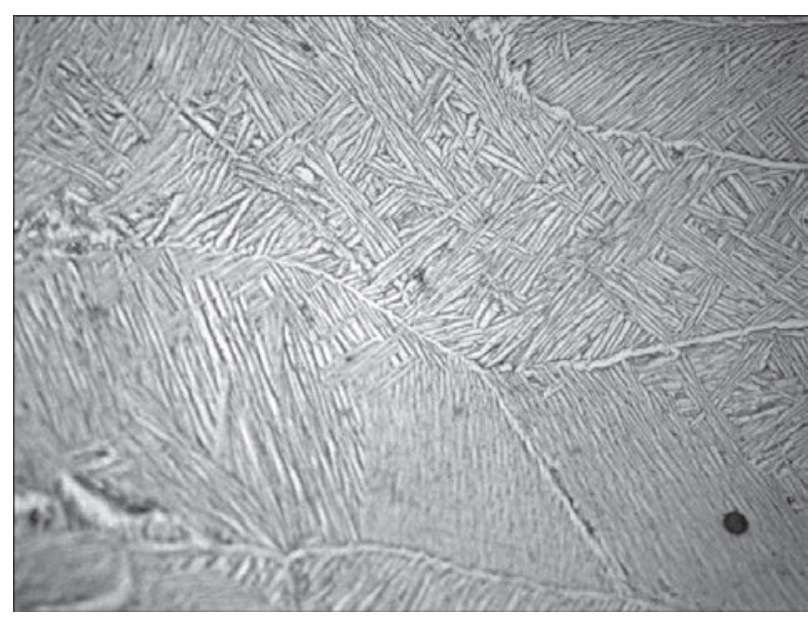

Figure 11. Microstructure $(\times 500)$ of the deposit metal $($ VT20 powder)

1. Nesterenkov, V.M., Matviichuk, V.A., Rusynik, M.O., Ovchinnikov, A.V. (2017) Application of additive electron beam technologies. The Paton Welding J., 3, 2-6.

2. Yanko, T.B., Ovchinnikov, A.V. (2018) Titanium in additive technologies. In: Construction, materials science and machine building: Starodubov Readings, 217-222 [in Russian].

3. Nesterenkov, V.M., Matviichuk, V.A., Rusynik, M.O. (2018) Manufacture of industrial products using electron beam technologies for 3D-printing. The Paton Welding J., 1, 24-28.

4. Nesterenkov, V.M., Khripko, K.S., Orsa, Yu.V., Matvejchuk, V.A. (2018) Electron beam technologies in aircraft construction. Materials Science: Achievements and prospects. In: 2 vol., Vol. 2, ed. By L. M. Lobanov. Kyiv, Akademperiodika, 192-221 [in Ukrainian].

5. Matviichuk, V.A, Nesterenkov, V.M., Rusynik, M.O. (2018) Application of additive electron-beam technologies for manufacture of metal products. Electrotechnica \& Electronica E+E, 3-4, 69-73.

6. Mahale, T.R. (2009) Electron beam melting of advanced materials and structures: Ph.D. dissertation, North Carolina State University, NC, US.

7. Gaytan, S., Murr, L., Medina, F. et al. (2009) Advanced metal powder based manufacturing of complex components by electron beam melting. Materials Technology, 24(3), 180-190.

8. Zäh, M.F., Lutzmann, S. (2010) Modelling and simulation of electron beam melting. Production Engineering, 4(1), 15-23.

9. Muth, T.R., Yamamoto, Y., Frederick, D.A. et al. (2018) Causal factors of weld porosity in gas tungsten arc welding of powder-metallurgy-produced titanium alloys. JOM, 65(5), 643-651.

10. Price, S., Cheng, B., Lydon, J. et al. (2015) On process temperature in powder-bed electron beam additive manufacturing: Process parameter effects. J. of Manufacturing Sci. and Eng., 136, 061019. 


\title{
EFFECT OF COOLING CYCLE OF WELDING ON STRUCTURE-PHASE COMPOSITION OF 15Kh2NMFA STEEL
}

\author{
O.V. MAKHNENKO, V.A. KOSTIN, V.V. ZHUKOV and E.S. KOSTENEVICH \\ E.O. Paton Electric Welding Institute of the NAS of Ukraine \\ 11 Kazymyr Malevych Str., 03150, Kyiv, Ukraine. E-mail: office@paton.kiev.ua
}

\begin{abstract}
In the recent years, mathematical methods are widely used for prediction of microstructure-phase composition of structural steels under thermal effect. Using mathematical modeling based on existing parametric regression equations there was carried out prediction of microstructure-phase transformations in HAZ metal of base material (steel 15Kh2NMFA) of WWER-1000 reactor vessel in arc cladding of protective anti-corrosion layer as well as performed comparative analysis of modeling results with obtained experimental data of dilatometric and metallographic analysis. The comparison of results ensures formation of bainite-martensite structure in HAZ metal of WWER-1000 reactor vessel, however a value of content of martensite in calculation and experimental determination is significantly different. For calculation determination of content of structural constituents it is necessary to use the experimental CCT diagrams of undercooled austenite decay for characteristic welding/cladding thermal cycles, which do not have long-term heating or holding at austenitizing temperature and cooling takes place with variable rate. CCT diagrams of undercooled austenite for typical cooling rates $3-5^{\circ} \mathrm{C} / \mathrm{s}$ and two maximum temperatures of thermal cycle, namely 1000 and $1350{ }^{\circ} \mathrm{C}$ were experimentally plotted for adequate evaluation of microstructure composition in HAZ metal of vessel steel 15Kh2NMFA in welding/ cladding. Obtained results can be used in calculation determination of residual stresses in WWER-1000 reactor vessel for grounding the extension of safe operation life. 32 Ref., 7 Tables, 12 Figures.
\end{abstract}

Keywords : WWER-1000 reactor vessel, steel 15Kh2NMFA, anti-corrosion cladding, microstructure transformations, mathematical modeling, dilatometry

In Ukraine the most part of nuclear power units is referred to WWER-1000 type, reactor vessel (RV) of which is made of thick-wall forged shells of low-alloy high-strength steels of pearlite class of 15Kh2NMFA grade, welded by girth welds. To protect RV from corrosion the austenite material is built up on its inner surface. Currently, an important scientific-technical problem is extension of safe operational life of working RV. Its substantiation requires taking into account residual stresses appearing as a result of welding or cladding heating, and their redistribution in process of further heat treatment.

Technological parameters of process of anti-corrosion cladding can have significant effect on microstructure-phase composition in heat-affected zone (HAZ) of 15Kh2NMFA steel as well as distribution of residual stresses in WWER-1000 RV.

Analysis of open access references shows [1-7] that they do not have data relatively to microstructure-phase composition of reactor vessel steel after arc cladding as well as there is no its complete CCT diagram of undercooled austenite decay. Existing metallurgical CCT diagrams of reactor steels $[8,9]$, obtained for typical in performance of heat treatment long-term holdings at maximum temperature and low cooling rates, do not allow determining final micro- structure-phase composition of metal in HAZ due to peculiarities of welding/cladding thermal cycle.

There are data [10] that there is formation of bainite-martensite microstructure in HAZ metal at cooling rate $3.3-28{ }^{\circ} \mathrm{C} / \mathrm{s}$ in $800-500{ }^{\circ} \mathrm{C}$ temperature range for steel 15Kh2NMFA and critical cooling rate, above which completely martensite structure is formed in HAZ metal, makes $30^{\circ} \mathrm{C} / \mathrm{s}$. The results, obtained in work [11], vice versa, show that typical welding cycle with metal cooling rate $3-6{ }^{\circ} \mathrm{C} / \mathrm{s}$ can provoke formation of mainly martensite microstructure. In foreign atlases and collections of CCT diagrams there are no data for reactor vessel steel 15Kh2NMFA at heat treatment and welding of steels [12-14].

New data [15-17] on transformations in reactor vessel steels 15Kh2MFA-A and 15Kh2NMFA under conditions of different thermal cycles of cooling were presented in the recent time. Analysis of CCT diagrams of these steels shows presence of specific differences of temperatures of start and end of phase transformations, critical cooling rates and fractions of structural constituents. These differences, apparently, are related, on the one hand, with various composition of researched reactor vessel steels (absence of nickel in steel 15Kh2MFA-A), and on the other hand with difference of methods (devices), used for determina- 
Table 1. Characteristics of conditions of CCT diagram plotting

\begin{tabular}{|c|c|c|c|c|c|c|}
\hline Reference & Type of device & $\begin{array}{c}\text { Dimensions of } \\
\text { sample, mm }\end{array}$ & $\begin{array}{c}\text { Austenitizing tem- } \\
\text { perature, }{ }^{\circ} \mathrm{C}\end{array}$ & $\begin{array}{c}\text { Austenitizing time, } \\
\text { min }\end{array}$ & $\begin{array}{c}\text { Range of cooling } \\
\text { rates, }{ }^{\circ} \mathrm{C} / \mathrm{s}\end{array}$ & Steel grade \\
\hline$[15]$ & BAHR DIL 805 & $10 \times 4$ & 1000 & 180 & $0.1-500$ & $15 \mathrm{Kh} 2 \mathrm{MFA}-\mathrm{A}$ \\
\hline$[16]$ & Linseis L78 RITA & $10 \times 3$ & 1000 & 20 & $0.01-50$ & $15 \mathrm{Kh} 2 \mathrm{MFA}-\mathrm{A}$ \\
\hline$[17]$ & Linseis L75VD1600C & $20 \times 6$ & 900 & 15 & $0.002-100$ & $15 \mathrm{Kh} 2 \mathrm{NMFA}$ \\
\hline
\end{tabular}

tion of temperature phase transformations, including, dimensions of samples and duration of holding in austenite area (Table 1).

In recent times, the mathematical models [18-21] got a large development for prediction of phase composition of structural steels at thermal effect. In this connection aim of the work lied in determination of possibility of application of mathematical modeling of kinetics of microstructure transformations in steel 15Kh2NMFA after arc cladding taking into account different technological parameters as well as performance of experimental verification (validation) of the calculation results using physical modeling of thermal-deformation state in welding/cladding.

Technological parameters of arc cladding of reactor vessel. In accordance to the requirements of reference documents [22] and following the documents of producing plant [23] automatic submerged-arc cladding with strip electrodes was used for cylinder part of reactor vessel and manual arc cladding with coated electrodes was used for surface of nozzle zone (inner surface of Du850 nozzle and their fillets) as well as other difficult-to-weld places of vessel. Table 2 provides cladding consumables.

According to [24-28] the technological parameters for automatic submerged-arc cladding by strips were the following, namely $I_{\mathrm{w}}=650 \mathrm{~A}$, voltage $U_{\mathrm{a}}=$ $32 \mathrm{~V}$, width of strip electrode $60 \mathrm{~mm}$, temperature of preheating and concurrent heating $T_{\mathrm{h}}=250^{\circ} \mathrm{C}$, cladding rate $v_{\mathrm{c}}=10 \mathrm{~m} / \mathrm{h}$.

Technological parameters for manual arc cladding with coated electrodes are the next [29], namely current intensity $I_{\mathrm{w}}=130-150 \mathrm{~A}, U_{\mathrm{a}}=26-30 \mathrm{~V}$, elec-

Table 2. Consumables for anti-corrosion cladding trodes of 4-5 mm diameter, temperature of preliminary and concurrent heating $T_{\mathrm{h}}=250{ }^{\circ} \mathrm{C}$, cladding rate $v_{\mathrm{s}}=3 \mathrm{~m} / \mathrm{h}$.

Composition of base material of steel 15Kh2NMFA RV is presented in Table 3 [30]. Thermal-physical properties of base metal and RV cladding consumable depending on temperature are given in works [31, 32].

Experimental procedure. Physical modeling on Gleeble 3800 unit using cylindrical samples of steel 15Kh2NMFA of $6 \mathrm{~mm}$ diameter and $76 \mathrm{~mm}$ length were used to get experimental results of microstructure composition of HAZ metal after arc cladding. CCT diagrams of austenite decay at cooling rates 1,3 , $5,7^{\circ} \mathrm{C} / \mathrm{s}$ were plotted.

Metallographic examinations were carried out after modeling of structural transformations in the samples. The samples were chemically etched in $4 \%$ alcoholic solution of nitric acid (nital) for microstructure detection. Examination of microstructures was carried out on NEOPHOT-32 microscope equipped with digital add-on device OLYMPUS at $\times 200$ and $\times 500$ magnifications. Vickers hardness measurement was performed on hardness gauge M-400 of LECO Company at $100 \mathrm{~g}$ and $1 \mathrm{~kg}$ loading. Composition of 15Kh2NMFA steel samples (Table 3) was determined on atomic emission spectrometer with inductively-coupled plasma ICAP 6500 DUO (TERMO FISHER SCIENTIFIC, USA). Content of carbon was determined by coulometric method. According to [3-5] the parts of RV from 15Kh2NMFA steel in initial state have bainite structure $\left(V_{\mathrm{b}}=1.0\right)$.

Mathematical model. Mathematical modeling was carried out on a model of nozzle zone of WWER-

\begin{tabular}{|c|c|c|c|}
\hline Surface type & Double-layer cladding & Grade of consumables & Flux \\
\hline \multirow{2}{*}{ Cylindrical surface of vessel } & First layer & Sv-07Kh25N13, TU 14-1-3146-81 & 48-OF-10, OST 5.9206-75 \\
\cline { 2 - 4 } & Second layer & Sv-04Kh10N19G2B, TU 141-14591-89 & FTs-18, OST 24.948.02-99 \\
\hline \multirow{2}{*}{ Inner surface of nozzles } & First layer & TsL-25/1, ZIO-8, GOST 9466-75 & - \\
\cline { 2 - 4 } & Second layer & EA-898/21B, TsT-15K, GOST 10052-75 & - \\
\hline
\end{tabular}

Table 3. Composition of examined steel 15Kh2NMFA, wt.\%

\begin{tabular}{|c|c|c|c|c|c|c|c|c|c|c|}
\hline \multirow{2}{*}{ Sample } & $\mathrm{C}$ & $\mathrm{Si}$ & $\mathrm{Mn}$ & $\mathrm{Cr}$ & $\mathrm{Ni}$ & $\mathrm{Mo}$ & $\mathrm{Cu}$ & $\mathrm{V}$ & $\mathrm{S}$ & $\mathrm{P}$ \\
\cline { 2 - 11 } & 0.17 & 0.28 & 0.41 & 2.04 & 1.37 & 0.63 & 0.03 & 0.12 & 0.01 & 0.01 \\
\hline
\end{tabular}




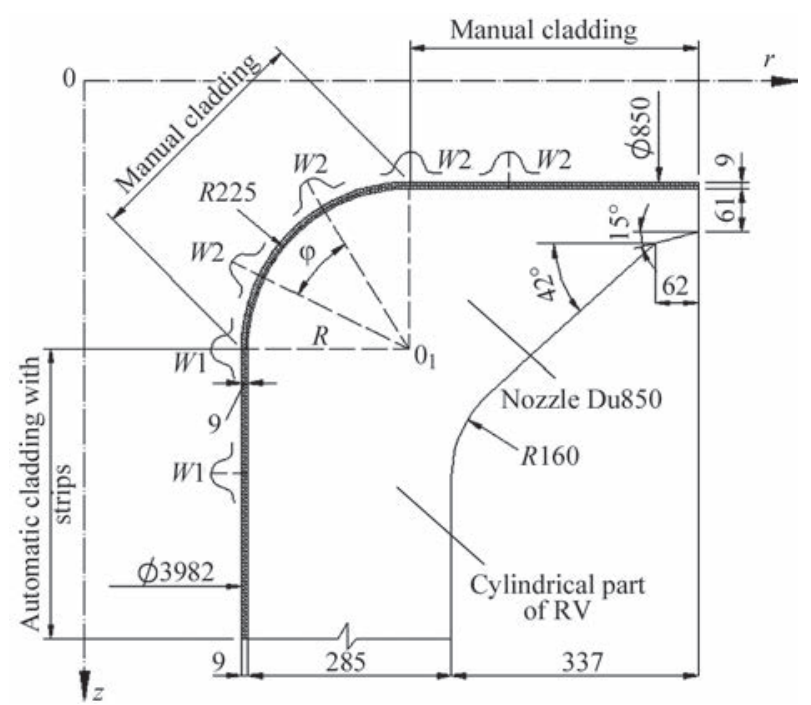

Figure 1. Scheme of nozzle zone of RV and location of areas with different technologies of arc cladding

$1000 \mathrm{RV}$, cladding of which is performed on both mentioned above technologies (Figure 1). In a calculation finite-element model of the nozzle zone there were used two types of sources of cladding heating (strip - for vessel shell and spot, simulating manual cladding with coated electrodes, for inner surface of Du850 nozzle as well as fillets). A temperature problem was solved in 2D problem formulation at assumption of fast moving heat source and axial symmetry of cladding of protective layers at boundary condition of convective heat exchange with environment. Distribution of heat power of strip source $\mathrm{W}_{1}$ and spot source $W_{2}$ with 2D formulation in a cylindrical coordinate system can be described by dependencies (1) and (2), respectively:

$$
\begin{gathered}
W_{1}(r, z, t)=\frac{2 Q \sqrt{K_{r} K_{z}}}{\pi v t_{\mathrm{h}}\left[1+\sqrt{\frac{K_{z}}{\partial}} b\right]} \times \\
\times \exp \left[-K_{r} D_{r}^{2}-K_{z} D_{z}^{2}\right] ; \\
W_{2}(r, z, t)=\frac{2 Q \sqrt{K_{r} K_{z}}}{\partial v t_{\mathrm{h}}} \exp \left[-K_{r} D_{r}^{2}-K_{\mathrm{z}} D_{z}^{2}\right],
\end{gathered}
$$

where $D_{z}=z-z_{0} ; D_{r}=r-r_{0} ; r, z$ are the coordinates (radial and axial) of considered point of the nozzle zone; $r_{0}, z_{0}$ are the coordinates of a center of moving heat source; $K_{r} ; K_{z}$ are the coefficients of concentration of specific heat flow; $t_{\mathrm{h}}$ is the heating time; $Q$ is the effective power of heating source $\left(Q=\eta I_{\mathrm{w}} U_{\mathrm{a}}\right) ; \eta$ is the efficiency coefficient; $v$ is the cladding rate; $b$ is the strip width.

Distribution of residual stresses in vessel material depends on microstructure composition and, respectively, mechanical properties in MZ and HAZ. In ac- cordance with calculation approach [18, 19], based on application of parametric regression equations, the results of calculation of weight fraction of each microstructure phase $\left(V_{\mathrm{m}}-\right.$ martensite; $V_{\mathrm{b}}$ - bainite; $V_{\mathrm{fp}}$ - ferrite-pearlite) in a final structure after cooling depend on composition of steel and typical time $\Delta t_{8 / 5}$ (s) of cooling from 800 to $500{ }^{\circ} \mathrm{C}$ temperature.

$$
\begin{gathered}
\text { Martensite } V_{\mathrm{m}}^{\mathrm{max}}=0.5\left[1-\operatorname{erf} \frac{\ln \Delta t_{8 / 5}-\ln \Delta t_{\mathrm{m}}^{50}}{\ln S_{\mathrm{m}}}\right] ; \\
\text { Ferrite-pearlite } V_{\mathrm{fp}}^{\max }= \\
=0.5\left[1+e r f \frac{\ln \Delta t_{8 / 5}-\ln \Delta t_{\mathrm{fp}}^{50}}{\ln S_{\mathrm{fp}}}\right] \\
\text { Bainite } V_{\mathrm{b}}^{\max }=1-V_{\mathrm{m}}^{\max }-V_{\mathrm{fp}}^{\max },
\end{gathered}
$$

where $\Delta t_{\mathrm{m}}^{50}$ is the time (s) of cooling from 800 to $500{ }^{\circ} \mathrm{C}$ temperature, at which in microstructure after cooling there is formation of $50 \%$ of martensite $\left(V_{\mathrm{m}}^{\max }=0.5\right) ; \quad{ }_{\mathrm{fp}}^{50}$ is the time (s) of cooling from $800^{\circ} \mathrm{C}$ to $500{ }^{\circ} \mathrm{C}$ temperature, at which in microstructure after cooling there is formation of $50 \%$ of ferrite-pearlite $\left(V_{\mathrm{fp}}^{\max }=0.5\right) ; S_{\mathrm{m}}, S_{\mathrm{fp}}$ are the parameters of model of austenite decay.

Values of parameters $\Delta t_{\mathrm{m}}^{50}, \Delta t_{\mathrm{fp}}^{50}, S_{\mathrm{m}}, S_{\mathrm{fp}}$ for low-alloy steels (weight fraction \%: $0.05 \leq \mathrm{C} \leq 0.4 ; \mathrm{Mn} \leq 2$; $\mathrm{Si} \leq 0.8 ; \mathrm{Cr} \leq 2 ; \mathrm{Mo} \leq 1 ; \mathrm{Ni} \leq 1.5 ; \mathrm{V} \leq 0.2 ; \mathrm{Ti} \leq 0.03$; $\mathrm{Al} \leq 0.05 ; \mathrm{Nb} \leq 0.03)$ are determined according to data of work [18] depending on steel composition.

Results of mathematical modeling. Solution of a nonstationary heat conduction problem provided the calculation data of fields of the maximum temperatures and typical thermal cycles in cladding, which allowed evaluating the dimensions of HAZ and cooling rates of metal of the nozzle zone at different technological parameters (Figure 2, Table 4).

Obtained modeling results for two technologies of arc cladding showed (Figure 3) that automatic cladding in HAZ metal provokes formation of bainite-martensite structure, martensite fraction makes up to $12 \%$. Fraction of martensite in HAZ metal reaches $48 \%$ in manual arc cladding with coated electrodes due to higher cooling rate.

Obtained calculation results relatively to bainite-martensite microstructure of 15Kh2NMFA steel after cladding have sufficiently good agreement with the reference data [11].

To check the obtained calculation data the experiments on physical modeling of thermal cycles 
Table 4. Results of calculation of HAZ size and cooling rates for different technological parameters of cladding

\begin{tabular}{|c|c|c|c|c|}
\hline $\begin{array}{c}\text { Technology of arc } \\
\text { cladding }\end{array}$ & $\begin{array}{c}\text { Width } \\
\text { of bead, } \\
\mathrm{mm}\end{array}$ & $\begin{array}{c}\text { Tempera- } \\
\text { ture of } \\
\text { preheating, } \\
{ }^{\circ} \mathrm{C}\end{array}$ & $\begin{array}{c}\text { HAZ size, } \\
\mathrm{mm}\end{array}$ & $\begin{array}{c}\text { Cooling } \\
\text { rate } w_{8 / 5}, \\
{ }^{\circ} \mathrm{C} / \mathrm{s}\end{array}$ \\
\hline $\begin{array}{c}\text { Manual with coated } \\
\text { electrodes }\end{array}$ & 15 & 250 & 6 & $8-9$ \\
\hline $\begin{array}{c}\text { Automatic } \\
\text { submerged-arc }\end{array}$ & 60 & 250 & 10 & $4-5$ \\
\hline
\end{tabular}

of cladding of samples from steel 15Kh2NMFA using Gleeble 3800 were carried out and examination of their microstructure was performed. Gleeble 3800 modeling provided research of several modes simulating thermal cycles of cladding, namely at constant cooling rates, with cooling on real thermal cycle of cladding, with holding and without holding at maximum temperature of thermal cycle, at different maximum temperature of welding cycle.

Physical modeling of thermal cycle with longterm holding at heating. Examined sample was heated to $1000{ }^{\circ} \mathrm{C}$ per $10 \mathrm{~min}$, was hold at $1000{ }^{\circ} \mathrm{C}$ temperature for $170 \mathrm{~min}$, that made the total time of heating $180 \mathrm{~min}$, with next cooling at constant rate 1 ; 3; $5 ; 7^{\circ} \mathrm{C} / \mathrm{s}$. Record of dilatometric data took place in process of thermal effect. They were used for plotting CCT diagram of undercooled austenite decay. To evaluate reliability of obtained results the experimental CCT diagram was compared with existing CCT diagram for steel 15Kh2NMFA [15] (Figure 4).

Analysis of obtained CCT diagram of steel 15Kh2NMFA showed that it considerably different from existing one. The differences lie in presence of a high-temperature field of bainite transformation within the limits of all investigated rates of cooling. Whereas, in the austenite decay diagram [15] bainite transformation finishes at $5{ }^{\circ} \mathrm{C} / \mathrm{s}$ cooling rate. The temperatures of start of bainite transformation in the

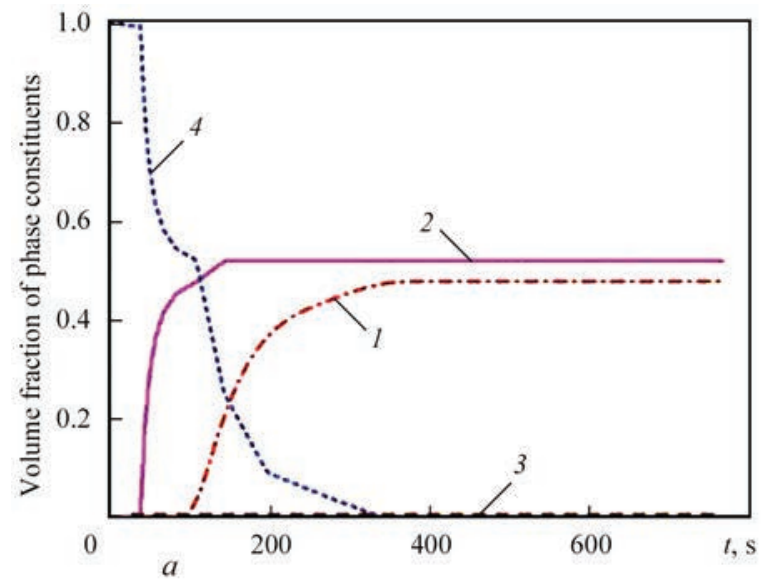

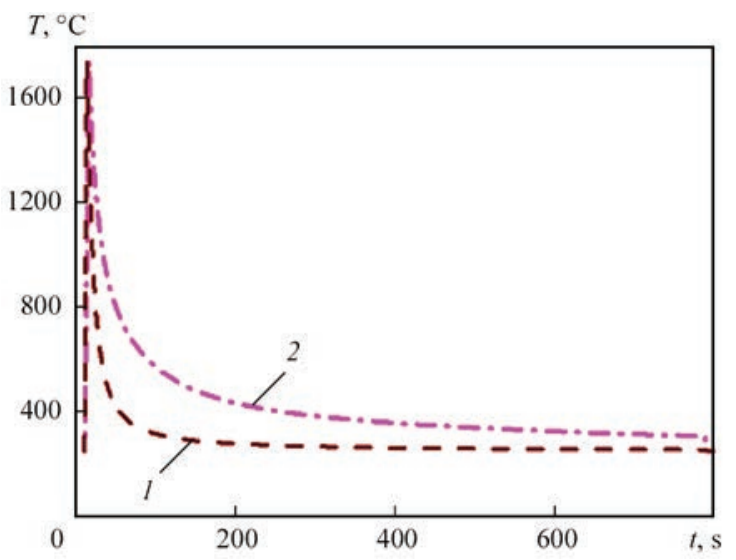

Figure 2. Typical thermal cycles in manual arc cladding with coated electrodes (1) and automatic submerged-arc cladding with $60 \mathrm{~mm}$ strip (2)

existing CCT diagram reach $550-560{ }^{\circ} \mathrm{C}$ for low cooling rates, whereas in the experimental diagram the temperature of start of bainite transformation reaches $607^{\circ} \mathrm{C}$ for cooling rate $1^{\circ} \mathrm{C} / \mathrm{s}$ (Table 5).

Temperature of start of martensite transformation in the examined samples is sufficiently close to the reference data. The results of metallographic examinations of the samples at cooling rates $1,3,5,7^{\circ} \mathrm{C} / \mathrm{s}$ are presented in Figure 5.

Fraction of structural constituents in the examined samples was determined using the methods of quantitative metallography (Table 6).

The analysis of obtained data showed that rise of cooling rate provokes increase of martensite fraction from 8 to $80 \%$ (based on the results of structural analysis) or from 26 to $66 \%$ (based on Gleeble results), and hardness of microstructure HV1 rises from 3530-3780 MPa to 4700-4820 MPa.

Physical modeling of thermal cycle without long-term holding at heating. Additional modeling was carried out at cooling rate $5^{\circ} \mathrm{C} / \mathrm{s}$, however, without long-term holding and at accelerated heat-

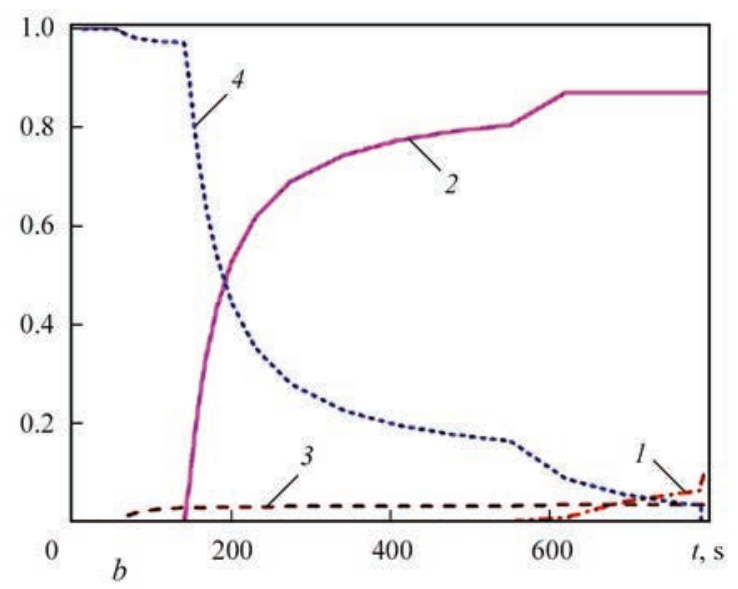

Figure 3. Results of calculation prediction of austenite decay kinetics in HAZ metal in arc cladding: $a$ - manual arc cladding with coated electrodes; $b$ - automatic submerged-arc cladding with strip $b=60 \mathrm{~mm}$ ( 1 - martensite; 2 - bainite; 3 - ferrite-pearlite; 4 - austenite) 


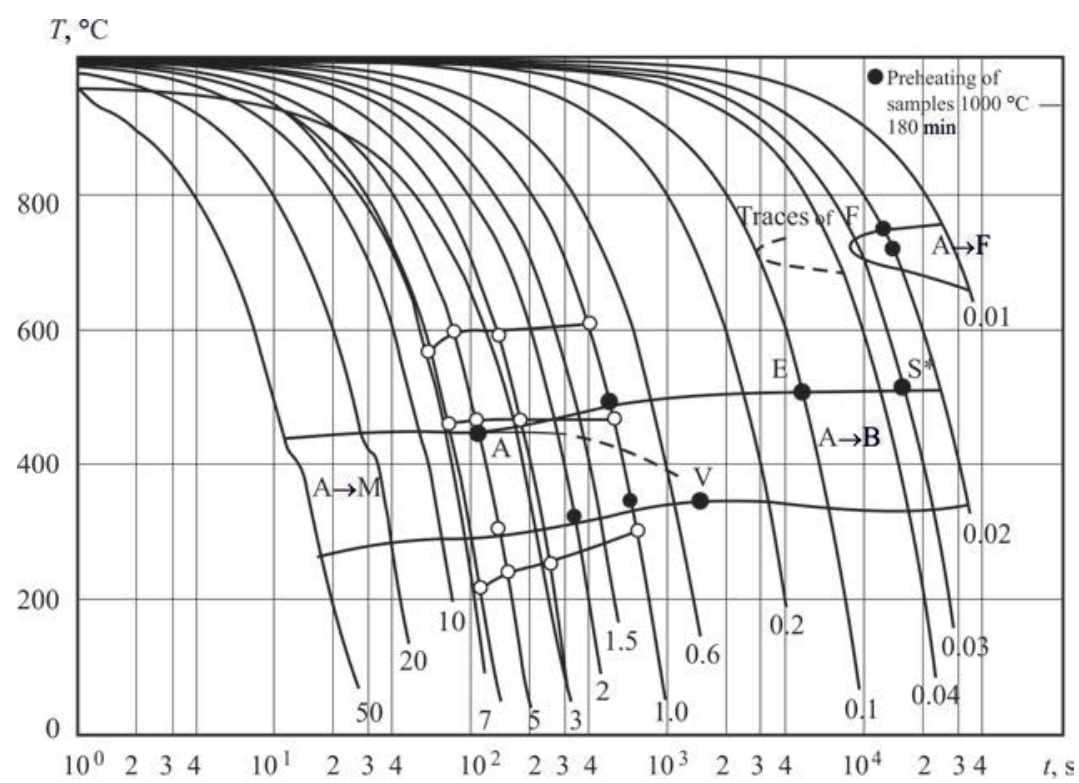

Figure 4. Comparison of obtained experimental (०) and existing $(\bullet)$ [15] CCT diagram of austenite decay of steel 15Kh2NMFA

Table 5. Temperatures of bainite and martensite transformation of steel 15Kh2NMFA

\begin{tabular}{|c|c|c|c|c|c|}
\hline $\begin{array}{c}\text { Cooling rate } w_{8 / 5}, \\
{ }^{\circ} \mathrm{C} / \mathrm{s}\end{array}$ & $\begin{array}{c}\text { Temperature of start of } \\
\text { bainite transformation, } \\
{ }^{\circ} \mathrm{C}\end{array}$ & $\begin{array}{c}\text { Temperature of } \\
\text { bainite-martensite } \\
\text { transformation, }{ }^{\circ} \mathrm{C}\end{array}$ & $\begin{array}{c}\text { Temperature of end of } \\
\text { martensite } \\
\text { transformation, }{ }^{\circ} \mathrm{C}\end{array}$ & $A_{c 1},{ }^{\circ} \mathrm{C}$ & $A_{c 3},{ }^{\circ} \mathrm{C}$ \\
\hline 1 & 607 & 464 & 302 & 683 & 858 \\
\hline 3 & 590 & 465 & 253 & 672 & 861 \\
\hline 5 & 600 & 464 & 243 & 704 & 861 \\
\hline 7 & 568 & 460 & 215 & 690 & 866 \\
\hline
\end{tabular}

ing in order to reduce metal staying in a high-temperature state. The proposed thermal mode included heating to $1000{ }^{\circ} \mathrm{C}$, holding at this temperature during $1 \mathrm{~s}$ and further cooling at constant rate $5{ }^{\circ} \mathrm{C} / \mathrm{s}$. The temperature mode being modeled has more reliable correspondence to real heating/cooling conditions of HAZ metal in arc welding/cladding of 15Kh2NMFA steel. The analysis showed sufficiently good correspondence of experimental data and data of work [15] on temperature transformations in steel 15Kh2NMFA at thermal cycle without long-term holding with constant cooling rate $5{ }^{\circ} \mathrm{C} / \mathrm{s}$. Thus, temperature of start of martensite transformation $452{ }^{\circ} \mathrm{C}$ well matches to similar temperature on CCT diagram, presented in work [15], which makes $445^{\circ} \mathrm{C}$. Temperature of end of martensite transformation $320^{\circ} \mathrm{C}$ also almost

Table 6. Results of metallographic analysis

\begin{tabular}{|c|c|c|c|}
\hline $\begin{array}{c}\text { Cooling } \\
\text { rate } w_{8 / 5}, \\
{ }^{\circ} \mathrm{C} / \mathrm{s}\end{array}$ & $\begin{array}{c}\text { Vickers hardness } \\
H V 1, \mathrm{MPa}\end{array}$ & $\begin{array}{c}\text { Fraction of } \\
\text { bainite/martensite } \\
\text { on results of } \\
\text { structure } \\
\text { analysis, } \%\end{array}$ & $\begin{array}{c}\text { Fraction of } \\
\text { bainite/martensite } \\
\text { on Gleeble results, } \\
\%\end{array}$ \\
\hline 1 & $353-378$ & $92 / 8$ & $74 / 26$ \\
\hline 3 & $407-467$ & $37 / 63$ & $44 / 55$ \\
\hline 5 & $439-476$ & $32 / 68$ & $41 / 59$ \\
\hline 7 & $470-482$ & $20 / 80$ & $34 / 66$ \\
\hline
\end{tabular}

matches with the temperature of martensite transformation end $300^{\circ} \mathrm{C}$ at given cooling rate. The results of quantitative analysis of microstructure verified formation of almost completely $100 \%$ martensite structure. Experimentally observed presence of an inflection on the transformation curve at $200{ }^{\circ} \mathrm{C}$, apparently, related with «rigid» nature of sample fixing in modeling.

Physical modeling of real welding thermal cycle. In real technological process of welding/cladding, metal cooling does not take place on a linear dependence, however, such approach allows significantly simplifying the process of physical modeling. The real cladding thermal cycle was programmed in the work. It corresponded to cooling from $1000{ }^{\circ} \mathrm{C}$ with $5{ }^{\circ} \mathrm{C} / \mathrm{s}$ rate in $800-500{ }^{\circ} \mathrm{C}$ temperature range.

Figure 6 shows a comparison of obtained data of real cooling cycle with cooling cycle at constant rate without long-term holding. Analysis of the transformation curves allowed determining the temperatures of transformation start, formation of intermediate (martensite) phase and temperature of transformation end (Table 7).

Figure 7 presents the comparison of dilatometric curves at different cooling cycles. Analysis of the dilatograms shows that transformation start for both thermal cycles takes place at temperature close 

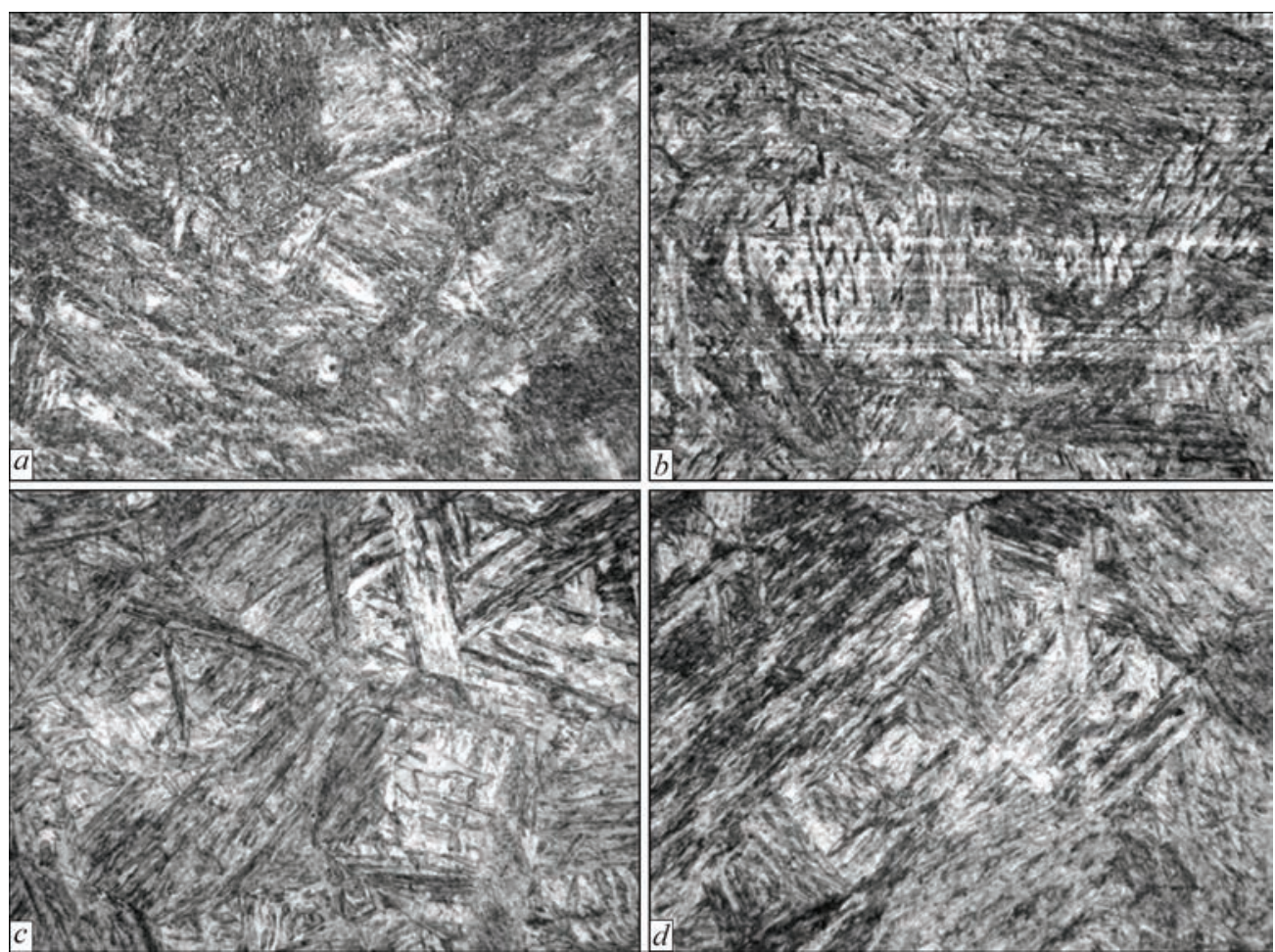

Figure 5. Microstructure $(\times 500)$ of samples of steel $15 \mathrm{Kh} 2 \mathrm{NMFA}$ after holding at $1000{ }^{\circ} \mathrm{C}$ temperature during 170 min and further cooling at rates: $a-1 ; b-3 ; c-5 ; d-7^{\circ} \mathrm{C} / \mathrm{s}$

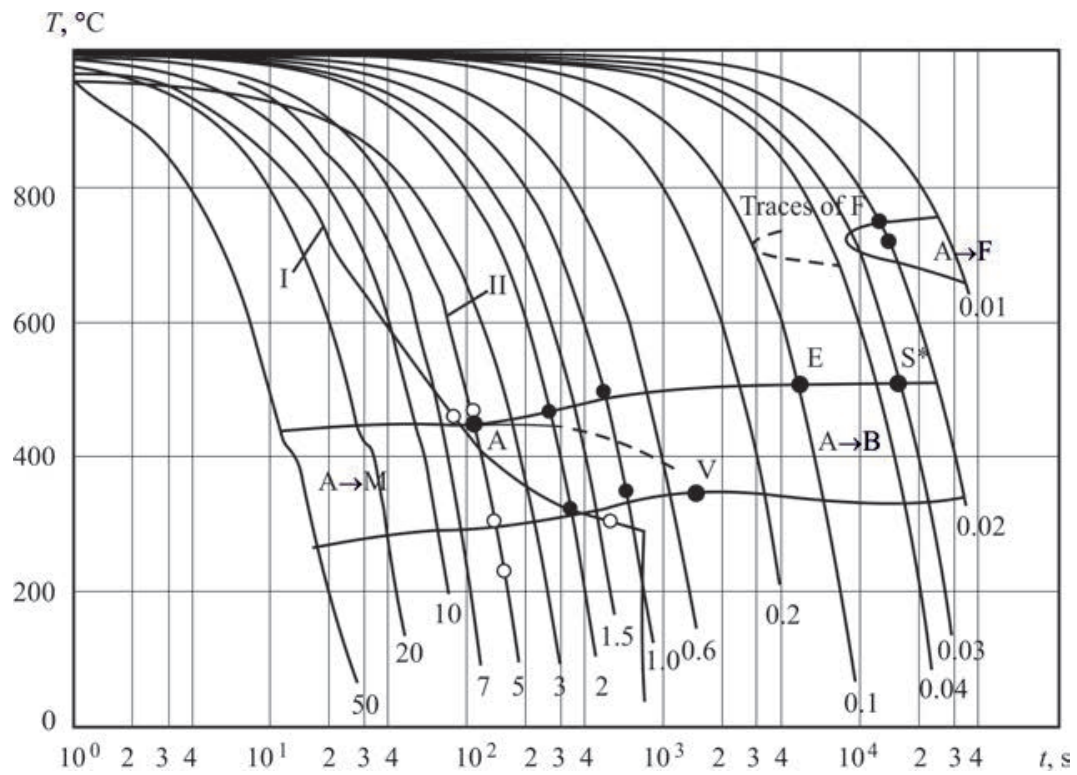

Figure 6. Comparison of data of transformation CCT diagram obtained at cooling of sample on real welding thermal cycle (I) and on thermal cycle with constant cooling rate (II) [15]

Table 7. Temperatures of bainite and martensite transformations of steel 15Kh2NMFA under conditions of thermal welding cycle

\begin{tabular}{|c|c|c|c|c|c|}
\hline Modeling conditions & $\begin{array}{c}\text { Temperature of } \\
\text { transformation } \\
\text { start, }{ }^{\circ} \mathrm{C}\end{array}$ & $\begin{array}{c}\text { Temperature } \\
\text { of intermediate } \\
\text { phase, }{ }^{\circ} \mathrm{C}\end{array}$ & $\begin{array}{c}\text { Temperature of } \\
\text { transformation } \\
\text { end, }{ }^{\circ} \mathrm{C}\end{array}$ & $A_{c 1},{ }^{\circ} \mathrm{C}$ & $A_{c 3},{ }^{\circ} \mathrm{C}$ \\
\hline Without long-term holding, at constant cooling rate & 466 & 306 & 231 & 683 & 858 \\
\hline Real thermal cycle & 460 & - & 304 & 672 & 861 \\
\hline
\end{tabular}




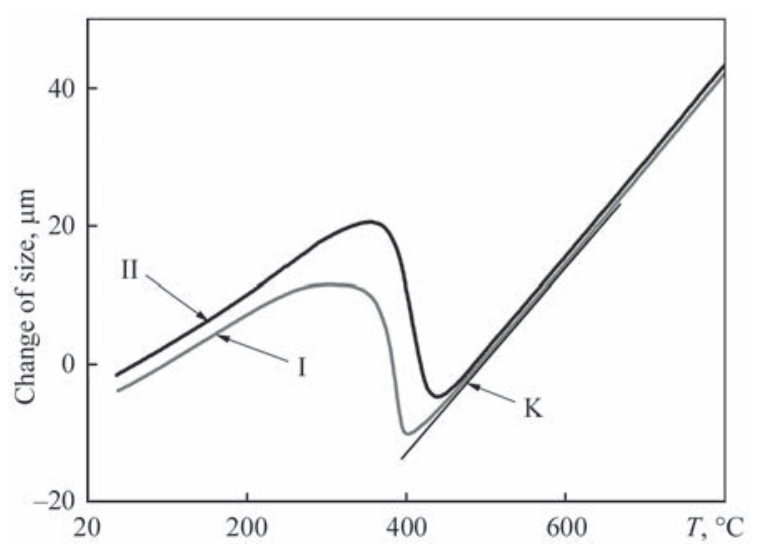

Figure 7. Dilatograms of transformations obtained at constant cooling rate (I) and at cooling on real thermal cycle of cladding (II); K - area of transformation start, deviation of both dilatograms from area of linear thermal expansion

to $460-466{ }^{\circ} \mathrm{C}$, and conditional transformation rate (change of fraction of phase depending on temperature) in the field of developed transformation (middle part) is also virtually similar (angle of curves' inclination). Significant differences in the transformation nature are observed in the field of martensite formation (250-350 ${ }^{\circ} \mathrm{C}$ ), where curves' nature is different.

Obtained data of dilatometric investigation allow making a conclusion that morphology of microcrystalline structure of the sample after thermal cycle at constant cooling rate and sample after real thermal cycle has small differences.

Figure 8 presents the comparison of microstructures of the samples, obtained at constant cooling rate without long-term holding and on real welding cycle.

Structure of the samples, obtained at constant cooling rate $5{ }^{\circ} \mathrm{C} / \mathrm{s}$ without long-term holding in austenite area presents itself the structure of fine acicular martensite (Figure 8, a). The sample can contain small amount of bainite up to 3-5\%. Vickers hardness HV1 of this structure changes from 4460 to $4580 \mathrm{MPa}$.

Structure of the sample, obtained on real welding cycle, is extremely inhomogeneous and presents itself banded structure consisting of alternating longitudi- nal areas of dispersed and coarse acicular structure (Figure 8, $b$ ). The areas of dispersed structure present themselves the areas of fine acicular martensite, and coarse acicular ones are the areas of lower bainite. Vickers hardness $H V 1$ of the given structure changes from 3940 to $4460 \mathrm{MPa}$. The results of quantitative metallography show that the fraction of structures in the examined samples made $80-90 \%$ of martensite and $10-20 \%$ of bainite.

Thus, comparison of microstructures of examined samples shows that regardless the fact that an average cooling rate in both samples in transformation area 800 $500{ }^{\circ} \mathrm{C}$ was almost similar and made $5{ }^{\circ} \mathrm{C} / \mathrm{s}$, the structures forming in the process of 15Kh2NMFA steel cooling somewhat differ from each other. In the one case, there is formation of completely martensite structure, whereas in the another it is martensite-bainite.

Metallographic examinations of samples of 15Kh2NMFA steel at different maximum temperatures of welding cycle. Metallographic examinations of the samples after simulation of real welding thermal cycles on Gleeble 3800 differing by maximum heating temperature are presented in Figure 9.

Structure of the sample, obtained on real welding thermal cycle at maximum heating temperature $1000^{\circ} \mathrm{C}$ is characterized with banded inhomogeneous structure consisting of alternating bands of dispersed fine acicular martensite (80-90 \%) and coarse acicular structure of lower bainite (10-20\%) (Figures 8, b, 9, $a$ ).

Structure of the sample, obtained on real welding thermal cycle at maximum heating temperature $1350{ }^{\circ} \mathrm{C}$ is characterized by homogeneous martensite structure (Figure 9, b). Size of the coarse martensite packages made 50-60 $\mu \mathrm{m}$ fine $-20-30 \mu \mathrm{m}$. Size of the martensite grains corresponds to 3.5-4 grain size number on ASTM (100-120 $\mu \mathrm{m})$. Vickers hardness $H V 1$ of given structure changes from 4130 to $4530 \mathrm{MPa}$. The fraction of structures in the examined sample based on the results of quantitative metallography made $100 \%$ of martensite.
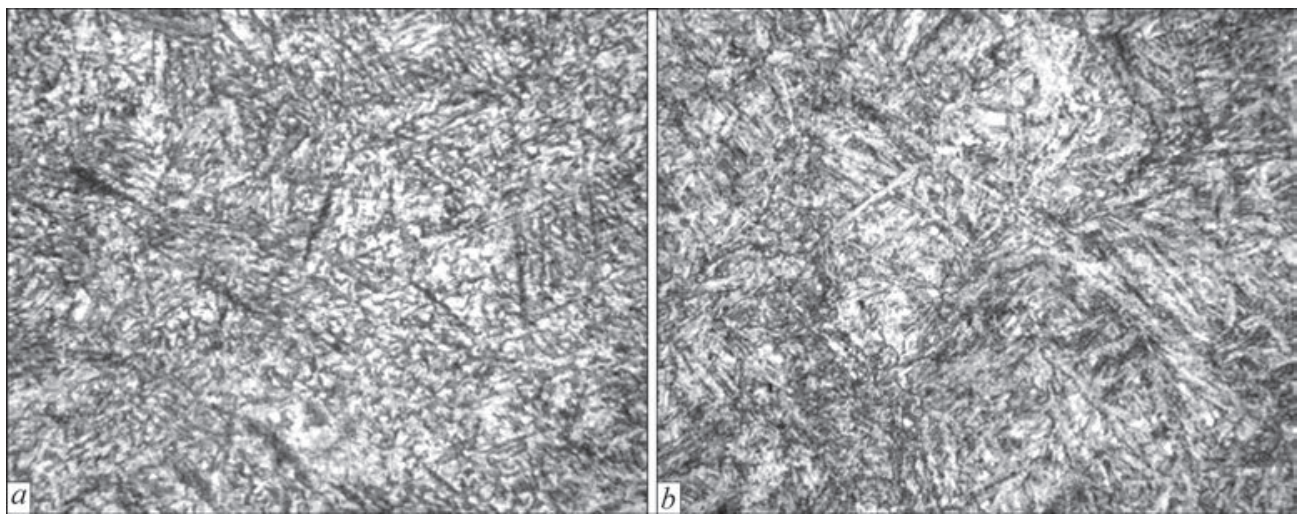

Figure 8. Microstructure $(\times 500)$ of sample at $5{ }^{\circ} \mathrm{C} / \mathrm{s}$ without long-term holding with constant cooling rate $(a)$ and obtained on real welding cycle (b) 

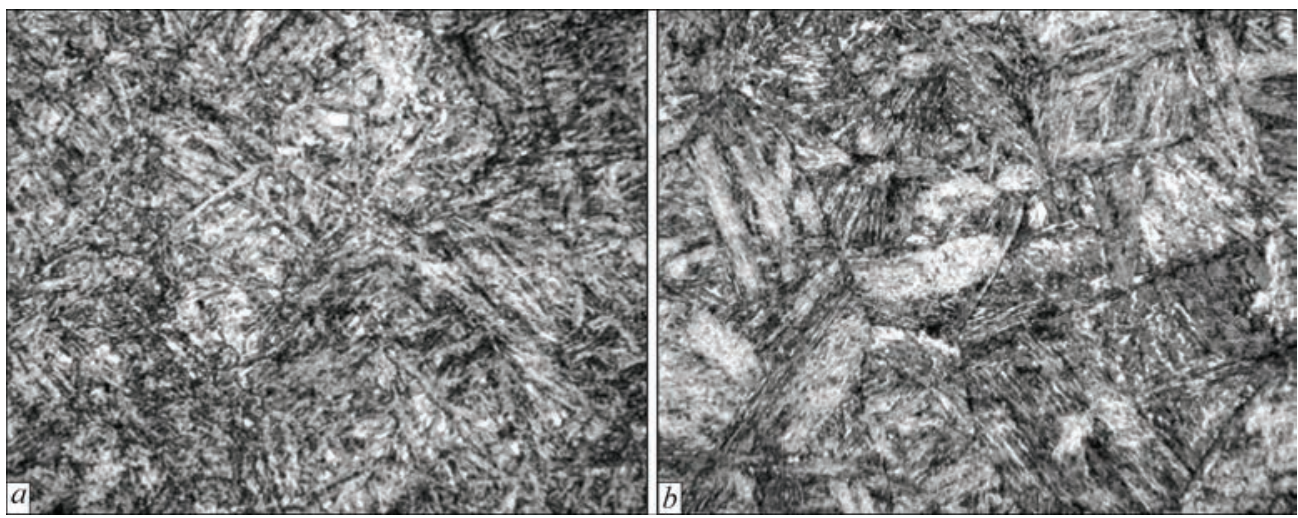

Figure 9. Microstrucutre $(\times 500)$ of sample at $5^{\circ} \mathrm{C} / \mathrm{s}$ obtained on real thermal cycle at maximum heating temperature $1000(a)$ and $1350{ }^{\circ} \mathrm{C}(b)$

Thus, comparison of microstructures of the examined samples shows that increase of the maximum heating temperature from 1000 to $1350{ }^{\circ} \mathrm{C}$ results in significant growth of primary austenite grain, completely eliminates banded orientation of the structure, caused by machining (rolling) of initial sheets of steel 15Kh2NMFA, and leads to formation of completely martensite structure with higher level of hardness in contrast to martensite-bainite structure, forming in the sample at maximum temperature cycle $1000{ }^{\circ} \mathrm{C}$.

Comparison of the dilatometric curves of real welding cycle, obtained at different maximum temperatures of the cycle without holding, is shown in Figure 10.

The analysis of obtained results showed that the transformation curves have various nature. On heating stage to $900{ }^{\circ} \mathrm{C}$ temperature the dilatometric curves completely correspond each other. At maximum heating temperature $1350{ }^{\circ} \mathrm{C}$ the transformation in high-frequency area starts at $1050{ }^{\circ} \mathrm{C}$ temperature and ends at $1250{ }^{\circ} \mathrm{C}$ temperature, that corresponds to formation in this area of $\delta$-ferrite structure. In modeling of the cycle with maximum heating temperature $1000{ }^{\circ} \mathrm{C}$, it becomes apparent that formation of $\delta$-ferrite is absent due to insufficient heating temperature.

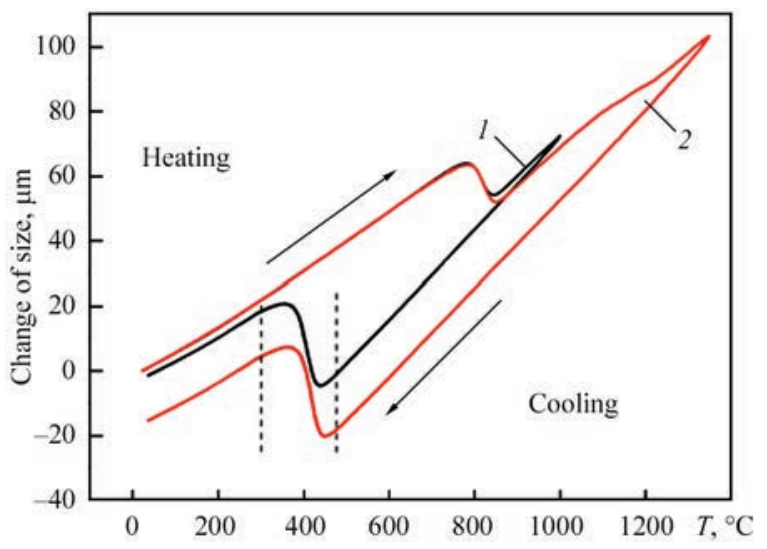

Figure 10. Dilatograms of transformations obtained at different maximum temperatures of thermal cycle: $1-1000 ; 2-1350{ }^{\circ} \mathrm{C}$
Investigation of transformation kinetics showed that the transformation takes place on a compatible mechanism and has similar nature. The difference in kinetic transformation curves for the maximum heating temperatures makes $10-15^{\circ} \mathrm{C}$ (Figure 11).

The analysis of obtained dilatometric results allows making a conclusion that change of the maximum temperature of heating almost has no effect on kinetics of formation of martensite phase, inconsiderably influences the temperatures of start and end of phase formation, but has obvious effect on total value of martensite transformation (dilatometric effect).

Plotting the CCT diagrams of austenite decay for two maximum temperatures of welding thermal cycle. Based on carried thermal deformation investigation using Gleeble 3800 unit and further metallographic analysis of the samples for typical thermal cycles of welding/cladding at different rate of cooling in $800-500{ }^{\circ} \mathrm{C}$ range and two different maximum temperatures of heating there were obtained two welding CCT diagrams for steel 15Kh2NMFA (Figure 12).

Comparison of experimental CCT diagrams with existing one [15] indicates small difference in the values of temperatures of start and end of transformations (in $50{ }^{\circ} \mathrm{C}$ limits) as well as the main difference - range of martensite-bainite transformation

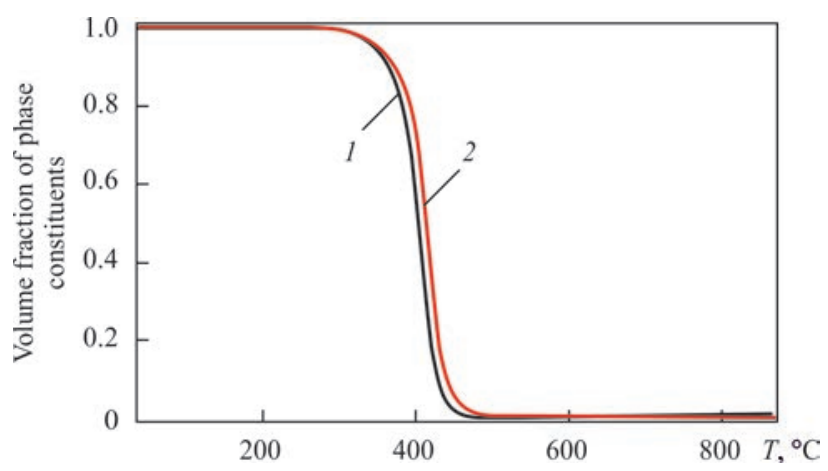

Figure 11. Dependence of fraction of forming phase on temperature for real thermal cycle depending on maximum temperature of heating: 1 - maximum heating temperature $1000 ; 2-1350{ }^{\circ} \mathrm{C}$ 

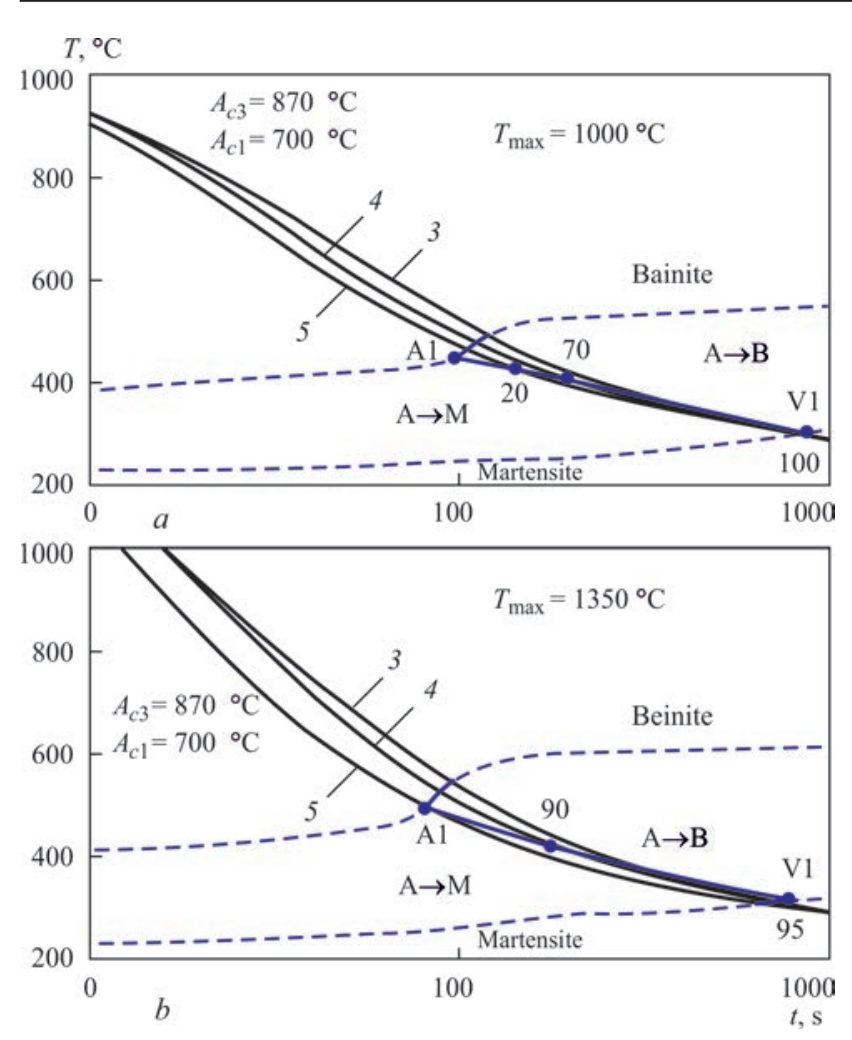

Figure 12. CCT diagrams of austenite decay for steel 15Kh2NMFA for typical welding cycles of cooling at maximum heating temperature: $a-1000 ; b-1350{ }^{\circ} \mathrm{C}(3-5-$ cooling rate) in $800-500{ }^{\circ} \mathrm{C}$ range

and its critical cooling rate. Following existing diagram point $A$ corresponds to start of range of martensite - bainite transformation (100\% of martensite, cooling rate $\left.5{ }^{\circ} \mathrm{C} / \mathrm{s}\right)$, point $B$ - end (100\% of bainite, $0.6^{\circ} \mathrm{C} / \mathrm{s}$ ). This is so called critical cooling rates in the range of martensite and bainite transformations.

According to the experimental diagrams in Figure 12 the points of start and end of range of martensite-bainite transformation correspond to the points $A 1$ and $B 1$, which do not match with points $A$ and $B$ of existing diagram in Figures 4, 6. Point $A 1$ (critical point of martensite transformation ) lies on the cooling curve $5{ }^{\circ} \mathrm{C} / \mathrm{s}$, the same as point $A$ and point $B 1$ (critical point of bainite transformation) on cooling curve $3{ }^{\circ} \mathrm{C} / \mathrm{s}$ that do not correspond point $B\left(0.6 \approx{ }^{\circ} \mathrm{C} / \mathrm{s}\right)$ of the diagram from work [15].

It can be concluded that following the experimental data obtained for real welding thermal cycles, range of cooling rates of martensite-bainite transformation is narrower than in the existing CCT diagrams of austenite decay $[8,15,16]$ obtained at long-term holding at the stage of heating and further constant cooling rate.

\section{Conclusions}

1. The comparative analysis of calculation results showed significant effect of technological parameters of the process of arc cladding on the kinetics of mi- crostructure transformations and residual microstructure-phase composition in HAZ metal of vessel steel 15Kh2NMFA. Application of the procedure based on parametric regression equations allows calculation of structure phase composition of HAZ metal: for a mode of manual arc cladding with coated electrodes $\left(w_{8 / 5}=8-9{ }^{\circ} \mathrm{C} / \mathrm{s}\right)$ the maximum content of martensite is around $50 \%$, for automatic submerged-arc cladding with strip electrodes $\left(w_{8 / 5}=4-5{ }^{\circ} \mathrm{C} / \mathrm{s}\right)$ the maximum content of martensite does not exceed $15 \%$.

2. Experimentally determined that in the researched range of cooling rates $1-7^{\circ} \mathrm{C} / \mathrm{s}$ the final microstructure of HAZ metal of steel 15Kh2NMFA at long-term holding $180 \mathrm{~min}$ at $1000{ }^{\circ} \mathrm{C}$ temperature in austenite area consists of bainite-martensite mixture, and at short-term holding $1 \mathrm{~s}$ from martensite. It can be concluded that long-term holding at $1000{ }^{\circ} \mathrm{C}$ temperature, designed for complete austenitizing of metal before cooling on welding thermal cycle is not adequate condition for reliable physical modeling.

3. Comparison of CCT diagram of the samples obtained at cooling with constant rate and on real welding cycle showed that kinetics of transformation at constant cooling rate takes place at lower by 20 $30{ }^{\circ} \mathrm{C}$ temperatures in comparison with the transformation on real welding cycle. The structure of sample obtained at constant cooling rate $5{ }^{\circ} \mathrm{C} / \mathrm{s}$ without longterm holding in austenite area presents itself a structure of fine acicular martensite, whereas the sample structure obtained on real cooling cycle of welding (average rate $5{ }^{\circ} \mathrm{C} / \mathrm{s}$ ), consists of areas of fine acicular martensite and lower bainite to $10-20 \%$.

4. It was shown how the maximum temperature of heating 1000 and $1350{ }^{\circ} \mathrm{C}$ effects the nature of transformation, microstructure, fraction of forming phases, position of temperatures of start and end of bainite and martensite transformation.

5. Comparison of obtained experimental data and results of mathematical modeling of microstructure transformations at real cooling cycle of cladding verify formation of bainite-martensite structure in HAZ metal of WWER-1000 RV, however the value of martensite content significantly differs (the difference makes up to $50 \%$ ). For calculation determination of content of structure-phase constituents it is necessary to use the experimental data of CCT diagram of undercooled austenite decay for typical welding/ cladding thermal cycles, in which long-term heating (holding) at austenitizing temperature is absent and cooling takes place with variable rate.

6. For adequate evaluation of microstructure phase composition in HAZ metal of vessel steel 15Kh2NMFA in welding/cladding there were plotted CCT diagrams of undercooled austenite decay for 
typical cooling rates $3-5{ }^{\circ} \mathrm{C}$ and two maximum temperatures of thermal cycle 1000 and $1350{ }^{\circ} \mathrm{C}$.

Obtained investigation results can be used for calculation determination of residual stresses in WWER-1000 $\mathrm{RV}$ at justification of extension of safe operation life.

1. (1989) PNAE G-7-002-86: Codes of design on strength of equipment and pipings of nuclear power plants. Gosatomenergonadzor SSSR. Moscow, Energoatomizdat [in Russian].

2. Khlybov, A.A., Uglov, A.L. (1998) Determination of physicomechanical characteristics of material of specimens subjected to radiation. Trudy NizhGTU, 1, 220-228 [in Russian].

3. Gurovich, B.A., Kuleshova, E.A., Fedotova, S.V. (2011) Influence of chemical composition and structural parameters of steels of WWER reactor vessels on susceptibility to embrittlement caused by formation of grain-boundary segregations, including under conditions typical for long-term operation of power plants. Moscow, NRC Kurchatov Institute [in Russian].

4. Frolov, A.S. (2013) Phase-structural state and operating characteristics of new compositions of steels for reactor vessels with higher power and service life: Syn. of Thesis for Cand. of Techn. Sci. Degree. Moscow, NRC Kurchatov Institute [in Russian].

5. Markov, S.I. (2012) Metal science principles of manufacture of billets for high-reliability elements of power and piping systems: Syn. of Thesis for Dr. of Techn. Sci. Degree. Moscow, TsNIITMASh [in Russian].

6. Margolin, B.Z., Shvetsova, V.A., Gulenko, A.G. et al. (2002) Prediction of crack resistance of vessel reactor steel based on concept of «Mastercurve» and probabilistic model. Problemy Prochnosti, 1, 5-21 [in Russian].

7. Fomenko, V.N. (2017) Prediction of fracture toughness for calculation of strength of WWER type reactor vessels on the base of witness-specimen tests and local criteria of brittle fracture: Syn. of Thesis for Cand. of Techn. Sci. Degree. Saint-Petersburg, CRI CM «Prometheus» [in Russian].

8. Popova, L.E., Popov, A.A. (1991) Transformation diagrams of austenite in steels and beta solution in titanium alloy: Refer. Book of heat-treater. 3rd Ed., Moscow, Metallurgiya [in Russian].

9. Karzov, G.P., Margolin, B.Z., Teplukhina, I.V., Piminov, V.A. (2016) Materials science aspects of increase of operation safety of WWER type power plants on the base of reactor vessel steel improvement. Saint-Petersburg, CRI CM «Prometheus», Podolsk, OKB Gidropress JSC [in Russian].

10. Livshits, L.S., Khakimov, A.N. (1989) Physical metallurgy of welding and heat treatment of welded joints. 2nd Ed., Moscow, Mashinostroenie [in Russian].

11. Margolin, B.Z., Varovin, A.Ya., Kostylyov, V.I. (2005) Determination of residual stresses in the WWER vessels after multirun welding, surfacing and high-temperature tempering. The Paton Welding J., 10, 14-20.

12. (1977) Atlas of isothermal transformation and cooling transformation diagrams. American Society for Metals.

13. Zhang Zhuyao, Farrar, R.A. (1995) An atlas of continuous cooling transformation diagrams (CCT) applicable to low carbon low alloy weld metals. London, Institute of Materials.

14. Zeyffarth, P. (1982) Atlas Schweiss-ZTU-Schaubilder. Berlin, VEB Verlag Technik, Duessseldorf, DVS-Verlag.

15. Center of modeling of casting processes and technologies. http://mip-cast.ru/treatment
16. Teplukhina, I.V., Golod, V.M., Tsvetkov, A.S. (2018) CCT diagram plotting based on the numerical analysis of dilatometric tests results. Letters on Materials, 8(1), 37-41.

17. Soloviov, I.V., Kornienko, O.Yu, Zhilyakov, A.Yu., Belorusets, A.M. (2017) Investigation of decay kinetics of overcooled austenite of steel 15Kh2NMFA during continuous cooling. In: Proc. of 18th Int. Sci.-Techn. Conf. of Ural School-Seminar of Metallurgists-Young Scientists (Russia, Ekaterinburg, 21-23 November 2017). UrFU, 250-252.

18. Kasatkin, O.G., Zeyffarth, P. (2002) Calculated models for evaluation of mechanical properties of HAZ metal in welding of low-alloy steels. In: Proc. of Int. Conf. on Mathematical Modeling and Information Technologies in Welding and Related Processes. Kiev.

19. Makhnenko, V.I., Velikoivanenko, E.A., Pochinok, V.E. et al.(1999) Numerical methods for the prediction of welding stress and distortions. Welding and Surfacing Reviews, 13, Pt 1, 1-146.

20. Dean Deng, Yangang Tong, Ninshu Ma, Hidekazu Murakawa (2013) Prediction of the residual welding stress in $2.25 \mathrm{Cr}-$ $1 \mathrm{Mo}$ steel by taking into account the effect of the solid-state phase transformations. Acta Metall. Sin., 26(3), 333-339.

21. Yukio Ueda, Hidekazu Murakawa, Yu Luo (1995) A computational model of phase transformation for welding processes. Transact. of JWRI, 24(1), 95-100.

22. (2003) PNAE G-7-009-89: Equipment and pipings of nuclear power plants. Welding and surfacing, fundamentals. Moscow [in Russian].

23. ZhNPP-1 reactor vessel. 1152.02.70.000. Certificate of pressure vessel [in Russian].

24. Dub, A.V. (2013) Development of main structural materials for WWER reactors, SRTs RF. Podolsk, NPO TsNIITMASh [in Russian].

25. Voronov, A.V. (2013) Improvement of quality of welded joints and deposited surfaces of NPP equipment. Saint-Petersburg, PJSC «Izhora Plants» [in Russian].

26. Iradj Sattari-Far, Magnus Andersson (2006) Cladding effects on structural integrity of nuclear components. SKI Report 2006:23, ISSN 1104-1374, ISRN SKI-R-06/23-SE.

27. Katsuyama, J., Udagawa, M., Nishikawa, H. et al. (2010) Evaluation of weld residual stress near the cladding and $\mathrm{J}$-weld in reactor pressure vessel head for the assessment of PWSCC behavior. E-J. of Advanced Maintenance, 2, Japan Society of Maintenology, 50-64.

28. Dupas, P., Moinereau, D. (1996) Evaluation of cladding residual stresses in clad blocks by measurements and numerical simulations. J. de Physique IV Colloque, 06(C1), 187-196.

29. Tsvitanovich, M., Postruzin, Zh., Munk, R. et al. (2011) Systems of ultrasonic testing of metal of NPP reactor vessel Kudankulam. In: Proc. of Conf. on Safety Assurance of NPP with WWER, Podolsk, OKB Gidropress [in Russian].

30. TU 108-765-78: Billets from steel of 15Kh2NMFA and 15KhNMFA-A grades for vessels and covers and other assemblies of reactor plants.

31. Kostylev, V.I., Margolin, B.Z. (2000) Determination of residual stress and strain fields caused by cladding and tempering of reactor pressure vessels. Int. J. of Pressure Vessels and Piping, 77.

32. (2000) Procedure for determination of service life of nuclear reactor vessels during operation (MRK-SKhR-2000), RD EO 0353-02, Saint-Petersburg-Moscow [in Russian]. 


\title{
HIGH CYCLE FATIGUE PROPERTY OF ELECTRON BEAM WELDED THICK SECTION OF Ti-6Al-4V PLATES*
}

\author{
ZHANG YP, DONG CL, WANG YQ, HOU B, YU C, FANG WP and XU WH \\ Advanced Materials Centre, Guangdong Welding Institute (China-Ukraine E.O. Paton Institute of Welding) \\ Guangzhou, 510651 PR, China. E-mail: wangyg@qwi.gd.cn
}

\begin{abstract}
The $100 \mathrm{~mm}$ thickness Ti-6Al-4V plates were welded by the electron beam (EBW) method. Microstructures and mechanical properties including tensile and fatigue fracture behavior of the joint have been studied. The results shown that the joint has obviously textural and mechanical heterogeneity in the thickness direction, the joint show excellent fatigue resistance though the middle layer of the joint has lower fatigue life at the same stress and survival rate. The fatigue crack initiates from the free surface of the specimen by the transgranular fracture mode. The fatigue deformation depicted by the dislocations of the joint in each layer is adapt to the planar-slip mechanism. 6 Ref., 1 Table, 5 Figures.
\end{abstract}

Ke yw ords : Ti-6Al-4V, microstructure, mechanical property, fatigue

Titanium alloy Ti-6Al-4V is one of the important base materials in the manufacture of aircraft and marine industries [1]. The Ti-6Al-4V titanium alloy has good weldability and corrosion resistance. However, in the case of the heavypiece parts (the thickness $\geq 30$ $\mathrm{mm}$ ), there have been few methods could be chosen to supply good welding quality besides the EBW and tungsten inert gas welding (TIG) methods. Actually, the casting, forging and heat treating states of the
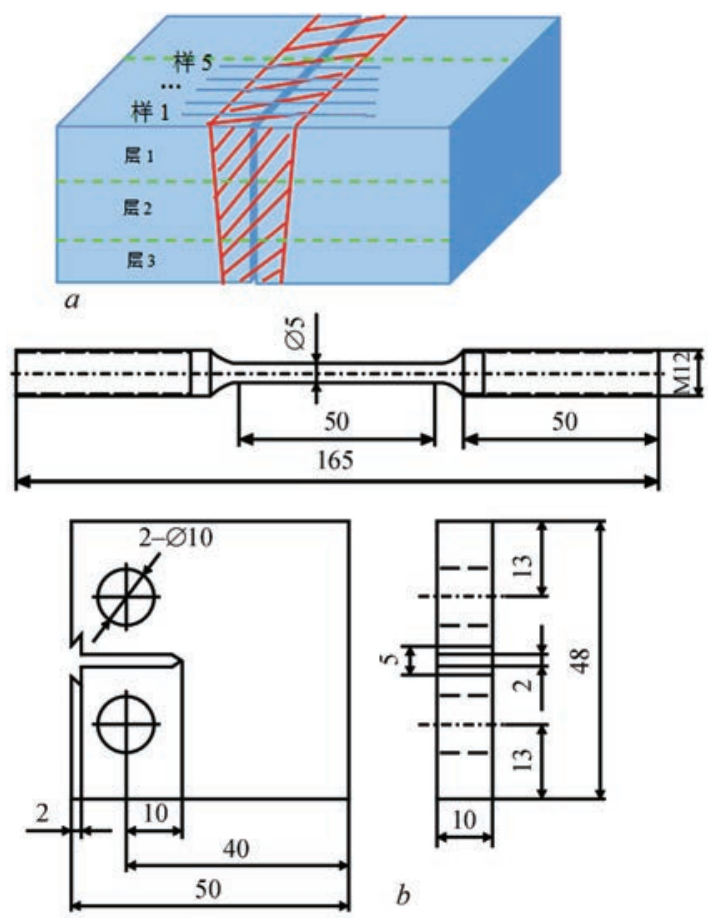

Figure 1. Fatigue specimens and cutting method: $a$ - cutting position of fatigue specimen; $b$ - fatigue specimens and fatigue crack propagation specimen pieces could greatly influence the heterogeneity of the mechanical property of the welding joint. Our former study revealed that the EBW welding seam has coarse $\beta$-phase and spiculate $\alpha^{\prime}$-phase, and the columnar crystals grow from the seam edge to the central line from both sides, moreover the grain size has the trend to decreases gradually from the upper side to the lower side in the vertical direction, although there may be anomaly grain growth in some local areas, for the EBW seam, there are also two defect concentration areas located near the seam surface and the nail tip. It has been known that the seam fusion zone of the Ti-6Al-4V have better tensile strength than that of the base metal because of the martensite phases in the seam, and the fatigue property of the joint is determined by the near-surface defects, moreover the seam zone have better fatigue strength than that of the base metal. The fatigue crack propagation rate of the fusion zone could be decreased by the ageing process, and the severe tortuous cracks have good crack propagation resistance. It could be seen that the fatigue property of the Ti-6Al-4V joint has been studied in various views, however most publication studies were done to the plate thickness lower than $30 \mathrm{~mm}$ [2-5]. As known, the fatigue properties of the joint will be different in the thickness direction of the joint. It is interesting to reveal the heterogeneity of the fatigue property of the heavy piece Ti-6Al-4V and found out the characteristics.

Experimental. The Ti-6Al-4V heavy pieces $\left(600 \times 150 \times 100 \mathrm{~mm}^{3}\right)$ have been heat treated at $750{ }^{\circ} \mathrm{C}$ for $2 \mathrm{hr}$ before the EBW welding. The as-welded joint was divided to 3 layers (layer $l_{1}, l_{2}$ and $l_{3}$ ) for

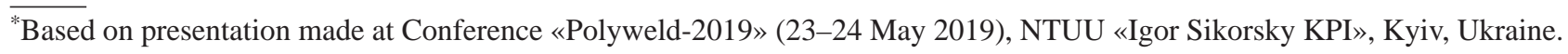


the fatigue property investigation (Figure 1, a). The fatigue specimens were cut from different layers to characterize the fatigue properties in the thickness directions, see Figure $1, b$. The specimens for the micrographs were polished by the abrasive polishing machine, cleaned by the acetone and hence etched by the distilled water, hydrofluoric acid (HF) and nitric acid $\mathrm{HNO}_{3}$ combinations. The microstructures of the specimens were investigated by the optical microscope (Axio Imager.M2m, ZEISS). The fatigue properties of the joint at different layers were tested by the HF fatigue testing machine (QBG-20, Changchun, CCQB), the one-way peak load is $100 \mathrm{KN}$, the cycle frequency is $100 \mathrm{~Hz}$, the cyclic waveform is the sinusoid. Six stress levels were chosen in at least 8 groups of tests. The cross-section morphologies of the fatigue fracture were observed by the scanning electron microscope (S-3400, Hitachi), and the microstructures of the fatigue fractures were analyzed by the transmission electron microscope (JEM-2100, JEOL).

Results and discussions. Microstructure heterogeneity. The microstructures of the seam zone, base metal and the heat affecting zone (HAZ) of the joint can be seen in Figure 2. The microstructures of the seam zone and the HAZ were shown from layer 1 to layer 5 of the joint. The gaps between the sampling positions of the micrograph in different layers are $10 \mathrm{~mm}$ (Figure 2, $a$ ). The base metal has equiaxed structure (Figure 2, $b$ ). It can also be seen that the seam zone has basket-weave microstructures. The acicular martensite phases interweave with several interfaces differentiate the dendrite orientation. From layer 1 to layer 3, the microstructures of the seam zone have almost the same morphology and metallurgical characteristic, just have different acicular martensite distribution and orientation because of the different observation positions and view angles. Furthermore, the microstructure in layer 3 has more dendritic crystals and the texture is finer than those of the layer 1 and layer 2 . And the microstructures of the layer 4 and layer 5 have further finer texture than that of the layer 3 . The seam textures are coincident with the asknown characteristics, however the texture difference between the area near the nail tip and the area close to the seam surface is bigger because the relatively higher thickness. The metallurgical characteristics were highly influenced by the heat input and radiation. The layers close to the seam surface has more heat input and the phases has the conditions to grow up before the formation of the lower half seam, moreover the layer 4 and layer 5 have better heat radiation conditions because being close to the radiation helping facilities.

It can be seen in Figure 2, $a$ that layer 1 has widmannstatten structure, in which the lamellar mar-

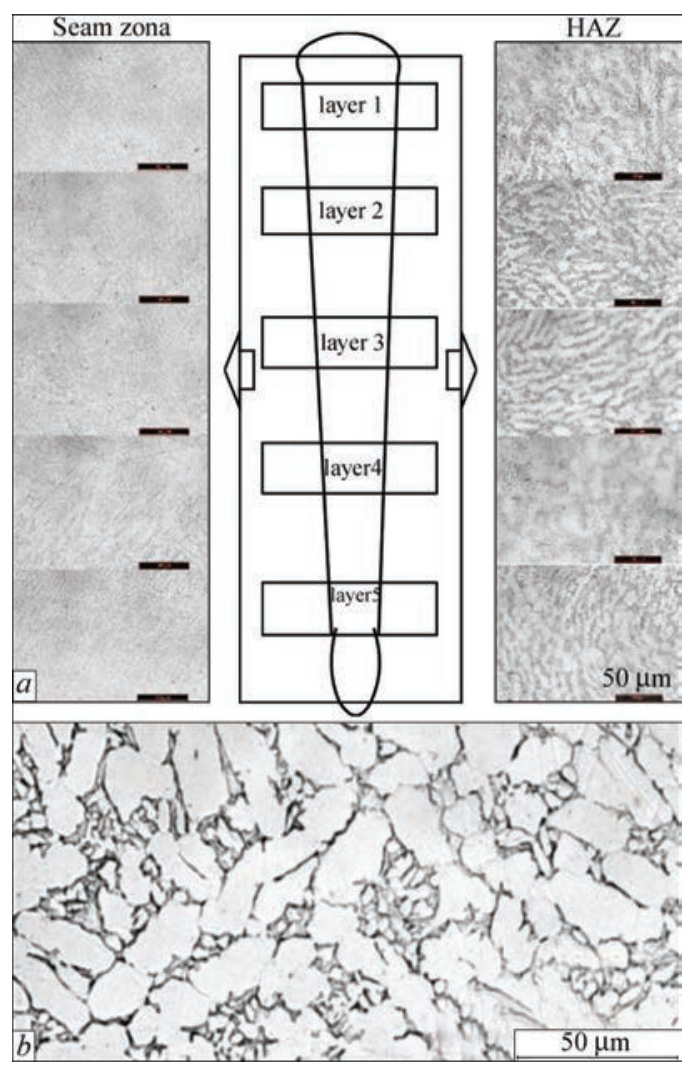

Figure 2. Microstructures of the joint: $a-$ microstructures of the seam zone and the HAZ in the thickness direction; $b-$ microstructure of the base metal

tensite and a few acicular martensite are the main phases. In the layer 2, the recrystallization happened and the microstructure of layer 2 began to transit to the crumby structure. The layer 3 mainly has crumby structure, and more acicular martensite phase could be found in layer 4 . In the layer 5 , the microstructure began to transit to basket-weave structure. It is clearly that, in the heat-treated zone, the microstructures have the trend to change from widmannstatten structure, crumby structure to basket-weave structure in the thickness direction. This trend could be attributed to the cooling speed increased gradually in the thickness direction, the lower cooling speed gave the condition to form the widmannstatten structure, the higher cooling speed facilitate the formation of the acicular martensite, hence the basket-weave structure would form when the cooling speed broke the threshold value, which has been convinced. The heterogeneity in the thickness direction will inevitably give influence on the mechanical properties of the joint.

Fatigue property. The Figure 3 showed the fatigue $S-N$ curves of different layers $\left(l_{1}, l_{2}\right.$ and $\left.l_{3}\right)$ of the joint. The average value of the specimen and the standard deviation were calculated by the next formulas, in which the $\bar{x}$ represent the average value of the specimen, the $x_{k}$ is the logarithm value of specimens, 

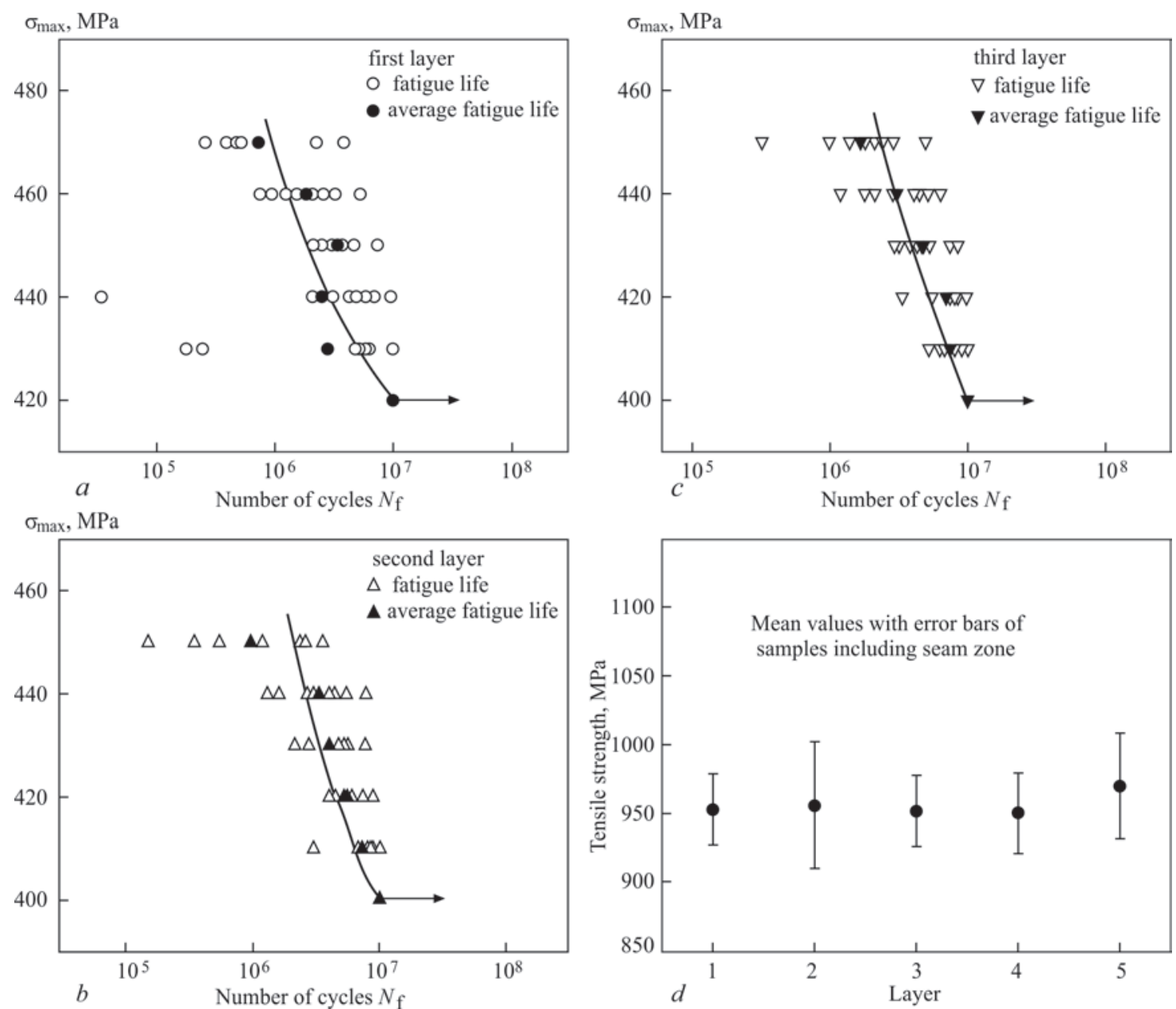

Figure 3. The fatigue $S-N$ curves of the joint: $a-S-N$ curve of layer $l_{1} ; b-S-N$ curve of layer $l_{2} ; c-S-N$ curve of layer $l_{3}$; $d-$ the tensile properties of different layers

$N_{i}$ is the fatigue life of the specimen and $s$ is the standard deviation of the specimens.

$$
\bar{x}=\frac{1}{n} \sum_{k-1}^{n} x_{k}, x_{k}=\lg \left(N_{i}\right), s=\sqrt{\frac{1}{n-1} \sum_{k=1}^{n}\left(x_{k}-\bar{x}\right)^{2}} .
$$

The standard normal deviation $\left(u_{p}\right)$ could be got by checking the normal distribution function value table and the survival probability $\left(1-p_{f}\right)$, and hence the fatigue life with the survival probability can be calculated by formulas.

$$
x_{p}=\bar{x}+u_{p} s, N_{p}=10^{x}
$$

The $x_{p}$ represent the logarithm fatigue life of the specimens, the $N_{p}$ is the calculated fatigue life. By calculated the $N_{p}$ values of the specimens represent different layers the $P-S-N$ curves can be got in Figure 4.

In Figure 3, the hollow points represent the fatigue life under different stress levels. The solid points represent the average fatigue life under different stress levels. It could be seen that the fatigue strength of the layers are $420 \mathrm{MPa}\left(l_{1}\right), 400 \mathrm{MPa}\left(l_{2}\right)$ and $420 \mathrm{MPa}$

$\left(l_{3}\right)$. The layer $l_{2}$ has relatively lower fatigue strength value. Compared with the tensile properties of the joint (Figure 3,d), it is clearly that the middle layers also have relatively lower tensile strength. It could be seen in the Figure 2, $a$ the middle layers have relatively finer textures. The low fatigue strength could only be attribute to the forging defects such as the residual casting structures, vortex and inner crack origination by the forging stress, which have been coming with the base metal, because the forging stress is relatively high and the forging defects are sensitive in the middle layer of the thick plate. It could also be seen that all the fatigue specimens of the 3 layers survive after the $10^{7}$ tensile $400 \mathrm{MPa}$ loading cycles. The joint welded by EBW has good fatigue resistance capability at the $400 \mathrm{MPa}$.

The fatigue life points of the 3 layers at different stress levels show the same trend, namely the distribution of the points at the lower stress levels are more concentrated, and the data points are dispersed under higher stress levels. That means the fatigue life of the specimens have big differences under high level stress. Since the cyclic waveform is the sinusoid and the specimens were tested at $100 \mathrm{~Hz}$ frequency, actu- 
Calculated constants of the crack propagation rate

\begin{tabular}{|c|c|c|c|}
\hline \multicolumn{2}{|c|}{ Specimen No. } & $C$ & $m$ \\
\hline \multirow{3}{*}{ Layer $l_{1}$} & 1 & $4.96 \cdot 10^{-11}$ & 4.60 \\
\cline { 2 - 4 } & 2 & $1.20 \cdot 10^{-12}$ & 5.64 \\
\cline { 2 - 4 } & 3 & $3.59 \cdot 10^{-14}$ & 6.71 \\
\hline \multirow{3}{*}{ Layer $l_{2}$} & 4 & $3.28 \cdot 10^{-10}$ & 4.42 \\
\cline { 2 - 4 } & 5 & $2.12 \cdot 10^{-11}$ & 5.21 \\
\cline { 2 - 4 } & 6 & $1.85 \cdot 10^{-12}$ & 4.11 \\
\hline \multirow{3}{*}{ Layer $l_{3}$} & 7 & $2.93 \cdot 10^{-14}$ & 6.83 \\
\cline { 2 - 4 } & 8 & $4.35 \cdot 10^{-16}$ & 8.24 \\
\cline { 2 - 4 } & 9 & $3.46 \cdot 10^{-16}$ & 7.97 \\
\hline
\end{tabular}

ally the distribution of the data points have relation with the loading rate. The high loading rate and the increasing loading force result dispersed distribution of the data point, and the lower loading rate and loading force could concentrate the data point. It can also be seen from Figure 3 that most specimens survive after loading $10^{5}$ cycles even at the higher stress level (460 MPa), the specimens tested at the $440 \mathrm{MPa}$ could survive after the $10^{6}$ cycles' load. The fatigue life of the second layer, namely the middle layer of the joint, have lower fatigue life at the same stress level. Figure 4 show the comparison of the $P-S-N$ curves of the 3 layers. It can be seen directly that the fatigue life of the $l_{3}$ layer under the $95 \%$ joint survival rate is higher than that of the $l_{1}$, and the fatigue life of the $l_{2}$ is the lowest one.

The fatigue crack propagation rate could be depicted by the following formula (see table) proposed by Paris [6]. The a represents the length of the fatigue crack, the $N$ is the loading cycle number, the $d a / d N$ represent the fatigue crack propagation rate, $\Delta K$ is the stress intensity factor of the crack tip, $C$ and $m$ are the material constants which have relationships with the experiment conditions. The calculated $C$ and $\mathrm{m}$ of the specimens taken from the 3 layers could be seen in Table, through which the fatigue crack propagation rate of the Ti-6Al-4V joint could be expressed as functions between the $d a / d N$ and the $\Delta K$. It could be found the trend by comparing the data in table1. If the $\Delta K$ is the same value, the crack propagation rate of the layer $l_{2}$ is the highest in the 3 layers. These results could further convince the conclusions of the $P-S-N$ curves in the end of last paragraph. Further work needs to be done to clarify the precise stress differences of the 3 layers, though we have already could deduce the differences of the stress between the layers are relatively small, which cannot change the trend of the fatigue life comparison of the layers (layer $l_{1}, l_{2}$ and $l_{3}$ ):

$$
d a / d N=C(\Delta K)^{m} .
$$

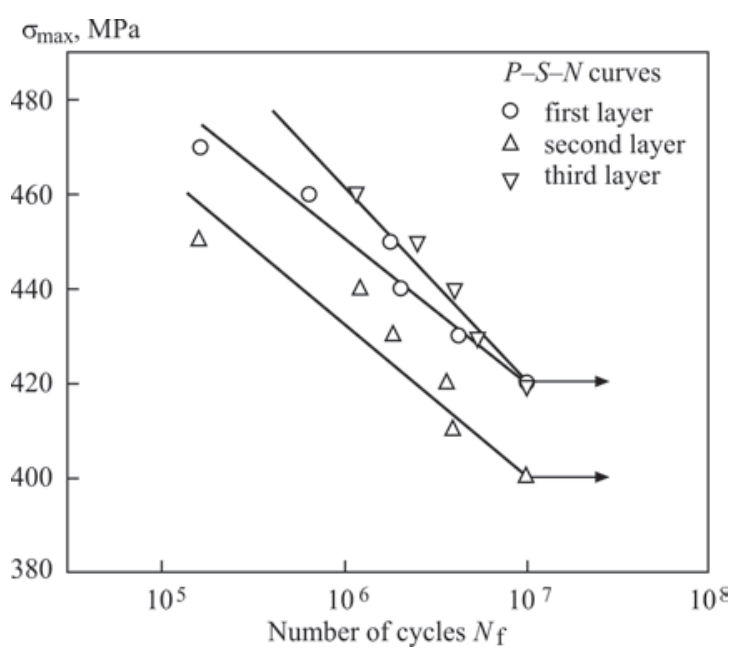

Figure 4. The comparison of the $P-S-N$ curves of different layers

Fatigue fracture surface analysis. Figure 5, a shown the fatigue crack origination zone of the specimens taken from the 3 layers, which were tested at $450 \mathrm{MPa}$. Figure $5, b$ is the representative results of the microstructure of the fatigue fractures at $440 \mathrm{MPa}$. The arrows in Figure $5, a$ point to the free surface. The results indicate that the fatigue cracks of the 3 layers originated at the free
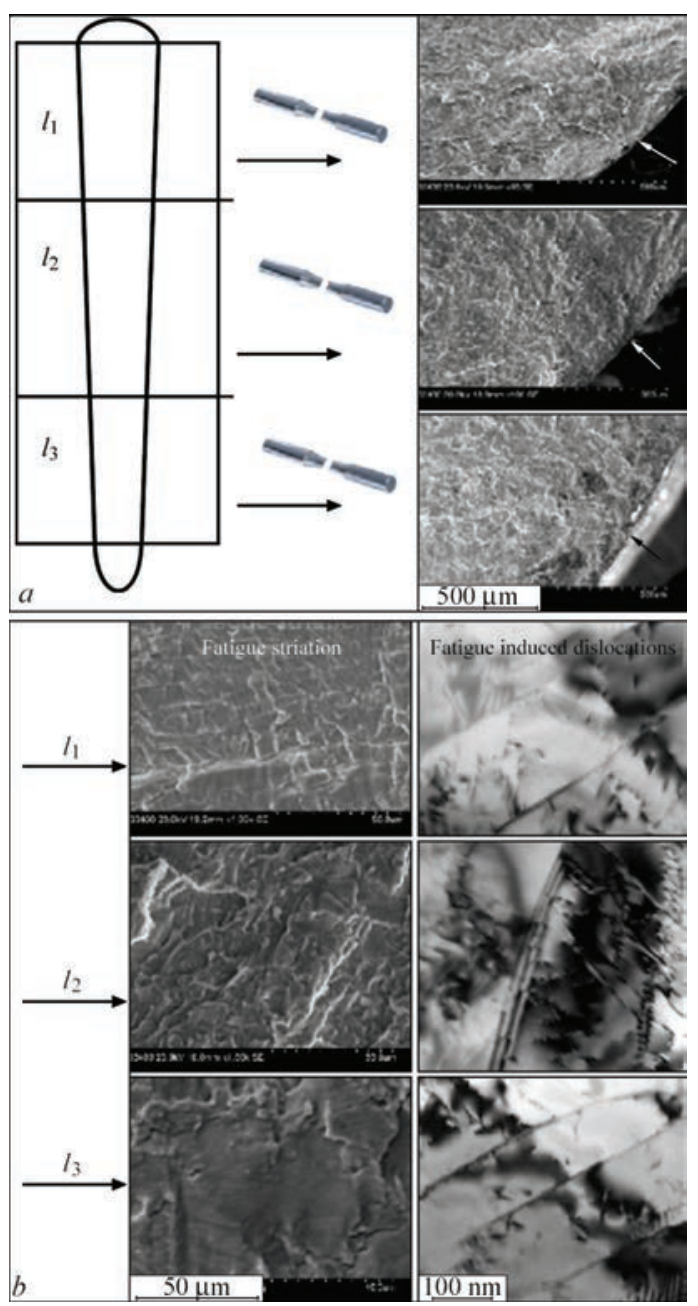

Figure 5. Fatigue fracture surface observation of the layers in the thickness direction: $a$ - fatigue crack origination; $b-$ fatigue striations and dislocations observation 
surfaces by the transgranular fracture mode, because the fatigue striations could be found in the morphologies of the fatigue propagation regions in all 3 layers (Figure 5, $b$ ). That means the 3 layers have the same fracture mode at $450 \mathrm{MPa}$. The microstructures of the fatigue fracture surfaces can be seen in the right side of the Figure 5, $b$. Low-density dislocation walls can be found in the specimen of the layer $l_{1}$ in Figure $5, b$, and the dislocation blocks can also be found between the dislocation walls. The explicit dislocation walls can be found in the specimen of the layer $l_{2}$ either, there are dislocation lines in different slipping directions which could be seen between the dislocation walls, no dislocation blocks were found between the dislocation walls. The low-density dislocation walls also were found in the specimen of the layer $l_{3}$, however there are few dislocation lines were found between the dislocation walls.

The results shown that the deformation mechanisms of the joint at 3 layers under high cycle fatigue are all planar-slip deformation mechanism. In the 3 layer, some of the dislocations show the dislocation wall characteristics, and the dislocation wall is formed by lots of short dislocations having the same orientation. The grain boundaries, the sub-grain boundaries and the phase boundaries are the zones in which the dislocation walls tend to easily form. The interactions between the boundaries and the dislocations usually be very complicated. The dislocation walls could react with the solo dislocation, the grain boundaries and the phase boundaries, as well as the sub-grain boundaries, which would be harmful for the fatigue life of the specimens.

\section{Conclusions}

The Ti-6Al-4V $100 \mathrm{~mm}$ thick part were welded by the EBW method under vacuum condition. The joint has heterogeneity not only in the microstructure but also in fatigue properties.

In the thickness direction, the microstructure of the seam has basket-weave microstructures, including acicular martensite and dendrite phases. The dendrite crystals have the trend to become finer and finer in the thickness direction from the upper seam surface to nail tip direction surface. The microstructures of the HAZ have the trend to change from widmannstatten structure, crumby structure to basket-weave structure.

The fatigue strength under $10^{7}$ cycle load of the layer $l_{2}$ is lower than those of the layer $l_{1}$ and layer $l_{3}$. The fatigue life of the $l_{3}$ layer under the $95 \%$ joint survival rate is higher than that of the $l_{1}$, and the fatigue life of the $l_{2}$ is the lowest one. The fatigue crack propagation functions have been got by the Paris formula and the experimental conditions.

The fatigue crack of all the 3 layers originated on the free surface and have transgranular fracture mode with the crack propagation. The dislocation wall structure could be found in the specimens taken from each layer. The fatigue deformations of the joints develop with the changing of the dislocations in the planar-slip mechanism.

Acknowledgement. This work is supported by the funding of the projects No.2016B070701025, No.2014B070705007, No.2017A070701026, No.2017GDASCX-0113, Pangang project-2014-03 and 2015-10.

1. Zhang HT, He P, Feng JC and Wu HQ, (2006) Interfacial microstructure and strength of the dissimilar joint $\mathrm{Ti}_{3} \mathrm{Al} / \mathrm{TC}_{4}$ welded by the electron beam process. Mater. Sci. and Eng. A 425, 255-259.

2. Barreda JL, Santamar Hma F, Azpiroz X, Irisarri AM, and Varona JM, (2001) Electron beam welded high thickness $\mathrm{Ti}_{6} \mathrm{Al}_{4} \mathrm{~V}$ plates using filler metal of similar and different composition to the base plate. Vacuum, 62, 143-150.

3. Hu MJ and Liu JH, (2009) Effect of zonal heat treatment on residual stresses and mechanical properties of electron beam welded $\mathrm{TC}_{4}$ alloy plates. Transact. Nonferrous Met. Soc. China, 19, 324-329.

4. Lu W, Shi YW, Lei YP and Li XY, (2012) Effect of electron beam welding on the microstructures and mechanical properties of thick TC4-DT alloy. Materials and Design, 34, 509515.

5. Li QH, Hu SB and Li XZ et. al., (2010) Microstructure heterogeneity and fatigue property of weld joints of $\mathrm{TC}_{4}$ titanium alloy. Mat. Eng. China, 1, 62-68.

6. Paris, P., Erdogan, F. (1963) A critical analysis of crack growth laws. J. of Basic Eng., Transact. of the ASME, 85, 528-5341.

Received 01.07.2019 


\title{
HEAT-RESISTANT THERMAL SPRAYED COATINGS BASED ON FeAICr INTERMETALLIDE WITH CeO ADDITIVES* $^{*}$
}

\author{
Yu.S. BORISOV ${ }^{1}$, A.L. BORISOVA ${ }^{1}$, T.V. TSYMBALISTA ${ }^{1}$, N.I. KAPORIK ${ }^{1}$ and M.A. VASILKOVSKAYA ${ }^{2}$ \\ ${ }^{1}$ E.O. Paton Electric Welding Institute of the NAS of Ukraine \\ 11 Kazymyr Malevych Str., 03150, Kyiv, Ukraine. E-mail: office@paton.kiev.ua \\ ${ }^{2}$ Frantsevich Institute for Problems of Materials Science \\ 3 Krzhizhanovskogo Str., 03680, Kyiv, Ukraine. E-mail: kiparis-gpk@ukr.net
}

\begin{abstract}
The paper presents the results of studying the heat resistance of coatings, produced by the methods of plasma (PS) and high-velocity oxy-fuel spraying (HVOF), using composite powder based on $\mathrm{FeAlCr}$ with addition of 2 wt.\% $\mathrm{CeO}_{2}$, as well as by the methods of electric arc metallization (EM) and activated electric arc metallization (AM) with using of flux-cored wire of the following composition: $98(82 \mathrm{Fe}+16 \mathrm{Al}+2 \mathrm{Cr})+2 \mathrm{CeO}_{2}$ (wt.\%). Composite powder was prepared by the method of mechanochemical synthesis (MS) by treating a mixture of powder components in a planetary-type mill. Heat resistance testing was performed in air at 800,900 and $1000^{\circ} \mathrm{C}$ for $7 \mathrm{~h}$ by weight method. Coating structure after heat resistance testing was studied with application of metallographic and X-ray structural analysis (XRD). It is found that during testing of coatings produced by PS and HVOF methods the delamination phenomenon is observed, whereas coatings produced by AM and EM methods preserve a tight bond strength with the substrate. Obtained kinetic curves of heat resistance showed that in the entire time interval of testing at $800-1000{ }^{\circ} \mathrm{C}$ the oxidation mechanism follows the parabolic law. The data of kinetic dependencies were used to plot the parametric heat resistance diagrams, allowing evaluation of fatigue life time of the studied protective coatings in the temperature range of $800-1000^{\circ} \mathrm{C}$. The highest heat resistance is found in $\mathrm{FeAlCrCeO}_{2}$ coatings produced by $\mathrm{AM}$ and $\mathrm{EM}$ methods with using of flux-cored wire. At $1000{ }^{\circ} \mathrm{C}$ it exceeds the resistance of steel 45 by 23-26 times, and corresponds to heat resistance of 08Cr17Ti steel. 12 Ref., 2 Tables, 8 Figures.
\end{abstract}

Keywords: thermal spraying, electric arc spraying, iron-aluminium intermetallides, mechanochemical synthesis, composite powder, flux-cored wire, parametric heat resistance diagram, $\mathrm{FeAlCr}-\mathrm{CeO}$ system

One of the modern actual tasks of surface engineering is the development of coatings and their technologies of deposition that provide protection of parts, structural elements and components of equipment from high-temperature corrosion and wear, in particular, heat power units and devices operating in combustion flows of different kinds of fuels. These include heating surfaces of boilers of heat power plants, waste burning plants, as well as elements of recuperators. The development of new designs of recuperators, which allow increasing the degree of using heat of exhaust gases by $15-20 \%$, is associated with the need in providing the protection of their elements by using of coating with an increased heat resistance.

In this regard, $\mathrm{Fe}_{3} \mathrm{~A} 1$ and FeA1 iron intermetallides, characterizing by a high heat resistance at $600-1000{ }^{\circ} \mathrm{C}$ and resistance to erosion wear under attack of gas flows, are promising materials as functional protective coatings for such practical purpose [1]. Their advantage over nickel intermetallides is the increased resistance to high-temperature corrosion in sulfur-containing gas environments [1, 2].
Theoretical and experimental works performed in the field of heat resistance of iron intermetallides showed that by optimizing the content of alloying elements, in particular chromium, it is possible to increase their resistance to high-temperature corrosion and mechanical properties [3, 4]. Another possibility of increasing heat resistance of high-temperature Feand Ni-alloys and coatings based on them is associated with the use of rare-earth metals alloys and oxides as alloying additives [5-7]. The results of experimental investigations of the effect of $\mathrm{CeO}_{2}$ additives in the intermetallide $\mathrm{FeAl}$-coating produced by $\mathrm{HVOF}$ methods showed that with its content being $2-5$ wt.\%, the resistance of FeA1- $\mathrm{CeO}_{2}$ material is increased by 2.0-2.5 times not only to oxidation, but also to erosion wear at $700-800{ }^{\circ} \mathrm{C}$. In addition, it was found that introduction of $\mathrm{CeO}_{2}$ reduces the rate of depletion of aluminum content in the coating, thus increasing the life time of protective properties of the coating [8].

The results of practical application of FeA1-coating in the conditions of a waste burning plant confirmed its effectiveness of protecting the surface of

${ }^{*}$ In the work A.N. Burlachenko, A.P. Grishchenko, I.A. Demyanov and V.N. Lopata participated. 


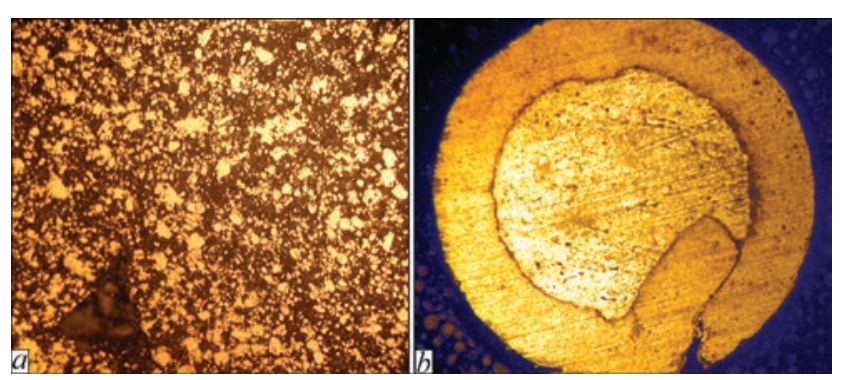

Figure 1. Microstructure $(\times 400)$ of powder $\mathrm{FeAlCr}+\mathrm{CeO}_{2}$ produced by the method of MS (a) and cross-section of flux-cored wire $\mathrm{Fe}+\mathrm{Al}+\mathrm{Cr}+\mathrm{CeO}_{2}(b)$

the equipment of such enterprises from corrosion and erosion wear [9].

The development of the technology of thermal spraying of protective FeA1-coatings is connected with the solution of the problem of starting materials production. The deposition of FeA1-coatings by high-velocity oxy-fuel spraying can be carried out using both powders as well as flux-cored wires $[9,10]$.

In the present work, deposition of coatings was carried out by both plasma and high-velocity oxy-fuel spraying using powders based on FeAl, as well as electric arc spraying of coatings from flux-cored wires based on FeA1 with introduction of $\mathrm{CeO}_{2}$.

Objects of investigations and experimental procedure. For manufacture of samples with heat-resistant coatings by thermal spraying methods, a composite powder (CP) of the following composition was prepared (wt.\%): $98(82 \mathrm{Fe}+16 \mathrm{~A} 1+2 \mathrm{Cr})+2 \mathrm{CeO}_{2}$.

As starting materials, the following powders were used: Fe, 63-160 $\mu \mathrm{m} ; \mathrm{Al}, 40-100 \mu \mathrm{m} ; \mathrm{Cr}<100 \mu \mathrm{m}$; $\mathrm{CeO}_{2}<40 \mu \mathrm{m}$.

Production of the composite powder was performed by the method of mechanochemical synthesis (MS), which was carried out in the planetary-type mill «Activator 2SL» (JSC «Activator», Novosibirsk, Russia) at a rotation speed of central disk being $1000 \mathrm{rpm}$, and that of drums, rotating in the opposite direction, being $1500 \mathrm{rpm}$. The MS process was carried out in the atmosphere of air for $5 \mathrm{~h}$. During the MS process, the water cooling of drums and planetary-type mechanism was performed. To eliminate sticking of the treated charge material onto the drum wall and grinding bodies at the beginning of the MS

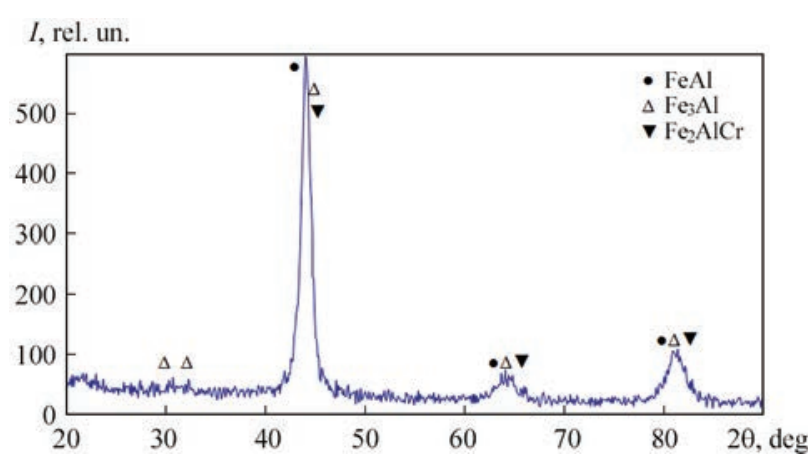

Figure 2. X-ray pattern of MS-powder $\mathrm{FeAlCr}+\mathrm{CeO}_{2}$ produced in the planetary-type mill during $5 \mathrm{~h}$

process, a surface-active substance (oleic acid, in the amount of $0.3 \mathrm{wt} . \%$ ) was added to the mixture.

For deposition of coatings using the methods of electric arc metallization (EM) and activated electric arc metallization (AM), a flux-cored wire (FCW) of $1.85 \mathrm{~mm}$ diameter was manufactured (Figure $1, b$ ) at a thickness of sheath of $0.5 \mathrm{~mm}$ of low-carbon rimmed steel 08. As a filler, a mechanical mixture of powders $\mathrm{Al}, \mathrm{Cr}$, and $\mathrm{CeO}_{2}$ in a ratio of 80:10:10 (wt.\%) was used. The degree of filling is $14 \mathrm{vol} \%$, the calculated composition of the flux-cored wire (wt.\%) is 98 $(82 \mathrm{Fe}+16 \mathrm{~A} 1+2 \mathrm{Cr})+2 \mathrm{CeO}_{2}$.

The microstructure of the MS-powder FeA1Cr + $\mathrm{CeO}_{2}$ and the cross-section of the flux-cored wire $\mathrm{FeAlCr}+\mathrm{CeO}_{2}$ are shown in Figure 1.

As was shown by the results of X-ray phase analysis (XRD) (Figure 2), during the MS process, a composite powder is formed containing the phases $\mathrm{FeAl}, \mathrm{Fe}_{2} \mathrm{~A} 1 \mathrm{Cr}$, $\mathrm{Fe}_{3} \mathrm{~A} 1$, which after the operation of conglomeration was used for deposition of coatings by plasma (PS) and high-velocity oxy-fuel (HVOF) spraying methods.

Plasma spraying (PS) of coatings was carried out by using of the installation UPU-8M with the following parameters: $I=500 \mathrm{~A}, U=45 \mathrm{~V}$, the rate of plasma-forming gas $\left(\mathrm{Ar}+\mathrm{N}_{2}\right)$ was $25 \mathrm{l} / \mathrm{min}$, the spraying distance was $L=120 \mathrm{~mm}$. For spraying, a powder with a particle size $<40 \mu \mathrm{m}$ was used.

Coating by HVOF spraying was deposited under the following process parameters:

- rate of propane-butane is $0.2 \mathrm{~m}^{3} / \mathrm{h}$, pressure is $4.5 \mathrm{~atm} ;$

- oxygen rate is $0.5 \mathrm{~m} / \mathrm{h}$, pressure is $7 \mathrm{~atm}$;

Table 1. Characterization of thermal coatings produced from the MS-powder FeCrA1 $+\mathrm{CeO}_{2}(\mathrm{PS}, \mathrm{HVOF})$ and $\mathrm{FCW} F e+\mathrm{A} 1+\mathrm{Cr}+$ $\mathrm{CeO}_{2}$ (EM and $\left.\mathrm{AM}\right)$

\begin{tabular}{|c|c|c|c|}
\hline Method of deposition & Thickness, $\mu \mathrm{m}$ & $\mathrm{H} \mu, \mathrm{MPa}$ & Phase composition \\
\hline PS & $250-300$ & $3890 \pm 1180$ & $\mathrm{FeAl}, \mathrm{Fe}_{3} \mathrm{Al}, \mathrm{FeCr}, \mathrm{CeAlO}{ }_{3}$ \\
\hline HSFS & $250-300$ & $3376 \pm 683$ & $\mathrm{FeAl}, \mathrm{Fe}_{3} \mathrm{Al}, \mathrm{Fe}_{2} \mathrm{AlCr}, \mathrm{CeAlO}, \mathrm{Al}_{4} \mathrm{Ce}$ \\
\hline AAM & $125-210$ & $2458 \pm 31$ & $\mathrm{Fe}, \mathrm{Al}, \mathrm{FeAl}, \mathrm{Fe}-\mathrm{Cr}, \mathrm{CrO}$ \\
\hline EAM & $440-700$ & $2150 \pm 433$ & $\mathrm{FeAl}, \mathrm{Fe}{ }_{3} \mathrm{Al}, \mathrm{Fe}-\mathrm{Cr}$ \\
\hline
\end{tabular}



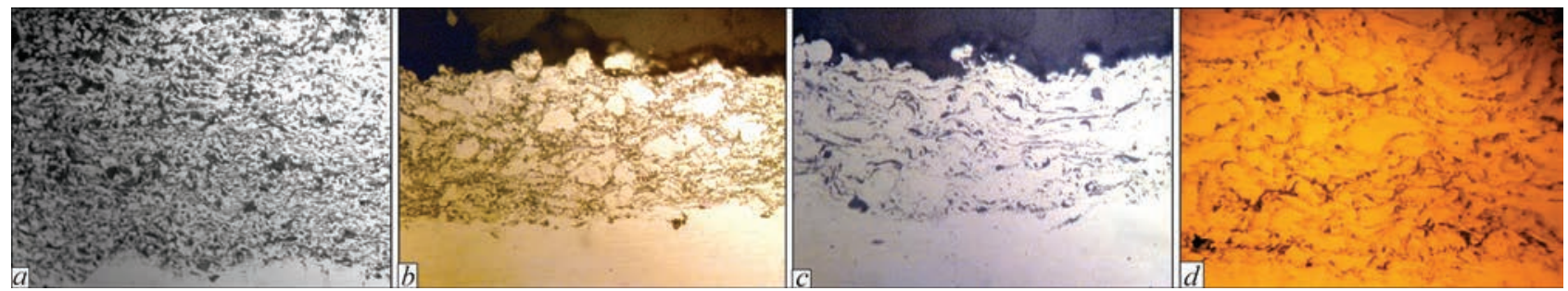

Figure 3. Microstructure $(\times 400)$ of coatings: PS $(a)$, HVOF $(b)$ from MS-powder FeAlCr $+\mathrm{CeO}_{2}$ and AM (c), EM (d) from flux-cored wire $\mathrm{FeAlCr}+\mathrm{CeO}_{2}$

- pressure of transporting gases (air and nitrogen) is $6 \mathrm{~atm}$;

- spraying distance is $120-150 \mathrm{~mm}$;

- particle size is $<63 \mu \mathrm{m}$.

The study of the heat resistance of coatings was carried out in the temperature range of $800-1000{ }^{\circ} \mathrm{C}$ in a specially designed installation by periodic weighing directly in the furnace at the test temperature.

The obtained results were compared with the test results of stainless steel $08 \mathrm{Cr} 17 \mathrm{Ti}$ and steel 45 , and for steel 45 the test temperatures were 700 and $800{ }^{\circ} \mathrm{C}$ due to its low heat resistance.

Producing coatings by the method of activated arc metallization was carried out using the AM-installation using of the following parameters:

- air pressure is $6 \mathrm{~atm}$;

- propane-butane pressure is $3 \mathrm{~atm}$;

- voltage is $30 \mathrm{~V}$, current strength is $250 \mathrm{~A}$;

- spraying distance is $100 \mathrm{~mm}$.
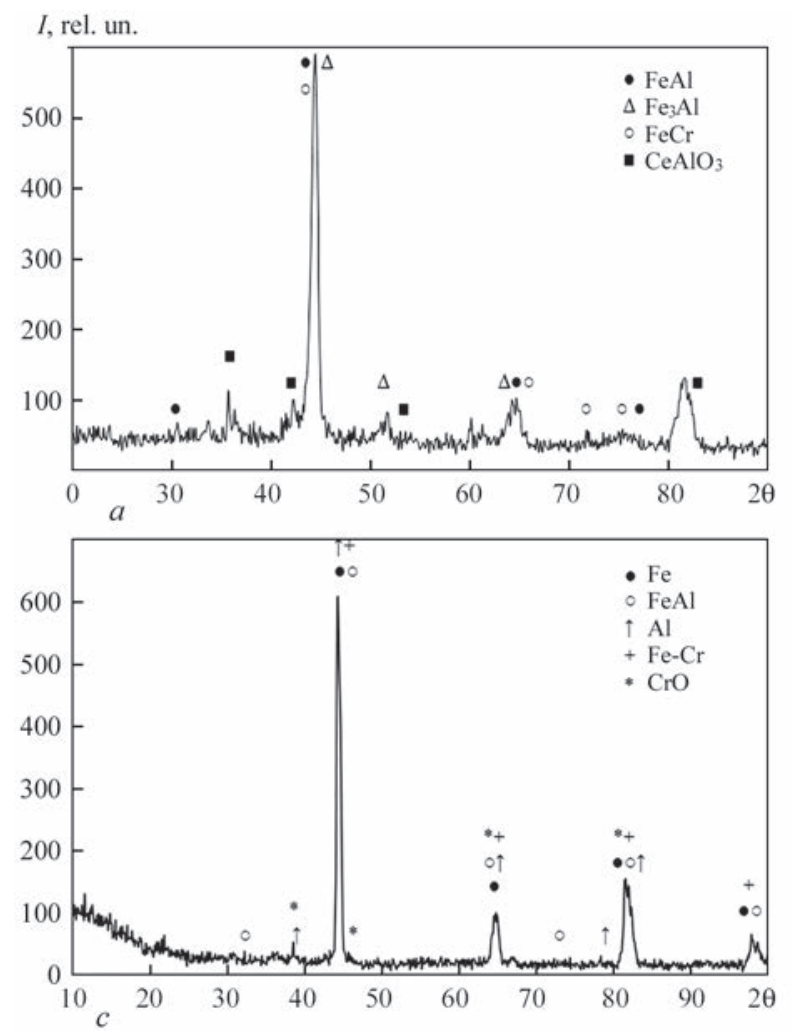

Parameters of the coating process by the method of electric arc metallization, carried out using the metal spray gun EM-14, were the following:

- air pressure is $6.5 \mathrm{~atm}$;

- voltage is $36 \mathrm{~V}$, current is $80 \mathrm{~A}$;

- spraying distance is $100-120 \mathrm{~mm}$.

Coatings were deposited on samples of steel 45 with a diameter of $10 \mathrm{~mm}$ with the shape of an acorn.

Experimental results and discussion. A metallographic analysis of sprayed coatings (Figure 3) showed that in all cases on the surface of samples of steel 45 dense coatings are formed that are homogeneous in structure and composition, without defects and delaminations at the interface with the substrate.

Using the XRD method, it was found that during the process of coating deposition from the powder $\mathrm{FeAlCr}+\mathrm{CeO}_{2}$ by PS and HVOF methods, the coatings which were formed, contain the products of interphase interaction of the spray composite powder, as well as oxides $\mathrm{Fe}_{3} \mathrm{O}_{4}, \mathrm{FeAl}_{2} \mathrm{O}_{4}$, and $\mathrm{CeAlO}_{3}$, that is the
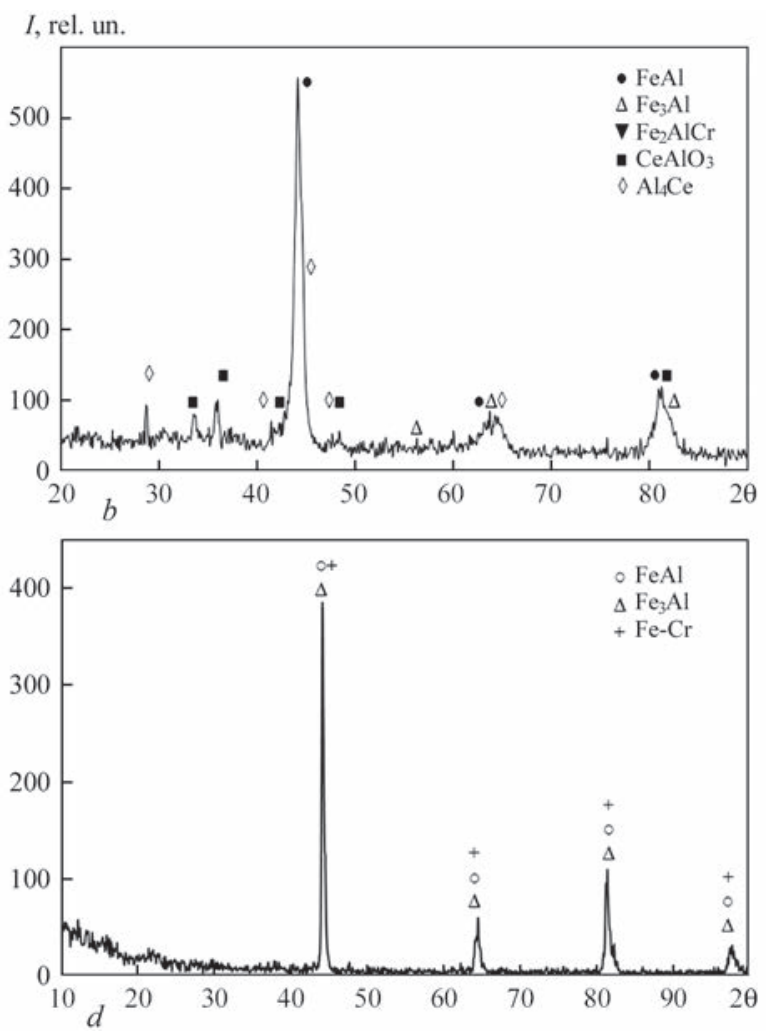

Figure 4. X-ray patterns of coatings: PS (a), HVOF (b), from MS-powder $\mathrm{FeAlCr}+\mathrm{CeO}_{2}$ and $\mathrm{AM}(c)$, EM (d) from flux-cored wire $\mathrm{Fe}+\mathrm{A} 1+\mathrm{Cr}+\mathrm{CeO}_{2}$ 

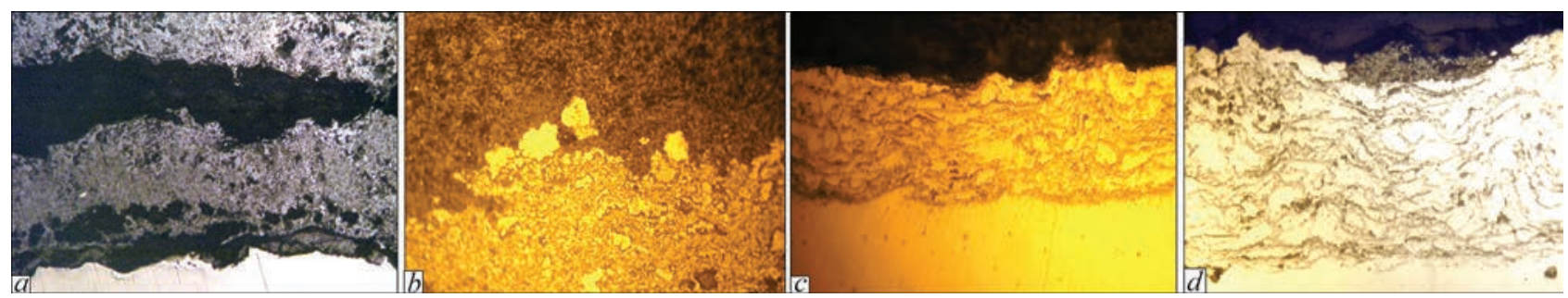

Figure 5. Microstructure $(\times 400)$ of TS-coatings produced from MS-powder $\mathrm{FeA} 1 \mathrm{Cr}+\mathrm{CeO}_{2}$ using the method of PS $(a)$, HVOF $(b)$ and $\mathrm{Fe}+\mathrm{Al}+\mathrm{Cr}+\mathrm{CeO}_{2}$ produced using methods of $\mathrm{AM}(c)$ and $\mathrm{EM}(d)$, after tests on heat resistance at $1000{ }^{\circ} \mathrm{C}$

result of $\mathrm{CP} \mathrm{FeAl}+\mathrm{CO}_{2}$ components oxidation during spraying process. In terms of qualitative composition, the coatings do not practically differ (Figure 3, $a, b$ ) and (Figure 4, $a, b$ ), but only a higher content of oxides in plasma coatings can be noted as compared to HVOF, which is probably connected with a higher degree of dispersion of sprayed particles.

In the AM- and EM-coatings, oxide phases as well as traces of $\mathrm{CeO}_{2}$ were not detected after applying the XRD method (Figure 4, $c, d$ ). The difference between the phase composition of AM- and EM-coatings formed by spraying from flux-cored wires is in the fact, that in the AM-coating, the reaction between the wires components Fe and A1 during the spraying process does not completely occur and these elements are contained in a pure form.

The results of metallographic analysis of coatings, that passed a heat resistance test showed, that plasma and thermal coatings (Figure 5, $a, b$ ) are cracked and delaminated from the substrate during oxidation, where as coatings deposited by electric arc metallization (AM and EM), are tightly bonded to the substrate and do not delaminate even after testing at a temperature of $100{ }^{\circ} \mathrm{C}$ for $5 \mathrm{~h}$. According to the results of XRD (Figure 6), for all types of coatings, including in EM- and AM-coatings, on their surface iron oxides and complex iron-chromium oxides and $\mathrm{CeAlO}_{3}$ oxide were found, which were not revealed in the initial state.

Figure 7 presents kinetic dependences of oxidation of thermal coatings and unprotected steels 45 and $08 \mathrm{Cr} 17 \mathrm{Ti}$ in the temperature range of $800-1000^{\circ} \mathrm{C}$ in air. The nature of the curves indicates that the oxidation mechanism in all the cases submits to the parabolic temporal law in the entire investigated temperature range of $800-1000^{\circ} \mathrm{C}$.
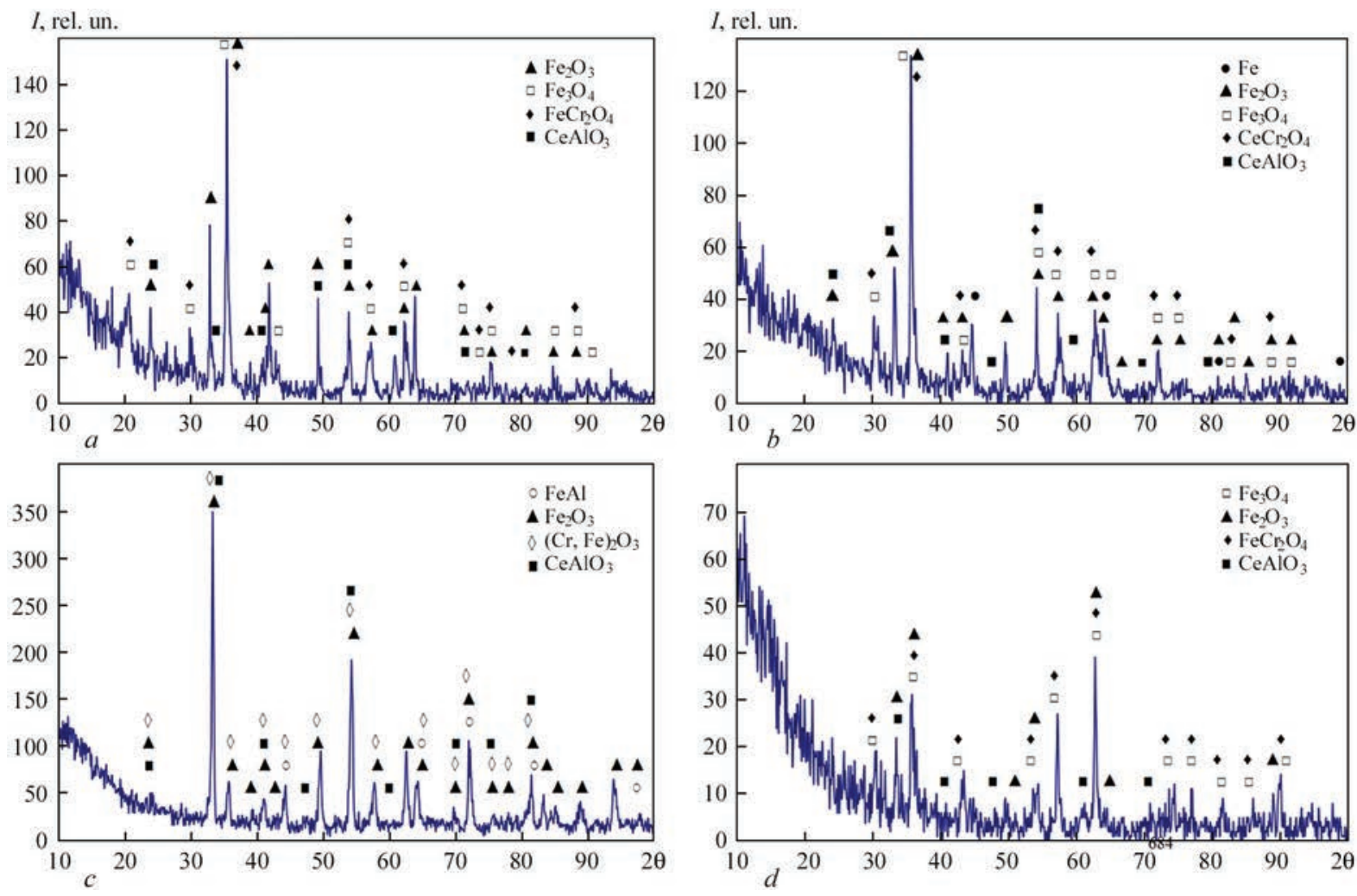

Figure 6. X-ray patterns of TS-coatings: PS (a), $\mathrm{HVOF}(b)$ from MS-powder FeA1Cr $+\mathrm{CeO}_{2}$, and $\mathrm{AM}(c)$ and $\mathrm{EM}(d)$ from flux-cored wire $\mathrm{Fe}+\mathrm{A} 1+\mathrm{Cr}+\mathrm{CeO}_{2}$ after heat resistance tests at $1000{ }^{\circ} \mathrm{C}$ 
$\Delta m / s, \mathrm{mg} / \mathrm{cm}^{2}$
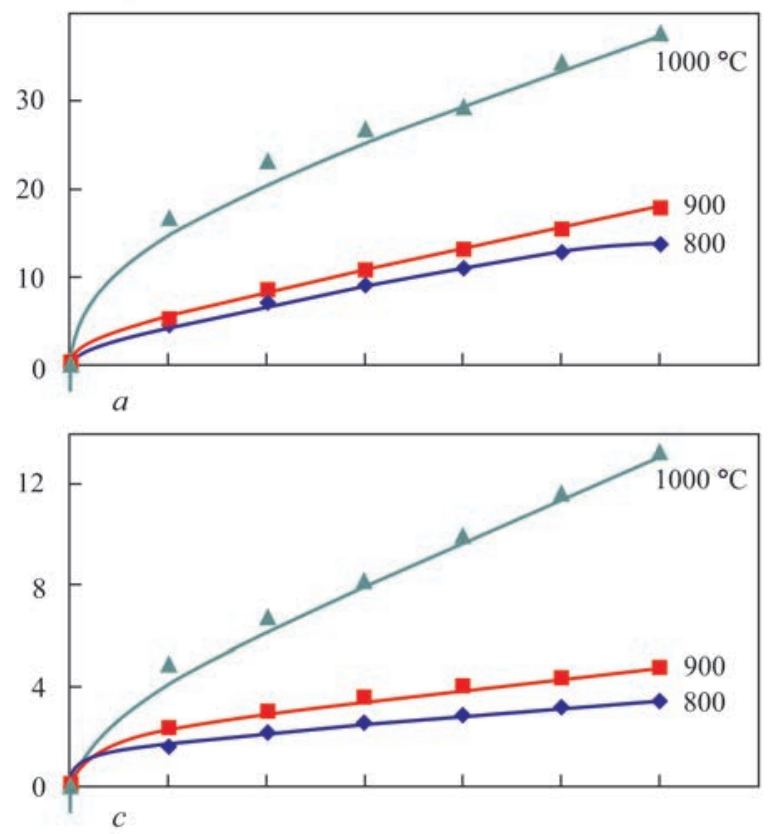

60

40

20
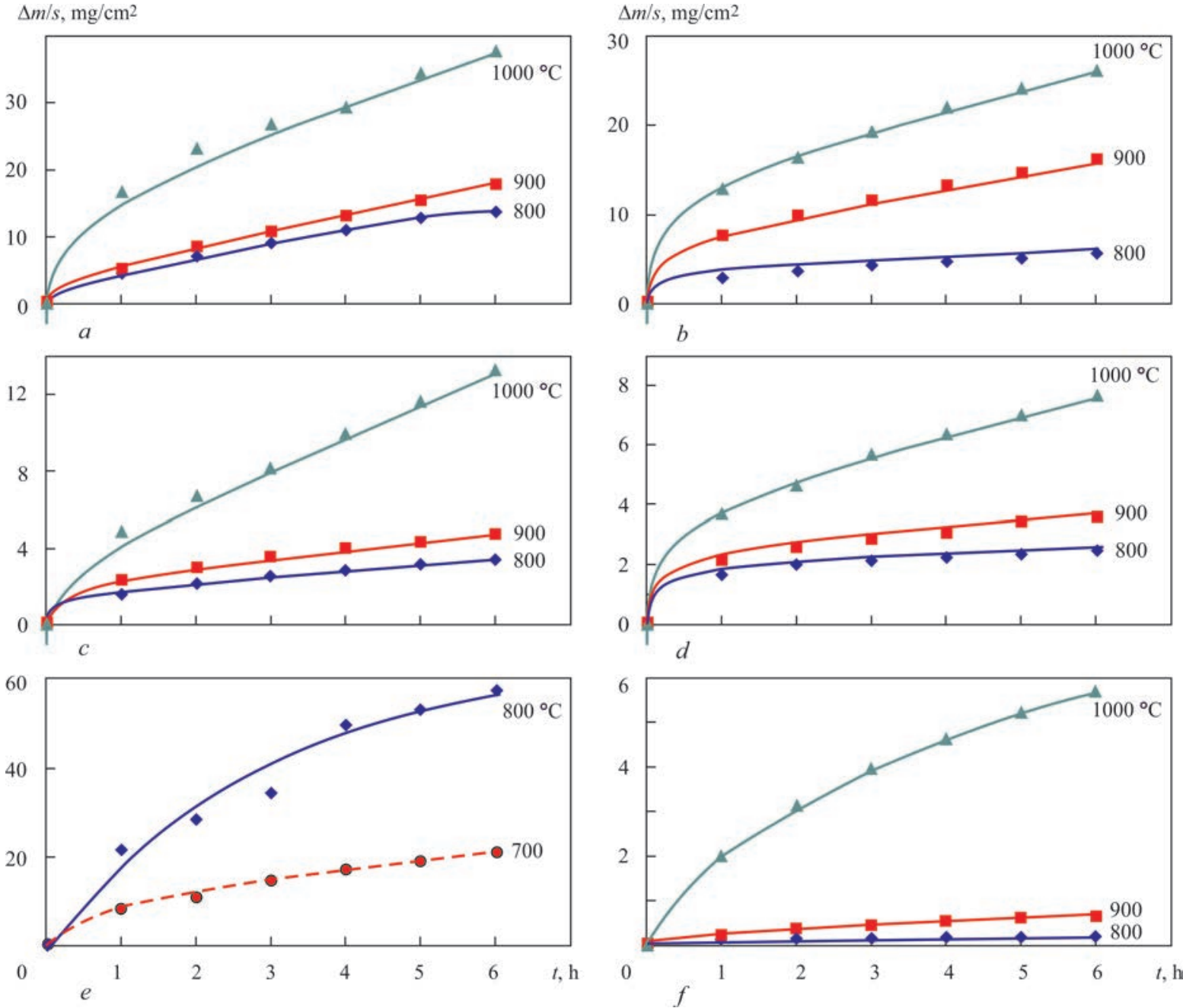

Figure 7. Kinetic dependences of oxidation of thermal sprayed coatings and unprotected steels at temperatures of 800,900 and $1000{ }^{\circ} \mathrm{C}$ in air: $a-\mathrm{PS} ; b-\mathrm{HVOF}$ produced from MS-powder $\mathrm{FeA} 1 \mathrm{Cr}+\mathrm{CeO}_{2} ; c-\mathrm{AM} ; d-\mathrm{EM}$ from $\mathrm{FCW} \mathrm{Fe}+\mathrm{A} 1+\mathrm{Cr}+\mathrm{CeO} ; d-$ steel $45 ; c$ - steel $08 \mathrm{Cr} 17 \mathrm{Ti}$

Table 2. Results of calculation of parameters of heat resistance of EM-coatings

\begin{tabular}{|c|c|c|c|c|c|c|c|}
\hline Temperature, K & $10^{3} / T, 1 / \mathrm{K}$ & $\begin{array}{c}\text { Oxidation } \\
\text { time, h }\end{array}$ & $\lg t$ & $\begin{array}{c}\text { Specific } \\
\text { increment of } \\
\text { mass, } \mathrm{mg} / \mathrm{cm}^{2}\end{array}$ & $\lg q$ & $(Q \lg e) / R T$ & $\begin{array}{c}\text { Heat resistance } \\
\text { parameter } P\end{array}$ \\
\hline \multirow{6}{*}{1074} & \multirow{6}{*}{0.932} & 1 & 0 & 1.646 & 0.216 & \multirow{6}{*}{8.53} & 8.53 \\
\hline & & 2 & 0.301 & 1.964 & 0.293 & & 8.2 \\
\hline & & 3 & 0.477 & 2.063 & 0.314 & & 8.05 \\
\hline & & 4 & 0.602 & 2.178 & 0.338 & & 7.9 \\
\hline & & 5 & 0.699 & 2.292 & 0.36 & & 7.8 \\
\hline & & 6 & 0.778 & 2.397 & 0.379 & & 7.75 \\
\hline \multirow{6}{*}{1173} & \multirow{6}{*}{0.852} & 1 & 0 & 2.078 & 0.318 & \multirow{6}{*}{7.8} & 7.8 \\
\hline & & 2 & 0.301 & 2.492 & 0.396 & & 7.5 \\
\hline & & 3 & 0.477 & 2.805 & 0.448 & & 7.3 \\
\hline & & 4 & 0.602 & 3.038 & 0.482 & & 7.2 \\
\hline & & 5 & 0.699 & 3.404 & 0.53 & & 7.1 \\
\hline & & 6 & 0.778 & 3.511 & 0.545 & & 7.02 \\
\hline \multirow{6}{*}{1273} & \multirow{6}{*}{0.785} & 1 & 0 & 3.718 & 0.57 & \multirow{6}{*}{7.2} & 7.2 \\
\hline & & 2 & 0.301 & 4.671 & 0.67 & & 6.88 \\
\hline & & 3 & 0.477 & 5.748 & 0.76 & & 6.71 \\
\hline & & 4 & 0.602 & 6.424 & 0.81 & & 6.58 \\
\hline & & 5 & 0.699 & 7.058 & 0.848 & & 6.49 \\
\hline & & 6 & 0.778 & 7.672 & 0.885 & & 6.41 \\
\hline
\end{tabular}



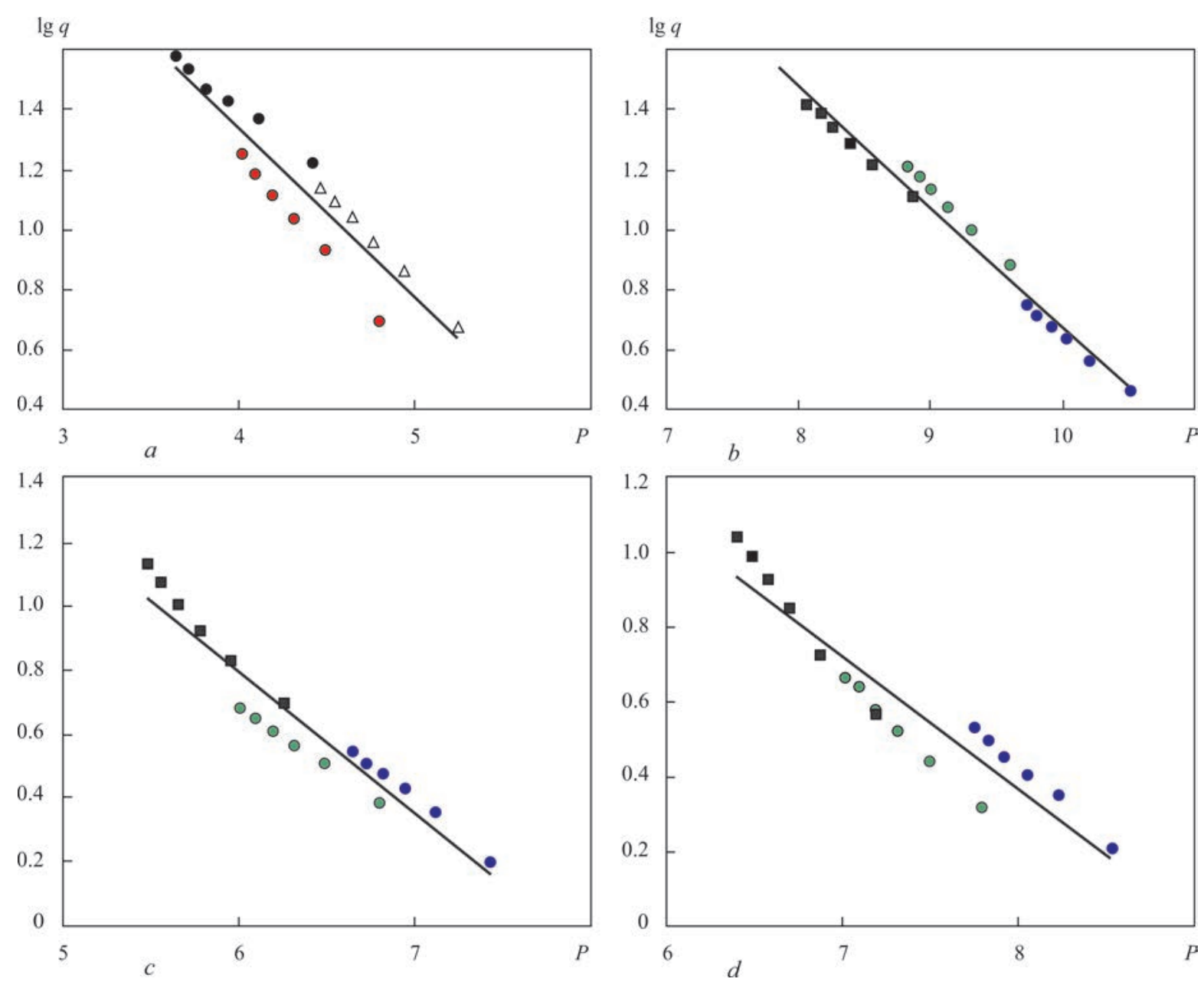

Figure 8. Parametric diagrams of heat resistance for PS (a) and HVOF (b) EM (c) and AM (d) according to results of tests on heat resistance at the temperatures of $800-1000{ }^{\circ} \mathrm{C}$ for $1-6 \mathrm{~h}$

One of the important characteristics of protective heat-resistant coatings is the prediction of their service life. Such a prediction can be made by plotting parametric heat resistance diagrams [11].

The heat resistance parametric diagram represents the dependence of the mass loss (increase) of the coating material during oxidation on the heat resistance parameter. The heat resistance parameter is a physical value, whose rate of change over time is proportional (with the opposite sign) to the intrinsic oxidation rate of the coating material, calculated from the values of relative losses (increase) of its mass [12].

The procedure for plotting parametric diagrams consists in determining the values $n$ and Q, where $n$ is the index of degree of parabolic dependence of the oxidation process and $Q$ is the activation energy.

The value $n$ is determined from the experimental kinetic dependence (Figure 7) of the specific increment (loss of mass) $q$ on time $t: q^{n}=K t$ ( $K$ is the oxidation rate constant), which during plotting in the logarithmic coordinates $\lg q-\lg t$ is transformed into a linear dependence

$$
n \lg q=\lg K+\lg t \text { or } \lg q=\frac{1}{n}(\lg K+\lg t) .
$$

Hence, $n=\operatorname{ctg} \alpha$ in the coordinates the time is $\Delta \mathrm{m} / \mathrm{s} \mathrm{mg} / \mathrm{cm}^{2}$, where $\alpha$ is the inclination angle of the straight line to the axis of abscissa, or can be calculated by the formula:

$$
n=\lg \left(t_{2} / t_{1}\right) / \lg \left(q_{2} / q_{1}\right)
$$

where $q_{1}$ and $q_{2}\left(\mathrm{~g} / \mathrm{cm}^{2}\right)$ is the specific increase (loss) of mass of coating during the oxidation time, equal to $t_{1}$ and $t_{2}$, respectively. The accuracy of calculating the value of the exponent $n$ by the formula (1) is the higher, the farther the values $t_{1}$ and $t_{2}$ are apart from each other.

The activation energy $Q$ of the oxidation process is determined using the temperature dependence $K=$ $K_{0} \exp (-Q / R T)$ through the tangent of the angle $\varphi$ formed by the straight line after taking the logarithm: $\lg K=\lg K_{0}-\lg e$.

Activation energy can also be calculated using the formula: 


$$
Q=n \lg \left(q_{2} / q_{1}\right) R / \lg e\left(\frac{1}{T_{1}}-\frac{1}{T_{2}}\right)
$$

where $e$ is the basis of natural logarithms; $R$ is the universal gas constant; $q_{1}$ and $q_{2}$ are the specific increase (loss) of mass at the temperatures $T_{1}$ and $T_{2}$, respectively.

As in the calculation of the value $n$, in this case it is recommended to choose the values of $T_{1}$ and $T_{2}$, which are sufficiently far apart from each other.

The value of the heat resistance parameter is determined on the basis of the activation energy of the coating oxidation process, calculated according to formulas (1) and (2), and also using the results of tests carried out to obtain the dependences $\lg q-\lg t$ and $\lg q-1 / T$ :

$$
P=\frac{Q \lg e}{R T}-\lg t .
$$

The results of calculating the heat resistance parameter on the example of an EM-coating of fluxcored wire $\mathrm{Fe}+\mathrm{A} 1+\mathrm{Cr}+\mathrm{CeO}_{2}$ are given in table 2, parametric diagrams - in Figure 8.

\section{Conclusion}

As a result of carried out investigations, it was found that thermal coatings produced from composite powder $\mathrm{FeA} 1 \mathrm{Cr}+\mathrm{CeO}_{2}$ and flux-cored wire $\mathrm{Fe}+\mathrm{A} 1+$ $\mathrm{Cr}+\mathrm{CeO}_{2}$ can protect steel 45 from oxidation, however, to a different extent, depending on the method of deposition.

Thus, at the temperature of $800{ }^{\circ} \mathrm{C}$, the resistance of PS-coatings exceeds steel 45 by more than 1.6 times, HVOF-coatings by 12.5 times, and AM- and EM-coatings by 23 and 26 times, respectively. AMand EM-coatings remain stable in the oxidizing environment at the level of stainless steel $08 \mathrm{Cr} 17 \mathrm{Ti}$ almost up to $1000{ }^{\circ} \mathrm{C}$. This allows recommending to substitute steel $08 \mathrm{Cr} 17 \mathrm{Ti}$ with a cheaper steel 45 with $\mathrm{AM}$ - or EM-coating of flux-cored wire $\mathrm{Fe}+\mathrm{A} 1+\mathrm{Cr}+$ $\mathrm{CeO}_{2}$ for deposition to external secondary radiators of recuperators.
Note. The article was prepared on the basis of the results of fulfillment of the project of the Program «Resurs-2» P5.1.2 «Improving life time and effectiveness of recuperative heat exchangers by deposition of heat-resistant radiating coatings to protect heating surfaces, operating in combustion flows, and modernization of inner secondary emitters».

1. Deevi, S.C., Sikka, V.K. (1996) Nickel and iron aluminides: An overview on properties, processing, and applications. Intermetallics, 4(5), 357-375.

2. Kai, W., Lee, S.H., Chiang, D.L.,Chu, J.P. (1998) The hightemperature corrosion of $\mathrm{Fe}-28 \mathrm{Al}$ and $\mathrm{Fe}-18 \mathrm{Al}-10 \mathrm{Nb}$ in a $\mathrm{H}_{2} / \mathrm{H}_{2} \mathrm{~S} / \mathrm{H}_{2} \mathrm{O}$ gas mixture. Materials Sci. and Eng. A, 258(12), 146-152.

3. Wei, S., Xu, B., Wang, H. et al. (2007) High-temperature corrosion-resistance performance of electro-thermal explosion plasma spraying FeAl-base coatings. Surface and Coatings Technology, 201(15), 6768-6771.

4. Tortorelli, P.F., Natesan, K. (1998) Critical factors affecting the high-temperature corrosion performance of iron aluminides. Materials Sci. and Eng. A, 258(1-2), 115-125.

5. Ignatov, D.V., Lazarev, E.M., Abramova, N.V. (1974) Effect of rare-earth metals on kinetics and oxidation mechanism of nickel-chromium-based alloys. In: Influence of physicochemical medium on high-temperature resistance of metallic materials. Moscow, Nauka, 68-72 [in Russian].

6. Nagai, H., Takebayashi, Y., Mitani, H. (1981) Effect of dispersed oxides of rare earths and other reactive elements on the high temperature oxidation resistance of $\mathrm{Fe}-20 \mathrm{Cr}$ alloy. Metallurgical and Materials Transact. A, 12(3), 435-442.

7. Xingwei, M., Zhuji, J., Shi, Y., Jiujun, X. (2009) Effect of $\mathrm{La}_{2} \mathrm{O}_{3}$ on microstructure and high-temperature wear property of hot-press sintering FeAl intermetallic compound. J. of Rare Earths, 27(6), 1031-1036.

8. Wang, Y., Yan, M. (2006) The effect of $\mathrm{CeO}_{2}$ on the erosion and abrasive wear of thermal sprayed $\mathrm{FeAl}$ intermetallic alloy coatings. Wear, 261, 1201-1207.

9. Xiao, Ch., Chen, W. (2006) Sulfidation resistance of $\mathrm{CeO}_{2}$-modified HVOF sprayed FeAl coatings at $700{ }^{\circ} \mathrm{C}$. Surface and Coatings Technology, 201, 3625-3632.

10. Magnee, A., Offergeld, M., Leroy, A. Lefort, A. (1998) FeAl intermetallic coatings applications to thermal energy conversion advanced systems. In: Proc. of the 15th ITSC, France, Nice, 1091-1096.

11. Nikitin, V.I. (1976) Calculation of heat resistance of metals. Moscow, Metallurgiya [in Russian].

12. Nikitin, V.I. (1981) Method of prediction of life of protective coatings. Fiz.-Khimich. Mekhanika Materialov, 3, 95-99 [in Russian]. 


\title{
EFFECT OF PRELIMINARY APPLICATION OF ALLOYING POWDERS ON THE STRUCTURE AND HARDNESS OF DEPOSITED METAL
}

\author{
V.V. PEREMITKO, I.V. KOLOMOETS and V.I. SUKHOMLIN \\ Dniprovsk State Technical University \\ 2 Dneprostroevskaya Str., Kamenskoe, Dnepropetrovskaya Region, Ukraine
}

\begin{abstract}
Considered was efficiency of use of different schemes of preliminary application of alloying powders on structure and hardness of metal deposited by arc method. The optimum parameters of the process and specific consumption of additional (alloying) materials with their preliminary fixing were determined. The highest indices of hardness of deposited metal are reached during local addition of TiC with its fixation by GF-021 primer. 11 Ref., 1 Tables, 4 Figures.
\end{abstract}

Ke y words : arc surfacing, alloying powders, additional alloying schemes, fixation of additional materials, surfacing modes, structure, hardness

For parts, especially of considerable sizes, nonuniform wear over the contact area is characteristic. In this regard, it seems logical to carry out restoration surfacing and preliminary strengthening of such surfaces using materials of variable composition, in accordance with the actual changes in linear dimensions.

At different times, the methods were proposed for staggered surfacing of layers and multiarc surfacing using high-carbon wires and alloying fluxes $[1,2]$. The disadvantage of such schemes is the need to substitute electrode material in order to achieve variability in composition and properties and the necessity to change wire feed speed, as well as the dubious constancy of specific volume of metal, applied along the length of the bead or across the surface area.

The practice of arc surfacing with preliminary introduction of additional materials allowed solving a number of problems to increase wear resistance of deposited metal. It was proposed several similar schemes, which were implemented in arc surfacing [3-9]. The following schemes based on the obtained data on hardness and wear resistance, can be considered the most effective among them: 1 - deposition of carbon fibers on bodies of revolution; 2 - introduction of nanopowders $\mathrm{SiO}_{2}$ into the weld pool; 3 application of the mixture $\mathrm{SiO}_{2}+\mathrm{Fe}$ on the treated surface in the form of a charge. In scheme 1, carbon fibers were deposited along the generatrix, which made it possible to obtain the hardness $H R C$ 60-65 and to reduce the mass loss by 2.7 times. Scheme 2 envisaged mixing nanopowders with flux. Applying such a scheme, the hardness of the deposited metal HRC 42 was obtained with a 6 times decrease in the mass loss. Surfacing according to the scheme 3 al-

(C) V.V. PEREMITKO, I.V. KOLOMOETS and V.I. SUKHOMLIN, 2019 lowed reducing the mass loss by 2.5 times with the hardness HRC 20.

From the point of view of a better transition of introduced alloying materials into deposited metal, scheme 3 should be considered as the most effective: the placement of additional powders at the bead periphery contributes to better preservation of the material due to lower temperatures in this zone.

Taking into account the challenge of introducing alloying materials into the weld pool and their role in structural transformations and improving mechanical properties of the metal, it is relevant to reveal the effect of the composition and method of preliminary fixation of such materials in arc welding processes.

The aim of the work is to determine the effectiveness of different schemes of additional introduction of alloying powder materials in arc surfacing on changes in the structure and hardness of deposited metal both in absolute value as well as in the zones of applied beads.

To study the effect of composition of additional materials on the properties of deposited metal, it was decided to choose a paste-like emulsion of TiC and fullerene fiber $\mathrm{C}_{60}$. Such a choice was justified by the influence of the abovementioned materials on the properties of the metal: $\mathrm{TiC}$ is the hardest among the existing carbides (20000 MPa) [10], and $\mathrm{C}_{60}$ increases the microhardness of welded joints [11]. The material was introduced in the form of strips, locally, on the periphery of the planned bead. This is predetermined by the fact that there is a risk of burnout of materials if they are located directly under the arc. To fix the emulsion of TiC, two variants were applied: the use of paste in its pure form and its fixation with the primer GF-021. Surfacing was performed with the overlapping of single beads on plates of steel 20 under 
Experiment results

\begin{tabular}{|c|c|c|c|c|c|}
\hline & & \multirow{2}{*}{$\begin{array}{c}\text { Specific } \\
\text { Consump- } \\
\text { number }\end{array}$} & Input heat & \multicolumn{3}{|c|}{ HB } \\
\cline { 4 - 6 } & $q_{\text {inp }}, \mathrm{J} / \mathrm{mm}$ & $\begin{array}{c}\text { tion of } \\
\text { materials } \\
n, \text { g/inp, } \\
\mathrm{mm}\end{array}$ & $\begin{array}{c}\text { on the pe- } \\
\text { riphery of } \\
\text { the bead }\end{array}$ & $\begin{array}{c}\text { in place of } \\
\text { over- } \\
\text { lapping }\end{array}$ & $\begin{array}{c}\text { in the bot- } \\
\text { tom part }\end{array}$ \\
\hline 1 & 1848 & 0.032 & 192 & 187 & 187 \\
\hline 2 & 1848 & 0 & 255 & 293 & 241 \\
\hline 3 & 1314 & 0.032 & 293 & 302 & 262 \\
\hline 4 & 1314 & 0 & 241 & 229 & 277 \\
\hline 5 & 1536 & 0.032 & 248 & 255 & 277 \\
\hline 6 & 1536 & 0 & 241 & 269 & 262 \\
\hline 7 & 1848 & 0.016 & 293 & 302 & 262 \\
\hline 8 & 1314 & 0.016 & 241 & 262 & 241 \\
\hline 9 & 1536 & 0.016 & 192 & 269 & 255 \\
\hline
\end{tabular}

flux AN-348A with wire Sv-08 A of $3 \mathrm{~mm}$ diameter in the installation of type ADS-1000. The parameters of the mode are the following: welding current is $500 \pm$ $\pm 10 \mathrm{~A}$, arc voltage is $30 \pm 1 \mathrm{~V}$, deposition rate is 25 $35 \mathrm{~m} / \mathrm{h}$, eccentricity of the application of layers of material is $\mathbf{5 - 8} \mathrm{mm}$. To study hardness of the deposited metal, $20 \mathrm{~mm}$ thick samples were cut out. For all the schemes, the modes remained unchanged.

During the experiments, a central composite rotatable second-order design was applied for two factors: input energy $q_{\text {inp }}, \mathrm{J} / \mathrm{mm}$, and specific material consumption $n$, g/inp.mm. Hardness measurements were performed in the hardness tester TK-2. The emphasis was placed on hardness values at the periphery and at the bottom part of the bead. Measurement was carried out roughly in those areas to reveal localization of zones of increased hardness. Processing of the experimental data was carried out using the mathematical package STATISTICA 7.0. The results of experiments are shown in Table.

Based on the processed data, regression dependencies were obtained:

$$
\begin{gathered}
H B_{\text {overlapping }}=282.1948-0.007 q-489.5833 n \\
H B_{\text {periphery }}=270.2357-0.016 q-41.6667 n \\
H B_{\text {bottom part }}=354.1273-0.0598 q+562.5 n
\end{gathered}
$$

These equations allow predicting by calculation the values of hardness in different areas of the deposited bead based on the heat input and the expected specific consumption.

When analyzing the constructed dependency diagrams (Figure 1), it was found that:

- a significant increase in hardness on the periphery of the bead is facilitated by an increase in heat input up to $1800-1900 \mathrm{~J} / \mathrm{mm}$ and specific consumption up to $0.8 \cdot 10^{-2}-1.6 \cdot 10^{-2} \mathrm{~g} / \mathrm{inp} . \mathrm{mm}$. This may be connected with a high coefficient of transition of additional material to the deposited metal while providing
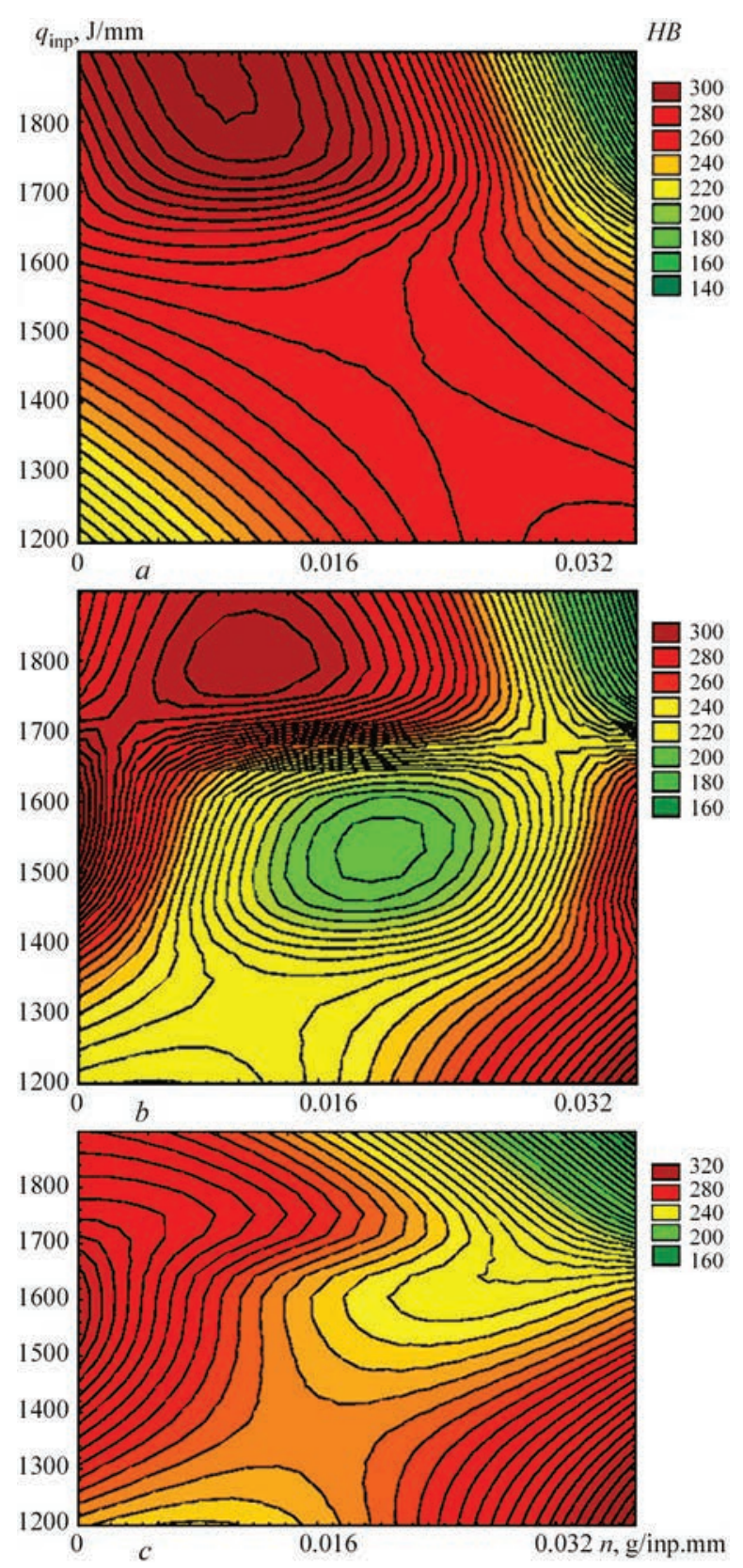

Figure 1. Dependence of hardness on heat input and specific consumption: $a-$ in the overlapping zone; $b-$ on the periphery of the bead; $c$ - in the bottom part of the bead

its moderate consumption and high heat input. Such conclusion is based on the fact that an increase in specific consumption within $1.6 \cdot 10^{-2}-3.2 \cdot 10^{-2}$ g/inp.mm at the same values of current, voltage and welding speed led to a decrease in hardness;

- at the bottom part of the bead a significant increase in hardness is observed at the heat input within the range of $1200-1300 \mathrm{~J} / \mathrm{mm}$ and the specific consumption of $1.6 \cdot 10^{-2}-3.2 \cdot 10^{-2} \mathrm{~g} / \mathrm{inp} . \mathrm{mm}$. These values confirm the conclusion formulated above that to provide a better preservation of additional materials in order to achieve the maximum effect from local fixation, it is necessary to provide specific consumption reversely proportional to heat input. 

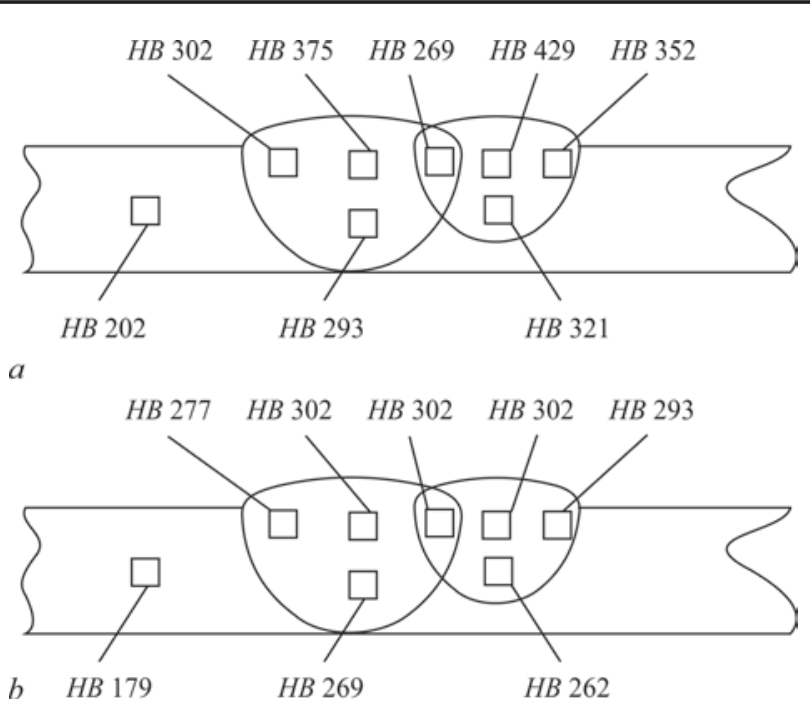

Figure 2. Results of measuring hardness of metal deposited using different methods of fixation of additional materials: $a-$ at the fixation of $\mathrm{TiC}$ using a primer; $b-$ at the fixation of $\mathrm{TiC}$ in a pure form

The maximum values of hardness were obtained at the introduction of TiC: at the periphery - HB 293, in the overlapping zone - HB 302 and in the bottom part of the bead - HB 277 at the hardness of base metal being $H B 197$.

Thus, optimal parameters and specific consumption of materials were established for the maximum surfacing effect with their preliminary fixation. However, under these conditions there is no localization of

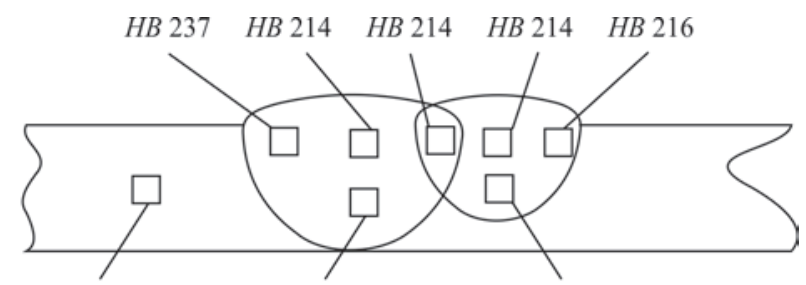

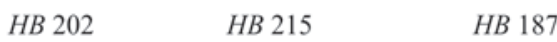

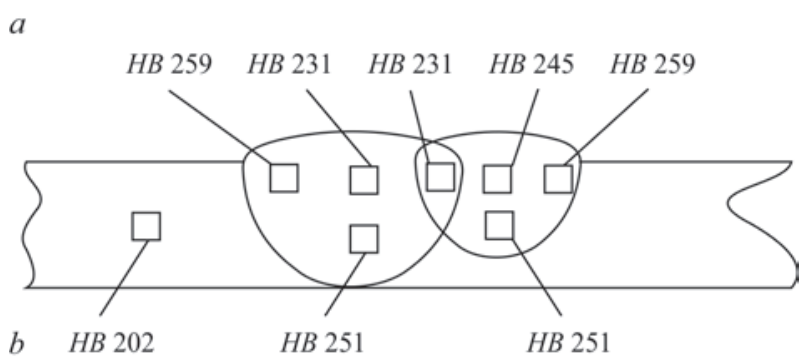

b HB 202

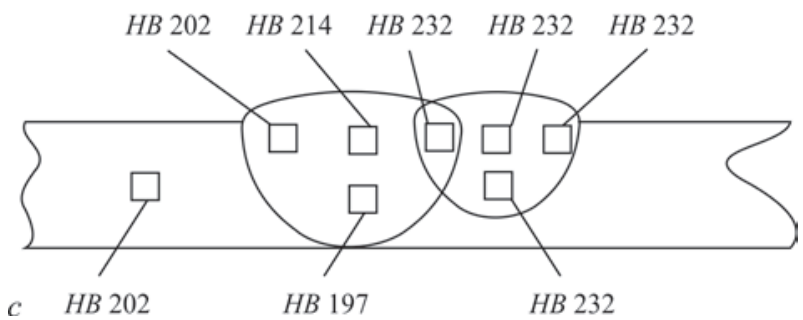

Figure 3. Results of measuring hardness of metal deposited using different methods of fixation of additional materials: $a-$ local introduction of fullerene; $b$ - local introduction of the mixture $\mathrm{TiC}+\mathrm{GF}-021 ; c$ - continuous introduction of $\mathrm{TiC}+\mathrm{GF}-021$ zones of increased hardness. Taking this into account, a comparison of schemes of fixation the emulsion of TiC with the primer GF-021 and in a pure form was made. For adequate comparison, a specific consumption of the material was $1.6 \cdot 10^{-2} \mathrm{~g} / \mathrm{mm}$.

The difference in the effects of the fixation method on the distribution of hardness in the section of deposited metal at the heat input of $1800 \mathrm{~J} / \mathrm{mm}$ and at specific consumption of $1.6 \cdot 10^{-2} \mathrm{~g} / \mathrm{inp} . \mathrm{mm}$ is shown in Figure 2.

The results of measuring hardness in the section of the deposited bead indicate that localization of hardening zone is facilitated by the fixation of the material using GF-021. The addition of TiC suspension in its pure form leads to a greater burnout of the material. Here, only a slight increase in hardness at the places of fixation is observed as compared to other zones.

To compare the effect of adding fullerene $\mathrm{C}_{60}$ and $\mathrm{TiC}$, the samples were surfaced using the parameters of the mode, described above, at $n=0.8 \cdot 10^{-2} \mathrm{~g} / \mathrm{inp}$. $\mathrm{mm}$. Hardness measurements revealed the following its distribution (Figure 3).

As is seen from Figure 3, TiC has the most significant effect on the hardness of the deposited metal. Its local application with fixation of a primer provides a maximum growth of hardness in the places of addition. With the continuous introduction of $\mathrm{TiC}$ and with the introduction of fibers of fullerene $\mathrm{C}_{60}$, lower values of hardness are observed. Such a result is obviously associated with the burnout of materials. Thus, a better preservation of material is contributed by the preliminary fixation of materials at the periphery. A more effective material to increase the hardness of the metal is titanium carbide.

From deposited workpieces the samples were made for the study of microstructure. The analysis of the microstructure was carried out in scanning electron microscope Zeiss EVO50. Comparing the structures of beads (Figure 4) deposited with preliminary fixation of fullerene with primer $(a), \mathrm{TiC}$ in a pure form $(b)$ and with a mixture of TiC + GF-021 (c), it can be concluded that the most significant structural

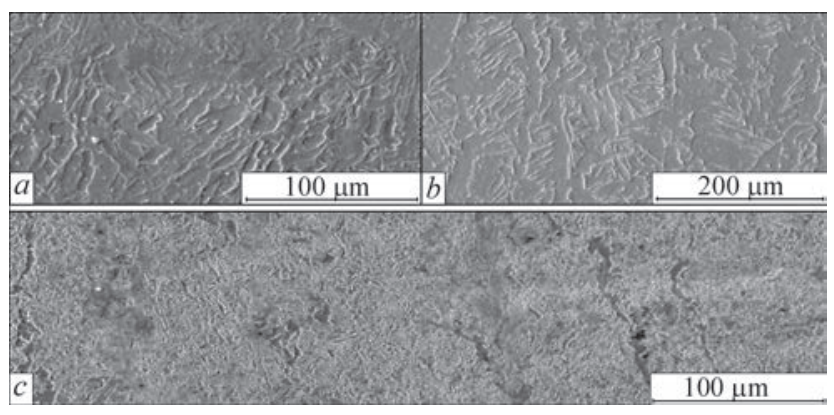

Figure 4. Structure of metal deposited with local introduction: $a-\mathrm{C}_{60}+\mathrm{GF}-021 ; b-\mathrm{TiC} ; c-\mathrm{TiC}+\mathrm{GF}-021$ 
transformations are affected precisely by the last variant of preliminary introduction. For metal deposited with this combination, a martensitic structure is characteristic $(c)$. At the places of introducing mixture of titanium carbide with the primer, coarser particles of carbides are observed than in the cases of the introduction of $\mathrm{C}_{60}+\mathrm{GF}-021(a)$ and TiC (b).

Carbide inclusions of maximum size are observed at the edge of the bead (Figure 4, c).

Thus, the abovementioned indicates the fact that different methods of preliminary fixation have a different effect on the structure and properties of deposited metal.

The range of problems that can be solved by preliminary application of additional materials is not limited to the problems of wear-resistant surfacing. In the future, it seems possible to test such a scheme during welding of dissimilar steels.

\section{Conclusions}

1. It was established that preliminary fixation of additional materials is an effective method of differentiating chemical composition and properties of deposited metal within the single beads.

2. Taking into account the indices of achieved hardness and pronounced structural and mechanical heterogeneity, the most effective is the preliminary local introduction of $\mathrm{TiC}$ with its fixation by a primer GF-021. This is connected with the protective effect of a primer and localization of the strengthening zone.

3 . The effectiveness of applying $\mathrm{TiC}+\mathrm{GF}-021$ as an additional reinforcing material is confirmed by the obtained indices of hardness: at the place of introduction, the hardness of base metal being HB 202, TiC al- lows increasing the hardness by 57 units at a specific consumption of carbide being $0.8 \cdot 10^{-2} \mathrm{~g} / \mathrm{inp} . \mathrm{mm}$ and by $100-150$ units at $1.6 \cdot 10^{-2} \mathrm{~g} / \mathrm{inp} . \mathrm{mm}$. This is by 22 units higher than during fixation of fullerene $\mathrm{C}_{60}$ by a primer.

1. Shenfeld, V.J. (2014) Improvement of wear resistance of steel parts by surfacing using carbon fiber materials: Syn. of Thesis for Cand. of Techn. Sci. Degree. Vinnytsya, VNTU [in Ukrainian].

2. Peremitko, V.V. (2014) Wear-resistant arc surfacing over the layer of alloying charge. The Paton Welding J., 8, 54-57.

3. Peremitko, V.V., Panfilov, A.I. (2017) Arc surfacing of layers of metal of varying composition and hardness. Ibid., 7, 38-42.

4. Kuznetsov, V.D., Stepanov, D.V. (2015) Structure and properties of weld metal modified with nanooxides. Ibid., 11, 10-16.

5. Kuznetsov, V.D., Stepanov, D.V. (2015) Wear-resistant surfacing with feeding of nanopowders to weld pool. Ibid., 5-6, $47-51$.

6. (2017) Method of electric arc welding and surfacing with feeding of nanocomponents to weld pool. Ukraine Pat. 116167, Int. Cl. B23/K 9/16, B23/K 9/18, B82Y40/00 [in Ukrainian].

7. (2017) Method of electric arc welding and surfacing with feeding of nanocomponents to weld pool. Ukraine Pat. 115309, Int. Cl. B23/K 9/16, B82Y40/00 [in Ukrainian].

8. Leshchinsky, L.K., Gulakov, S.V., Stepnov, K.K., Nosovsky, B.I. (1985) Rolls with deposited layer of new design improve the efficiency of mills operation. In: Surfacing. Experience and efficiency of application. Ed. by P.V. Gladky, Kiev, 17-20 [in Russian].

9. Yariza-Stetsenko, A.V. (2012) Improvement of arc surfacing technology of variable chemical composition by its alloying from flux: Syn. of Thesis for Cand. of Techn. Sci. Degree. Kramatorsk [in Ukrainian].

10. Ryabtsev, I.A., Panfilov, A.I., Babinets, A.A., Ryabtsev, I.I. et al. (2015) Structure and abrasive wear resistance of deposited metal hardened with carbides of different types. The Paton Welding J., 5-6, 78-82.

11. Golovko, V.V., Kuznetsov, V.D., Fomichov, S.K., Loboda, P.I. (2016) Nanotechnologies in welding of low-alloy highstrength steels. Kyiv, NTUU KPI, Politekhnika [in Ukrainian].

Received 31.05.2019

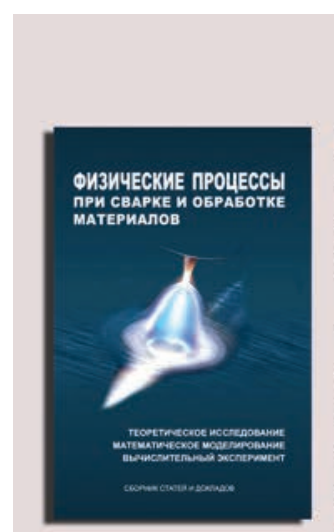

\section{NEW BOOK}

Physical processes in welding and material treatment. Theoretical investigation, mathematical modelling, numerical simulation collection of articles and reports: Collection of articles and reports edited by Prof. I.V. Krivtsun. Kyiv: International Association «Welding», 2018. - 642 p. ISBN 978-617-7015-74-0 (in Russian, English, Ukrainian).

The collection includes 86 papers and reports of research workers of the Department of physics of gas discharge and plasma technique at the E.O. Paton Electric Welding Institute of the NAS of Ukraine, being published in the period of 1978-2018. It generalizes the forty-year experience of research activity of the Department in the field of theoretical research and computer modelling of physical phenomena taking place in arc, plasma, laser and hybrid processes of welding, surfacing and coating deposition. It can be interesting and useful to the scientists, engineers and technologists dealing with the problems of arc, plasma, laser and hybrid welding and material treatment as well as post graduates and students studying theoretical basics of welding and related processes.

Orders for the collection, please send to the Editorial Board.

Collection in the open acces:

https://patonpublishinghouse.com/compilations/Krivtsun_Sbornik_2018_small.pdf 


\title{
ECONOMIC AND STATISTICAL REVIEW OF THE WORLD AND REGIONAL MARKETS OF WELDING MATERIALS
}

\author{
A.A. MAZUR, O.K. MAKOVETSKAYA, S.V. PUSTOVOJT and V.S. PETRUK \\ E.O. Paton Electric Welding Institute of the NAS of Ukraine \\ 11 Kazymyr Malevych Str., 03150, Kyiv, Ukraine. E-mail: office@paton.kiev.ua
}

\begin{abstract}
Electric arc welding is one of the basic technologies of the industrial economy, with the help of which a significant share of GDP in industrialized countries is created. In such countries, one can observe a steady development of welding production - an increase in the consumption of structural materials, appearance of new materials, technologies and equipment for welding at the market. The main structural material for manufacture of welded structures is steel (its share is over $90 \%$ ). The state-of-the-art of steel and alloys production largely determines the dynamics of development of welding production. The article presents economic and statistical information on the development of world production and consumption of steel, dynamics of the world market of welding materials, analysis of which allows making the conclusion about the increase in the volume of welding production in the world in the foreseeable future and the growth of demand for welding materials. The growth in consumption of welding materials in the world is largely determined by the rate of development of welding production in China, which is far ahead of other countries and regions in this regard. The development of welding production leads to gradual reduction in the share of manual arc welding and a wider use of semi-automatic and automatic welding. The level of mechanization and automation of arc welding is constantly increasing both in separate countries, as well as in the world as a whole. 8 Ref., 5 Tables, 9 Figures.
\end{abstract}

Ke y word s : welding, welding production, structural and welding materials, technologies, steel production, market, state-of-the-art, prospects

Over the many centuries, welding has proved to be a flexible technology for creating permanent joints, organically fitting into each new spiral of scientific and technological progress. It is impossible to imagine modern civilization without welding and related processes. If all welded, brazed and other permanent joints had suddenly collapsed, humanity would have

Table 1. Prospects for the development of the European market of welding equipment and technologies for the next 10 years

\begin{tabular}{|l|c|c|c|}
\hline $\begin{array}{c}\text { Technological sector of the } \\
\text { market }\end{array}$ & $\begin{array}{c}\text { No changes } \\
\text { or slight } \\
\text { growth }\end{array}$ & Growth & $\begin{array}{c}\text { Significant } \\
\text { growth }\end{array}$ \\
\hline $\begin{array}{l}\text { Consumable electrode arc } \\
\text { welding }\end{array}$ & $\mathrm{X}$ & $\mathrm{X}$ & \\
\hline $\begin{array}{l}\text { Nonconsumable electrode } \\
\text { arc welding }\end{array}$ & $\mathrm{X}$ & $\mathrm{X}$ & \\
\hline $\begin{array}{l}\text { Submerged arc welding or } \\
\text { electroslag welding }\end{array}$ & $\mathrm{X}$ & $\mathrm{X}$ & \\
\hline Plasma arc welding & & $\mathrm{X}$ & $\mathrm{X}$ \\
\hline Laser welding & $\mathrm{X}$ & $\mathrm{X}$ \\
\hline Electron beam welding & & $\mathrm{X}$ & $\mathrm{X}$ \\
\hline $\begin{array}{l}\text { Resistance spot and seam } \\
\text { welding }\end{array}$ & $\mathrm{X}$ & $\mathrm{X}$ & \\
\hline Flash butt welding & & $\mathrm{X}$ & $\mathrm{X}$ \\
\hline Friction welding & $\mathrm{X}$ & $\mathrm{X}$ & $\mathrm{X}$ \\
\hline Ultrasonic welding & & & $\mathrm{X}$ \\
\hline High-frequency welding & & \\
\hline Brazing & & $\mathrm{X}$ & \\
\hline Bonding & & $\mathrm{X}$ & \\
\hline Mechanical joining & & $\mathrm{X}$ & \\
\hline
\end{tabular}

remained without most of the machines, mechanisms, devices, communications, transport, energy, buildings and structures.

Electric arc welding in the XX century has become one of the basic technologies of industrial economy. That is the reason for attention paid in the world to the development of welding science and technology.

According to the estimates of domestic and foreign specialists, in the foreseeable future, new methods of welding using highly-concentrated heat sources or without melting metal at all are gaining more importance, but, nevertheless, arc welding maintains its leading positions (Table 1).

The main structural materials for welded structures are steel (93-95\%), aluminium, titanium and other non-ferrous metals and plastics (in total 5-7\%), so the development of steel industry is one of the main factors determining the state and dynamics of the development of welding production not only today, but also in the foreseeable future (Figure 1, curve 1). No other material has such a combination of strength, ductility, flexibility and cost as steel. All the produced steel becomes a resource with an unlimited cycle of using and can be recycled.

Despite the fact that steel industry faces a lot of obstacles, such as excessive capacities, volatility of raw and energy markets, risks of protectionist policies, steel keeps on remaining one of the most important materials for the modern economy. 


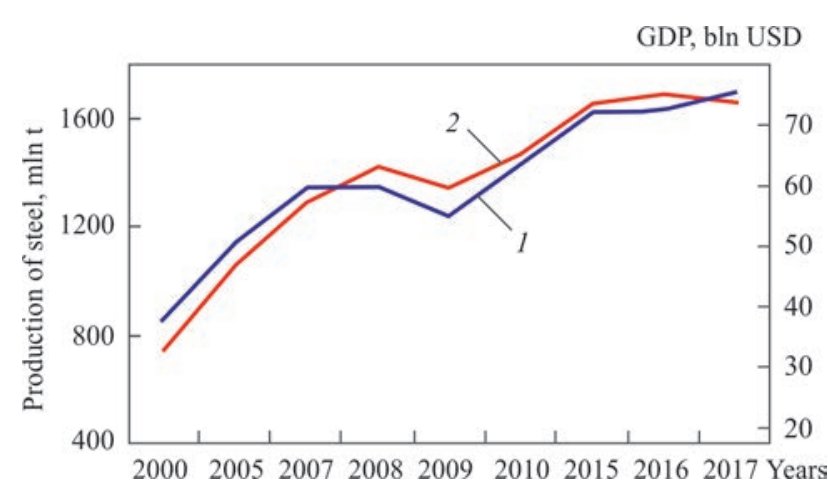

Figure 1. Dynamics of steel production (1) and GDP (2) in the world

The production of aluminium (Figure 2) and the consumption of aluminium-magnesium alloys used in aircraft and rocket science have increased.

The scope of application of polyethylene pipes in the construction of most modern networks for different purposes is increasing.

In the world steel production more than $4 \mathrm{mln}$ workers are employed and another $4 \mathrm{mln}$ people are employed in auxiliary industries. The steel production industry is the second largest in the world in energy consumption, despite the fact that energy intensity of its production over the past 30 years has decreased by $50 \%$. Steel is the engine that provides the development of global industry, and industry indicators reflect the global economic situation $[1,2]$. The total influence of metallurgical industry is 2.9 bln US dollars of added value and $96 \mathrm{mln}$ jobs worldwide [3].

Figure 1 shows close relationship between the world steel production and GDP. Over the past decade, global steel output has increased by 1.7 times and GDP has grown by more than 2 times. On average, for every 100 US dollars of GDP growth it is necessary to produce $2 \mathrm{~kg}$ of steel.

The results of 2018 make it possible to consider the forecast of both experts of the World Steel Association (WSA) and the International Iron and Steel Institute (IISI) about the growth by 2025 close to real numbers up to 2.5 milliard t per year of demand for rolled steel and about its average annual growth rate, which will amount to $3.7 \%$ (Figure 3).

According to recently published data of WSA, the world steel production in 2018 increased by $4.6 \%$ as compared to 2017 and amounted to 1.809 milliard t [4]. At the same time, the steel production grew in almost all countries except of the European Union.

In Asia 1.271 milliard t of steel was produced $(+5.6 \%$ as compared to 2017), almost $3 / 4$ of steel production of which falls to China, i.e. $928.3 \mathrm{mln} \mathrm{t}(+6.6 \%)$. At the same time, the share of China in the global production amounted to $51.3 \%$ (in $2017-50.3 \%$ ).

In India, the volume of production amounted to $106.5 \mathrm{mln} \mathrm{t}$ of steel $(+4.9 \%)$, which allowed it to

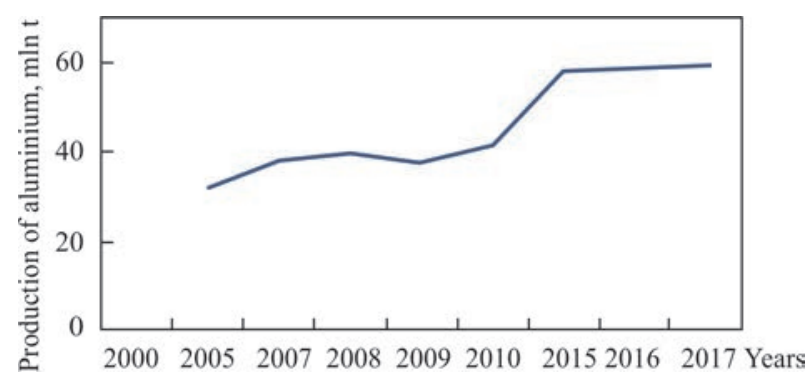

Figure 2. Dynamics of aluminium production in the world

become the second steel manufacturer in the world after China, having outstripped Japan, which produced $104.3 \mathrm{mln}$ t of steel $(-0.3 \%)$. In South Korea, $72.5 \mathrm{mln}$ t of steel were produced $(+2 \%)$.

The steel production in the region of Middle East amounted to $38.5 \mathrm{mln} \mathrm{t}(+11.7 \%)$. Iran produced $25 \mathrm{mln}$ t of steel in $2018(+17.7 \%)$, Turkey $37.3 \mathrm{mln} \mathrm{t}(-0.6 \%)$.

The European Union produced $168.1 \mathrm{mln} \mathrm{t}$ of steel, which is $0.3 \%$ less than the number of 2017. In Germany, $42.4 \mathrm{mln}$ t of steel ( $-2 \%)$ were melted, in Italy $-24.5 \mathrm{mln} \mathrm{t}(+1.7 \%)$, in France $-15.4 \mathrm{mln} \mathrm{t}$ $(-0.7 \%)$, in Spain -14.3 mln $\mathrm{t}(-0.1 \%)$.

The steel production in North America in 2017 amounted to $120.5 \mathrm{mln} \mathrm{t}(+4.1 \%)$, of which $86.7 \mathrm{mln} \mathrm{t}$ were in the USA, which is by $6.2 \%$ more than in 2017.

The steel production in the CIS region increased slightly (by $0.3 \%$ ) to $101.3 \mathrm{mln}$ t. The steel production in Russia amounted to $71.7 \mathrm{mln} \mathrm{t}(+0.3 \%)$, in Ukraine - $21.1 \mathrm{mln} \mathrm{t}(-1.1 \%)$.

The steel production in South America increased by $1.3 \%$ to $44.3 \mathrm{mln} \mathrm{t}$ as compared to 2017 , including in Brazil — by $1.1 \%$ to $34.7 \mathrm{mln}$ t.

According to data [4], the highest growth in steel production was noted in Vietnam $(+23.2 \%)$, Iran $(+17.7 \%)$, Egypt $(+13.6 \%$, at the production of $7.8 \mathrm{mln} \mathrm{t})$, China $(+6.6 \%)$, USA (+6.2\%), India (+4.9\%).

Some changes in the ranking positions of the countries, which were the largest steel manufacturers, occurred. Thus, India took the second place instead of the third in 2017, South Korea rose to the fifth place.

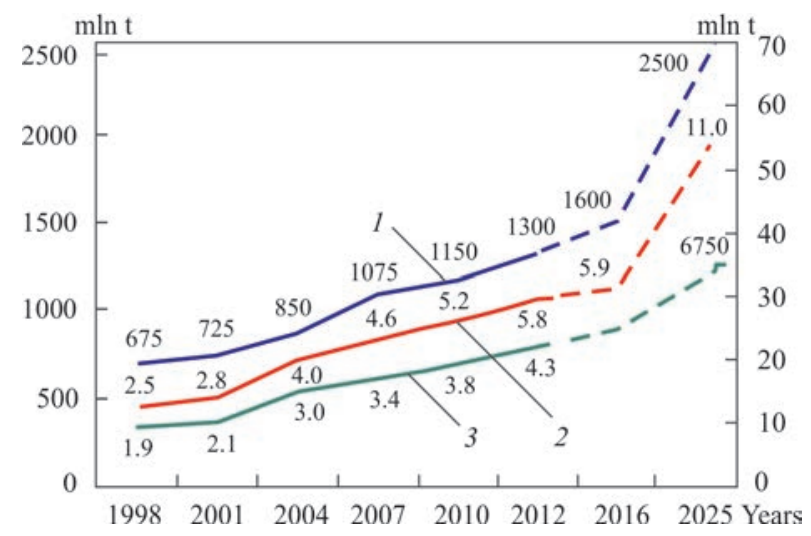

Figure 3. World consumption of rolled metal (1), welding materials (2) and deposited metal (3) 

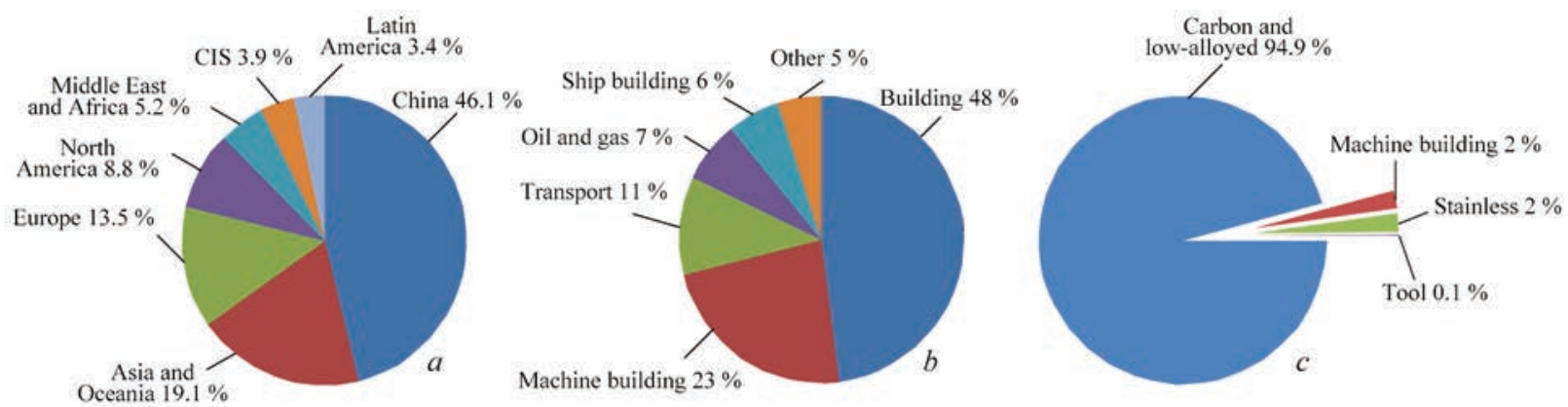

Figure 4. Distribution of world steel consumption by regions $(a)$, industries $(b)$ and structure of consumption by steel grades (c)

Russia is in the sixth place on this list. Iran entered the top 10 steel manufacturers in the world, having outstripped Italy. Ukraine at the end of 2018 is at the thirteenth position, and in 2016 it was at the tenth. Vietnam took seventeenth place, having outstripped Poland and Canada, and came close to Spain in terms of steel production volume.

It can be expected that by 2025 the volumes of metal consumption can reach $2500 \mathrm{mln} t$ and those of welding materials consumption - $11 \mathrm{mln} \mathrm{t}$. As the basis for such an assertion the data can serve, shown in Figure 3, concerning the global consumption of rolled metal, welding materials and the mass of metal deposited during welding for the period of 1998-2012, as well as the abovementioned data on the growth in demand for steel by 2025.

The construction sector will account for $48 \%$ of steel consumption, automotive industry $-11 \%$, production of technological machinery and equipment (mechanical engineering) - $23 \%$.

Figure 4 shows distribution of the world steel consumption by regions, industries and steel grades.

The structure of rolled steel consumption by steel grades indicates that $94.9 \%$ of rolled metal is produced using carbon and low-carbon steel, which is the main structural material used in welding.

By 2025, $90 \%$ of the expected growth in steel consumption will be provided mainly by the following industries:

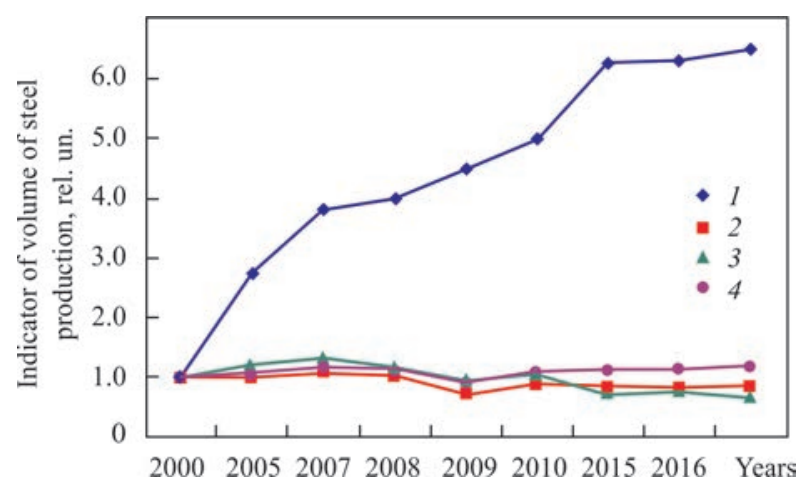

Figure 5. Production of steel in China, Ukraine and world (indicators of volume of production for 2000 are accepted as one): 1 China; 2 - EU; 3 - Ukraine; 4 - whole world without China
- housing construction, infrastructure projects in the countries with developing economy (68 \% of growth);

- technological machine building (13\%);

- oil-gas and other pipes (9\%).

The most striking example, confirming the general trend of the relationship between the growth in steel consumption and the general economic level of countries, having a high growth rate of GDP, is China (Figure 5).

In recent years, China has the highest and most stable growth rate of GDP (8-10\%) and takes the first place in the world in terms of volume and growth rate of steel production and consumption. According to the results of 2018, its share in the world steel production increased to $51.3 \%$, and in the world consumption - up to $40 \%$.

For comparison, Table 2 shows data over the past few years on the dynamics of steel production and consumption in the world, as well as on major manufacturers and consumers [5].

In the world scientific and technical literature, two concepts are sometimes confused: «welding materials» and «materials for welding», which leads to misunderstandings when comparing statistical indicators. The first includes materials, the bulk of which forms the composition of weld metal during welding process (for arc welding these are solid and flux-cored wires, coated and other consumable electrodes, fluxes), and the second one is shielding active and inert gases and other materials, including auxiliary, which are involved in providing welding processes.

It can be argued about the attribution of welding fluxes to welding materials, but this is our common practice. Therefore, in the future we will use namely this interpretation of the term "welding materials», although in a number of countries the national statistics takes into account namely «materials for welding», which should be borne in mind when comparing the relevant indicators at the international level.

According to the estimates of ESAB Company specialists, in 2006 the sales value of the global market for welding materials was 45 against $55 \%$ of welding equipment. At present, the sales value of the 
Table 2. Dynamics of production and consumption of steel, mln t

\begin{tabular}{|c|c|c|c|c|c|c|c|c|}
\hline & \multicolumn{4}{|c|}{ Production } & \multicolumn{4}{|c|}{ Consumption } \\
\hline & 2015 & 2016 & 2017 & $2018^{*}$ & 2015 & 2016 & 2017 & 2018 \\
\hline World, in total & 1623 & 1605 & 1630 & $1650-1670$ & 1506 & 1500 & 1520 & $1540-1560$ \\
\hline Asia $^{* 1}$ & 1075 & 1055 & 1070 & $1080-1090$ & 900 & 1000 & 1050 & $1060-1070$ \\
\hline China & 8004 & 808 & 810 & $790-820$ & 675 & 645 & 630 & $620-650$ \\
\hline America $^{* 2}$ & 160 & 155 & 162 & 165-175 & 170 & 160 & 165 & 165-180 \\
\hline USA & 80 & 79 & 80 & $80-82$ & 96 & 95 & 98 & 100-102 \\
\hline Europe $^{* 3}$ & 200 & 202 & 200 & 198-205 & 157 & 196 & 198 & $195-200$ \\
\hline EU28 & 169 & 162 & 164 & $162-165$ & 145 & 155 & 158 & 155-160 \\
\hline
\end{tabular}

world market for welding materials is $60 \%$ of the total market of welding equipment (Table 3 ).

The annual income of the market for welding materials in 2016 amounted to more than 20 billion US dollars. In the coming years, it is expected to grow and by 2022 may exceed 32 billion US dollars (Figure 6).

Comparing the dynamics of the volumes of markets for welding equipment and welding materials, it should be noted that the market of equipment is more susceptible to ups-and-downs than the market of materials. Therefore, a wide range of companies and enterprises specialized in the production of welding equipment begins to produce welding materials as well. In the coming years, the main drivers for increasing the consumption of welding materials will be the fulfillment of large projects in a number of metal-intensive industries, including:

- power engineering - $9 \%$;

- ship building - $11 \%$;

- oil and gas industry - $12 \%$;

- construction - $20 \%$;

- automotive industry - $23 \%$;

- other industries - $25 \%$.

We usually correlate our data with Japanese data published in the journal «The Japan Welding News for the World» so that we can be sure in their reliability. These data are sufficiently close to the results that we obtain in the course of our investigations. The advantage of Japanese data lies in the wider coverage of regions and, most importantly, in the regularity and efficiency of publication in print (Figure 7).

Table 3. Global market for welding equipment (according to the results of 2017)

\begin{tabular}{|c|c|c|c|c|}
\hline Region & $\begin{array}{c}\text { Equipment, } \\
\text { bln USD }\end{array}$ & $\begin{array}{c}\text { Welding } \\
\text { materials, } \\
\text { bln USD }\end{array}$ & $\begin{array}{c}\text { Total, bln } \\
\text { USD }\end{array}$ & $\begin{array}{c}\text { Market } \\
\text { share, \% }\end{array}$ \\
\hline North America & 1.7 & 3.0 & 4.7 & 23 \\
\hline Europe & 1.6 & 3.6 & 5.2 & 25 \\
\hline Asia & 3.4 & 5.8 & 9.2 & 44 \\
\hline South America & 0.6 & 1.0 & 1.6 & 8 \\
\hline Total & 7.2 & 12.4 & 20.7 & 100 \\
\hline
\end{tabular}

The global consumption of welding materials (Table 4) [6-8], which in 2010 amounted to $5.5 \mathrm{mln} \mathrm{t}$, increased by $4.2 \%$ in 2016 and reached $6 \mathrm{mln}$ t.

The growth in the world consumption of welding materials was determined, first of all, by the rate of development of China's welding production, which is far ahead of other regions in this respect. In 2016, China accounted for $51.7 \%$ of the total world consumption of welding materials (3200 thou t). The EU countries are far behind - 8.9 \% (550 thou t) and North America (USA, Canada, Mexico) - $6.9 \%$ (430 thou t).

From 300 to 200 thou $t$ per year is consumed by Japan (283 thou t), ASEAN (280 thou t), India (270 thou t), Korea (240 thou t), CIS countries (230 thou t), Latin America (210 thou t), Near and Middle East (190 thou t), Africa (150 thou t). This list of regions is closed by Taiwan (80 thou t) and other smaller countries with a total consumption of 70 thou $t$.

The availability of reliable and complete information on the consumption volumes of welding materials makes it possible to determine the specific structure of fusion arc welding methods used in the world, regions, and in a particular country.

Usually, the mass of the deposited metal is used as a criterion, with the help of which the percentage of manual arc welding with coated electrodes (MAW), welding with a solid electrode wire in shielding gases $\left(\mathrm{CO}_{2}\right)$, flux-cored wire (FCW) and automatic submerged arc welding (AF) is determined.

The information, given in Table 5 , indicates that the share of manual arc welding, which in leading

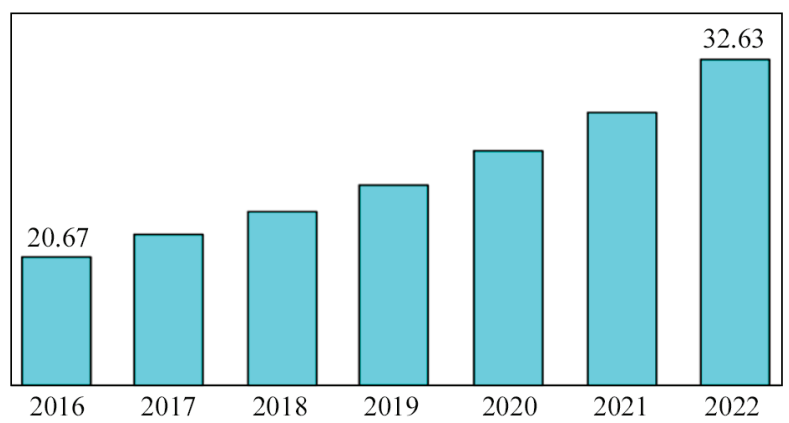

Figure 6. Annual income of welding materials market, bln USD 


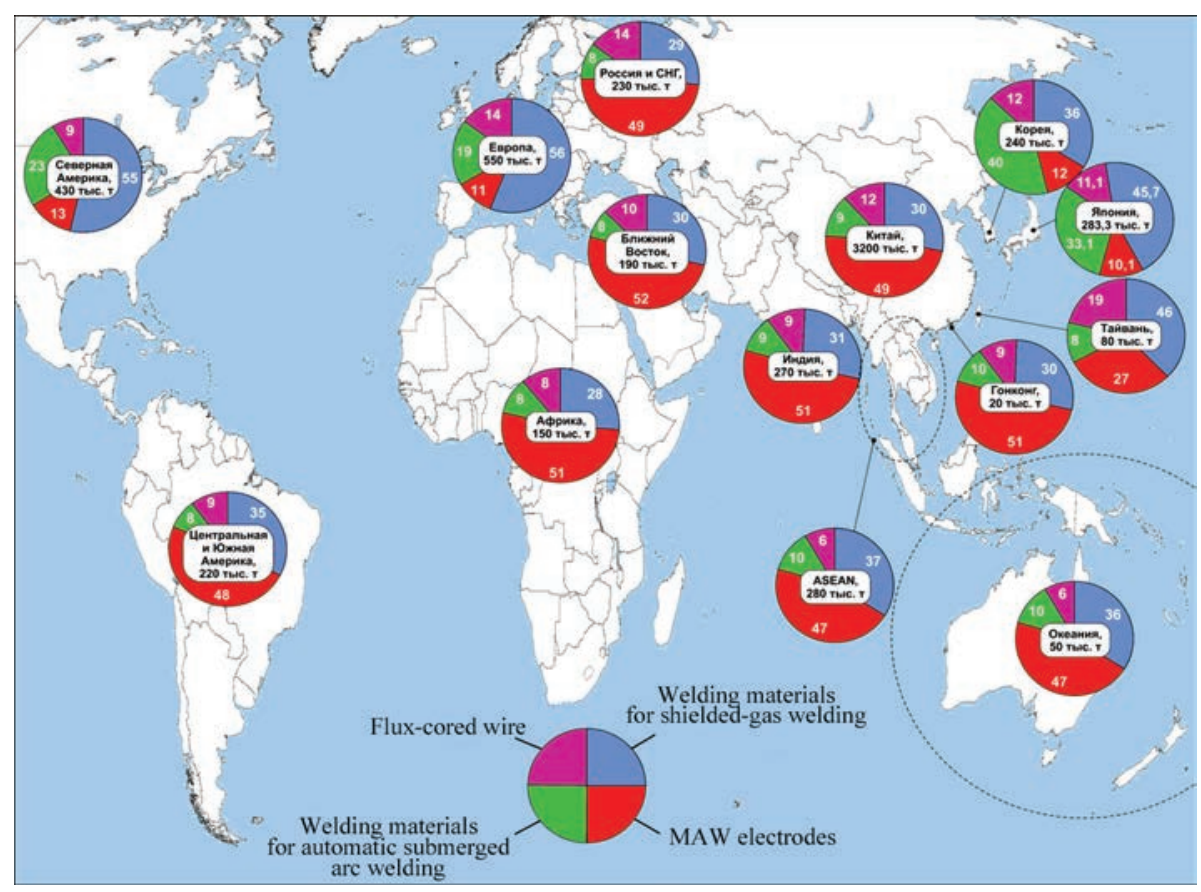

Figure 7. Consumption of welding materials in the regions and countries of the world (2016)

countries amounted to 80-90 \% in 1965, decreased in half over 25 years and in 1990 was at the level of 35-45 \%.

By then, super optimists of technological progress in welding production insisted that over the next 25 years, the share of manual arc welding with coated electrodes would be practically equal to zero or slightly higher.

In our forecasts, we believed that this welding method will have a right to exist in the foreseeable future, and its share will be about $20 \%$. As we see, not only super optimists were mistaken in the forecasts, but we also did: today the share of manual arc welding in Japan is $7.3 \%$, in the EU - $8.9 \%$, in South Korea $-9.6 \%$ and in North America (USA, Canada and Mexico) - $10.3 \%$. Globally, the share of manu- al arc welding is constantly decreasing and currently stands at $33.7 \%$, mainly due to China (43.7 \%), India (45\%), the CIS (44\%) and other countries where the share of manual arc welding is $22-52 \%$.

The share of welding in shielding gases in the whole world is $44 \%$. The leaders in using this welding method are EU (63.9 \%), USA (61.4 \%), Taiwan (54.8\%) and Japan (49.5\%). The leaders in the use of welding with flux-cored wire are South Korea (40\%), Japan (35.9 \%) and USA (22.1\%). Globally, welding with flux-cored wire is $14 \%$.

Automatic submerged arc welding, which worldwide accounts for only $7.9 \%$ of metal deposited during welding, is the most widely used in China (8.7\%) and in the EU (8.1\%). Over the past 40 years, the share of

Table 4. Volume and structure of consumption of welding materials in the main world markets

\begin{tabular}{|c|c|c|c|c|c|c|c|c|c|c|}
\hline \multirow[t]{2}{*}{ Region/country } & \multicolumn{2}{|c|}{ Coated electrodes, \% } & \multicolumn{2}{|c|}{ Solid wire, \% } & \multicolumn{2}{|c|}{ Flux-cored wire, \% } & \multicolumn{2}{|c|}{$\begin{array}{c}\text { Materials for } \\
\text { submerged arc } \\
\text { welding, \% }\end{array}$} & \multicolumn{2}{|c|}{ Total, thou t } \\
\hline & 2010 & 2016 & 2010 & 2016 & 2010 & 2016 & 2010 & 2016 & 2010 & 2016 \\
\hline China & 57 & 40 & 26 & 37 & 6 & 12 & 11 & 11 & 2700 & 2800 \\
\hline Europe & 12 & 10 & 56 & 54 & 18 & 23 & 14 & 13 & 540 & 540 \\
\hline North America & 15 & 11 & 54 & 55 & 22 & 24 & 9 & 10 & 410 & 480 \\
\hline Japan & 11 & 9 & 42 & 43.5 & 35 & 37.2 & 12 & 10.3 & 289 & 263.4 \\
\hline ASEAN countries & 51 & 42 & 35 & 39 & 8 & 13 & 6 & 6 & 260 & 290 \\
\hline Korea & 14 & 11 & 34 & 38 & 40 & 39 & 12 & 12 & 210 & 230 \\
\hline Russia and CIS countries & 56 & 45 & 26 & 33 & 5 & 8 & 13 & 14 & 200 & 220 \\
\hline India & 59 & 45 & 26 & 36 & 7 & 10 & 8 & 9 & 250 & 310 \\
\hline Central and South America & 53 & 44 & 32 & 37 & 6 & 11 & 9 & 8 & 185 & 210 \\
\hline Middle East & 59 & 46 & 26 & 35 & 5 & 9 & 10 & 10 & 160 & 200 \\
\hline Africa & 62 & 49 & 25 & 33 & 5 & 9 & 8 & 9 & 130 & 150 \\
\hline Taiwan & 29 & 25 & 46 & 46 & 18 & 20 & 7 & 9 & 70 & 90 \\
\hline Oceania & 49 & 43 & 36 & 38 & 6 & 10 & 9 & 9 & 50 & 60 \\
\hline Total & & & & & & & & & 5474 & 5900 \\
\hline
\end{tabular}




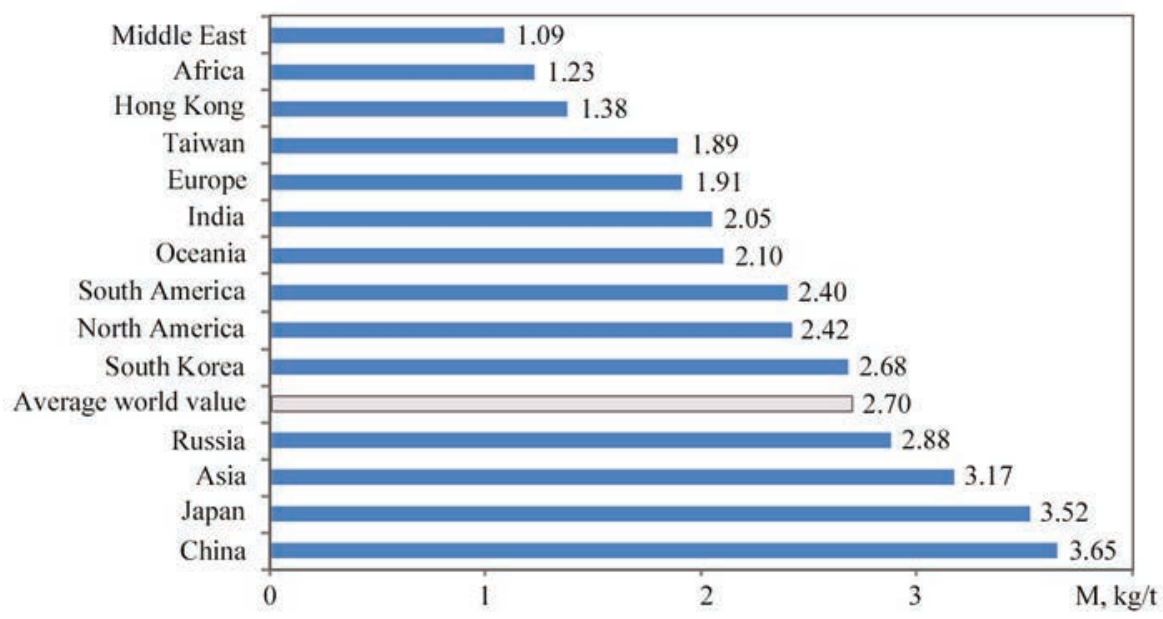

Figure 8. Regional indicators of mass of deposited metal in welding per one ton of steel $\mathrm{M}$, $\mathrm{kg} / \mathrm{t}$

automatic submerged arc welding is almost stable, its fluctuations were: in the EU from 6 to $8.1 \%$; in the USA from 9 to $6.2 \%$; in Japan from 9 to $7.3 \%$.

Figure 8 shows the specific indicators of mass of the metal deposited during welding (kg per ton of steel). These data, taking into account the abovementioned regional indicators of metal consumption and the shares of the used welding methods, allow determining with sufficient level of accuracy the market demand of a particular country (or region) for the welding materials it needs, which, in turn, is necessary for the development of business strategies of companies-manufacturers of welding materials.

In conclusion, it should be noted that in the foreseeable future welding is the basic technology in many industries and in construction. Industrialized countries are characterized by a fairly stable dynamics in the development of welding production and welding market, which is determined by the steady growth in the consumption of structural materials and expansion of their assortment, as well as appearance of new advanced materials, technologies and equipment for welding and related processes on the welding market.

The economic and statistical information on the state and prospects of the development of world production and consumption of steel, the main structural material in the manufacture of welded metal structures, as well as the dynamics of the global market for welding materials allow suggesting that the volume of world welding production will grow in the near future. Accordingly, in spite of temporary crisis phenomena in certain regional markets, the demand for welding materials will grow. The level of mechanization and automation of welding works, which is determined mainly by the scope of application of manual arc welding, is constantly increasing due to a reduction in its share and an increase in the mass of
Table 5. Structure of methods of arc welding around the world, regions and countries (\% on deposited metal)

\begin{tabular}{|c|c|c|c|c|}
\hline Country/region & MAW & $\mathrm{CO}_{2}$ & FCW & AF \\
\hline World & 33.7 & 44.4 & 14 & 7.9 \\
\hline China & 43.7 & 38.4 & 9.3 & 8.7 \\
\hline EU & 8.9 & 63.9 & 19.1 & 8.1 \\
\hline USA & 10.3 & 61.5 & 22.1 & 6.2 \\
\hline Japan & 7.3 & 49.5 & 35.9 & 7.3 \\
\hline India & 45 & 39.4 & 9.2 & 6.5 \\
\hline Korea & 9.6 & 43 & 40 & 7.5 \\
\hline Russia & 44 & 38.7 & 7.1 & 10.3 \\
\hline Ukraine & 48.9 & 32.5 & 1.4 & 14.2 \\
\hline Latin America & 41.8 & 30.9 & 8 & 6.4 \\
\hline Middle East & 46.5 & 38.5 & 8.2 & 7.3 \\
\hline Africa & 51.2 & 36.2 & 7.1 & 5.9 \\
\hline Taiwan & 21.6 & 54.8 & 18.8 & 5.2 \\
\hline Other & 44.4 & 42.5 & 7.7 & 6.8 \\
\hline ACRAN & 40.3 & 45.8 & 10.1 & 4.2 \\
\hline
\end{tabular}

metal deposited using semi-automatic and automatic welding in shielding gases, automatic submerged arc welding, as well as with flux-cored wire.

1. World Steel Association. https://www.worldsteel.org/steelby-topic/statistics/Steel-industry-economic-impact-.html

2. World Steel Association. https://www.worldsteel.org/en/dam/ jcr:fdf44918-de3b-455b-9083-f770afa4a214/OE\%2520Executive \%2520Summary.pdf

3. Askerov, E. (2019) Economic impact of world steel industry. https://www.worldsteel.org/media-centre/blog/2019/economic-impact-of-the-global-steel-industry.html

4. World Steel Association. https://www.worldsteel.org/mediacentre/press-releases/2019/Global-crude-steel-outputincreases-by-4.6--in-2018.html

5. Metallurgy in 2017. https://wtcmoscow.ru/services/international-partnership/analitycs/metallurgiya-v-2017-godu/

6. (2012) Worldwide demand for welding consumables. The Japan Welding News For The World, 16(59), 5.

7. (2013) Worldwide demand for welding consumables. Ibid., 17(63), 6.

8. (2017) Worldwide demand for welding consumables. Ibid., 21(79), 5. 


\title{
CALCULATION OF THE RADIUS OF TRANSITION OF THE WELD TO BASE METAL OF ALUMINIUM ALLOY WELDED JOINTS
}

\author{
A.V. MOLTASOV and I.N. KLOCHKOV
}

E.O. Paton Electric Welding Institute of the NAS of Ukraine

11 Kazymyr Malevych Str., 03150, Kyiv, Ukraine. E-mail: office@paton.kiev.ua

\begin{abstract}
The objective of the work was establishing a mathematical dependence between the radius of the weld transition to base metal and ratio of weld height to its width in butt welded joints of aluminium alloys. During investigations, the authors used the published data on geometrical dimensions of butt joints of aluminium alloys of the second, fifth, sixth and seventh series to DSTU ISO 209-1:2002 made by consumable and nonconsumable electrode argon-arc welding, as well as consumable electrode pulsed-arc welding. When plotting the sought dependencies, regression analysis was conducted with application of MathCAD system. An analytical formula was obtained in the form of a polynomial with fractional powers to determine the radius of weld transition to base metal, as a function of the ratio of reinforcement height to its width on the joint face side. It is found that the proposed formula can also be recommended for determination of the radius of transition of the weld back bead to base metal. 19 Ref., 3 Tables, 2 Figures.
\end{abstract}

Keywords : butt welded joint, aluminium alloys, gas-shielded welding, weld geometry, radius of weld transition to base metal, back bead, regression analysis

Stress concentration in a zone of transition from weld to base metal is one of the main factors determining fatigue resistance of welded joints [1]. The experience shows that stress concentration shall be taken into account not only at vibration loading, but also at static loading and impact, when brittle fracture is possible [2]. Besides, stress concentration can be a reason of crack formation in process of heat treatment [3], which is used for welded joints in order to eliminate residual stresses and deformations [4].

The dominant effect on a level of stress concentration in welded joint has a radius of weld transition to base metal $r$ [5]. The procedures of measurement of this radius is very labor-consuming and present known difficulties [6], therefore determination of its relationship with height $h$ and width $g$ of reinforcement of butt weld, which are relatively easy for measurement, considerably simplifies and accelerates practical calculations of strength and durability of welded structures.

Dependencies of such type were earlier obtained for steels [7]. However, a value of transition radius and parameters of weld convexity depend, in particular, on mode of welding and thermophysical properties of metal being joined $[8,9]$. Therefore, acquiring of such dependencies for joints of aluminium alloys, obtained using arc welding processes, is still relevant today.

Table 1. Geometry parameters of butt welded joints of aluminium alloys

\begin{tabular}{|c|c|c|c|c|c|c|c|}
\hline No. & Alloy & Welding method & Thickness $\delta, \mathrm{mm}$ & $\begin{array}{c}\text { Transition radius } \\
r, \mathrm{~mm}\end{array}$ & $\begin{array}{c}\text { Reinforcement } \\
\text { height } h, \mathrm{~mm}\end{array}$ & $\begin{array}{c}\text { Reinforcement } \\
\text { width } g, \mathrm{~mm}\end{array}$ & Source \\
\hline 1 & 1915T & MIG & $1.7-2.0$ & 2.65 & 0.30 & 7.60 & {$[10]$} \\
\hline 2 & AD33T1 & MIG & 6.0 & 1.32 & 1.39 & 21.20 & {$[11]$} \\
\hline 3 & AMg2M & MIG & 1.45 & 1.27 & 0.80 & 8.18 & {$[12]$} \\
\hline 4 & AD33T1 & MIG & 6.0 & 1.13 & 1.67 & 16.90 & {$[11]$} \\
\hline 5 & AD33T1 & MIG Pulse & 6.0 & 1.10 & 1.73 & 17.40 & {$[11]$} \\
\hline 6 & AD33T1 & MIG Pulse & 2.0 & 1.01 & 1.23 & 7.20 & {$[14]$} \\
\hline 7 & AMg6 & MIG Pulse & 2.0 & 1.00 & 1.10 & 9.05 & {$[13]$} \\
\hline 8 & AMr6 & MIG Pulse & 6.0 & 0.75 & 2.55 & 18.20 & {$[12]$} \\
\hline 9 & 1915T & MIG & $1.7-2.0$ & 0.51 & 1.30 & 6.80 & {$[10]$} \\
\hline 10 & AMg6 & MIG Pulse & 2.0 & 0.55 & 1.34 & 6.59 & {$[14]$} \\
\hline 11 & D16T & MIG Pulse & 2.0 & 0.54 & 1.15 & 5.20 & {$[13]$} \\
\hline 12 & D16T & MIG Pulse & 2.0 & 0.39 & 1.19 & 5.33 & {$[14]$} \\
\hline 13 & 1915T & MIG & $1.7-2.0$ & 0.24 & 1.60 & 6.00 & {$[10]$} \\
\hline 14 & 1915T & MIG & $1.7-2.0$ & 0.20 & 2.15 & 6.20 & {$[10]$} \\
\hline Note. Metal inert gas welding - MIG; tungsten inert gas welding - TIG; Pulse metal inert gas welding - MIG Pulse.
\end{tabular}


Table 2. Relationship of height to width of reinforcements of butt welded joints and corresponding to them values of transition radiuses from weld to base metal

\begin{tabular}{|c|c|c|}
\hline No. & $h / g$ & Transition radius $r, \mathrm{~mm}$ \\
\hline 1 & 0.039 & 2.65 \\
\hline 2 & 0.066 & 1.32 \\
\hline 3 & 0.098 & 1.27 \\
\hline 4 & 0.099 & 1.13 \\
\hline 5 & 0.100 & 1.10 \\
\hline 6 & 0.171 & 1.01 \\
\hline 7 & 0.122 & 1.00 \\
\hline 8 & 0.140 & 0.75 \\
\hline 9 & 0.191 & 0.51 \\
\hline 10 & 0.203 & 0.55 \\
\hline 11 & 0.221 & 0.54 \\
\hline 12 & 0.223 & 0.39 \\
\hline 13 & 0.267 & 0.24 \\
\hline 14 & 0.347 & 0.20 \\
\hline Note. Numbers correspond to numbers in Table 1. \\
\hline \multicolumn{2}{|c}{} \\
\hline
\end{tabular}

In course of several decades the Department of strength of welded structures of E.O. Paton Electric Welding Institute has been carrying the measurements of profiles of butt welded joints of aluminium alloys of different series to DSTU ISO 209-1:2002, made by different gas-shielded arc welding methods (Table 1).

Based on discrete data the computer assisted design system MathCAD provides the possibility to plot a regression dependence of one value from another in form of n-power polynomial, where $n$ is the positive integer [15]. However, application of integral indices at small number of terms of the polynomial provides low accuracy of approximation, since in the considered case (Table 2) $h / g$ relationship takes the values differing from each other almost by order. Therefore, the dependence of radius of transition from the weld to base metal on $h / g$ parameter is reasonable to seek in form of the polynomial with fractional powers [7]:

$$
r\left(\frac{h}{g}\right)=\sum_{i=0}^{n} a_{i}\left(\frac{h}{g}\right)^{\frac{i}{2}},
$$

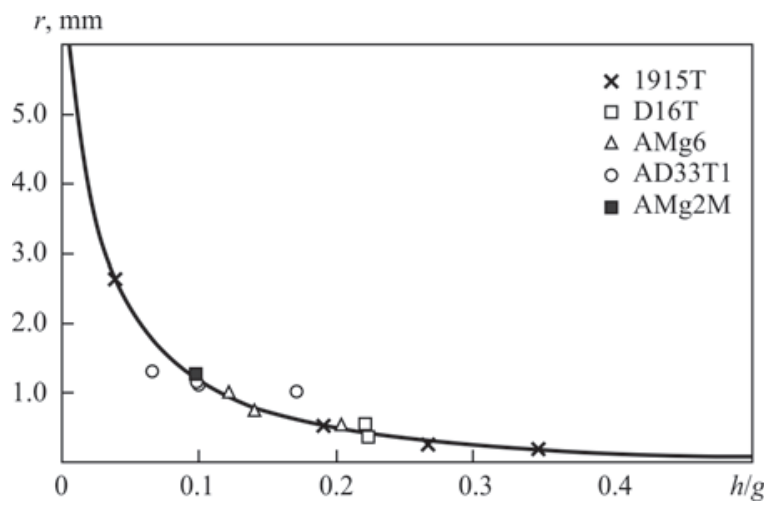

Figure 1. Dependence of transition radius from weld to base metal on relationship of height to width of reinforcement and calculation curve on equation (2) for butt joints of aluminium alloys made by gas-shielded arc welding

where $a_{i}$ is the coefficient of regression function.

Accuracy in use of the first eight terms of the approximating series with integral indices is lower than when using the first five terms of such series with fractional powers.

Besides, in the considered case the function described by high power polynomial is not monotone in the investigated interval of change of $h / g$ relationship from 0 to 0.5 .

Using the first five terms of approximating series (1) allowed getting the function

$$
\begin{aligned}
r\left(\frac{h}{g}\right)= & 9.215-53.22\left(\frac{h}{g}\right)^{1 / 2}+127.05\left(\frac{h}{g}\right)- \\
& -143.43\left(\frac{h}{g}\right)^{3 / 2}+62.74\left(\frac{h}{g}\right)^{2},
\end{aligned}
$$

which demonstrates a strict monotone decrease in the interval of change of $h / g$ relationship from 0 to 0.5 and does not have inflections in this interval (Figure 1).

The separate interest is the transition radius from weld to base metal on the root side of butt welded joint, since the maximum level of stress concentration

Table 3. Geometry parameters of root side of butt welded joints of aluminium alloys

\begin{tabular}{|c|c|c|c|c|c|c|c|c|}
\hline No. & Alloy & $\begin{array}{c}\text { Welding } \\
\text { method }\end{array}$ & $\begin{array}{c}\text { Thickness } \\
\delta, \mathrm{mm}\end{array}$ & $\begin{array}{c}\text { Transition radius } \\
r, \mathrm{~mm}\end{array}$ & $\begin{array}{c}\text { Reinforcement } \\
\text { height } h, \mathrm{~mm}\end{array}$ & $\begin{array}{c}\text { Reinforcement } \\
\text { width } g, \mathrm{~mm}\end{array}$ & $h / g$ & Source \\
\hline 1 & AD33T1 & MIG Pulse & 6.0 & 0.76 & 1.38 & 7.90 & 0.175 & {$[11]$} \\
\hline 2 & AD33T1 & MIG Pulse & 6.0 & 0.72 & 1.38 & 7.80 & 0.177 & {$[11]$} \\
\hline 3 & D16T & MIG Pulse & 5.0 & 0.52 & 1.03 & 4.51 & 0.228 & {$[12]$} \\
\hline 4 & AMg6 & MIG Pulse & 6.0 & 0.51 & 1.29 & 4.38 & 0.295 & {$[11]$} \\
\hline 5 & $1915 T$ & MIG & $1.7-2.0$ & 0.45 & 2.30 & 7.60 & 0.303 & {$[10]$} \\
\hline 6 & AD33T1 & MIG Pulse & 2.0 & 0.37 & 1.37 & 4.70 & 0.291 & {$[14]$} \\
\hline 7 & $1915 \mathrm{~T}$ & MIG & $1.7-2.0$ & 0.31 & 1.40 & 5.10 & 0.275 & {$[10]$} \\
\hline 8 & D16T & MIG Pulse & 2.0 & 0.31 & 1.20 & 3.75 & 0.320 & {$[13]$} \\
\hline 9 & AMg6 & MIG Pulse & 2.0 & 0.31 & 1.10 & 3.72 & 0.296 & {$[14]$} \\
\hline 10 & AMg6 & MIG Pulse & 1.5 & 0.30 & 0.56 & 2.33 & 0.240 & {$[12]$} \\
\hline 11 & D16T & MIG Pulse & 2.0 & 0.26 & 0.97 & 3.50 & 0.277 & {$[13]$} \\
\hline 12 & $1915 T$ & MIG & $1.7-2.0$ & 0.18 & 1.20 & 4.50 & 0.267 & {$[10]$} \\
\hline 13 & $1915 T$ & MIG & $1.7-2.0$ & 0.07 & 2.00 & 5.40 & 0.370 & {$[10]$} \\
\hline
\end{tabular}




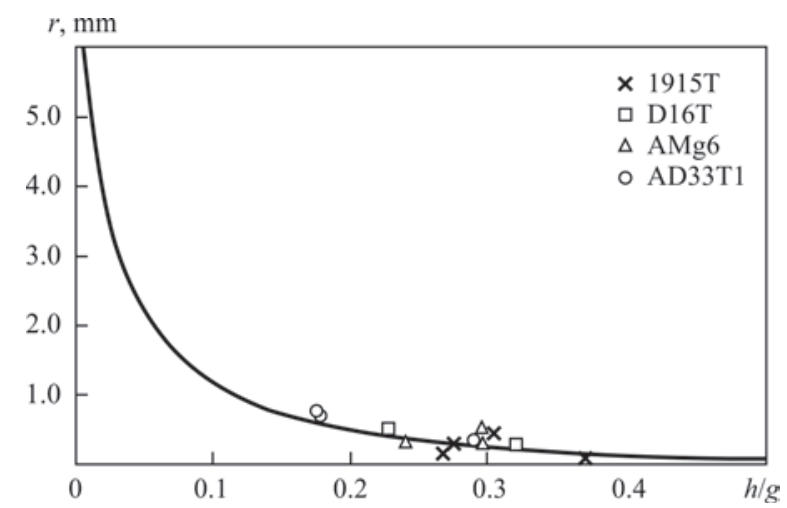

Figure 2. Dependence of transition radius from weld back bead to base metal on relationship of height to width of weld reinforcement and calculation curve on equation (2) for butt joints of aluminium alloys made by gas-shielded arc welding

at specific relationships of dimensions occurs close to back bead [16].

The processes of deformation of face and root surfaces of weld pool under effect of gas-dynamic arc pressure are significantly different [17]. Besides, in order to eliminate metal burn-through and provide quality formation of back side of the weld there is use of removable backing forming elements [18].

Geometry parameters of root convexity are virtually determined by dimensions of groove of forming backing $[14,19]$. At that it is unkown whether the determined connection is preserved between the transition radius from the weld root part to base metal with relationship of height to width of the back bead.

The experimental measurements [10-14] showed that the same as on the face side, the radius of transition from the weld root part to base metal rises with decrease of relationship of height to width of back bead (Table 3).

The experimental points (Table 3 ) give sufficiently accurate description of the calculation curve (Figure 2), therefore, formula (2) can be recommended for determination of the transition radius from weld to base metal on face as well as root side of butt joints of aluminium alloys of different alloying systems made by gas-shielded arc welding methods.

\section{Conclusions}

1. The data from different authors on experimental measurements of the transition radius from weld to base metal in butt joints of aluminium alloys made by gas-shielded arc welding methods were collected and arranged.

2. A functional dependence of fillet radius of the weld with base metal from relationship of height to width of weld reinforcement on face side of butt welded joint was obtained by means of regression analysis of discrete experimental data using computer assisted design system MathCAD.

3. Further analysis showed that the obtained dependence can also be used for calculation determination of fillet radius of the weld back bead with base metal on the root side of welded joint through relationship of height to width of back bead.

1. Trufyakov, V.I., Dvoretsky, V.I., Mikheev, P.P. et al. (1990) Strength of welded joints under alternating loads. Ed. by V.I. Trufyakov. Kiev, Naukova Dumka [in Russian].

2. Navrotsky, D.I. (1968) Design of welded structures taking into account stress concentration. Leningrad, Mashinostroenie [in Russian].

3. Lakhtin, Yu.M. (1983) Physical metallurgy and heat treatment of metals. Moscow, Metallurgiya [in Russian].

4. Vinokurov, V.A. (1973) Stress-relief tempering of welded structures. Moscow, Mashinostroenie [in Russian].

5. Makarov, I.I., Lutsuk, O.A., Grebenchuk, V.G. (1977) Influence of fillet weld parameters on fatigue strength of welded T-joints. Svarochn. Proizvodstvo, 6, 18-21 [in Russian].

6. Asnis, A.E., Ivashchenko, G.A., Anderson, Ya.E. (1982) Influence of radius of weld transition to base metal on fatigue resistance of welded joints. Avtomatich. Svarka, 4, 48-51 [in Rusian].

7. Moltasov, A.V. (2017) Approximate calculation of radius of weld transition to base metal of welded butt joint by normalized parameters. The Paton Welding J., 9, 50-52. https://doi. org/10.15407/tpwj2017.09.09.

8. Berezovsky, B.M., Stikhin, V.A. (1977) Influence of surface tension forces on formation of weld reinforcement. Svaroch. Proizvodstvo, 1, 51-53 [in Russian].

9. Mashin, V.S., Pashulya, M.P., Shonin, V.A., Klochkov, I.N. (2010) Consumable electrode pulsed argon-arc welding of sheet aluminium alloys. The Paton Welding J., 5, 38-41.

10. Shonin, V.A., Yakubovsky, V.V., Ignatiev, V.G. (1991) Resistance to low-cycle fatigue of welded joints of $1915 \mathrm{~T}$ alloy panels. Ibid., 1, 22-25 [in Russian].

11. Shonin, V.A., Gushcha, O.I., Mashin, V.S. et al. (2005) Influence of sizes of welded joint sample of aluminium alloy on residual stress intensity and fatigue resistance. Ibid., 2, 21-31 [in Russian].

12. Kirian, V.I., Knysh, V.V., Kovalchuk, V.S., Solovej, S.A. et al. (2011) Study of fatigue resistance of aluminium alloy welded joints performed by modern welding methods. In: Report on research (Conclus.). Kiev, PWI [in Russian].

13. Kyryan, V.I., Shonin, V.A., Klochkov, I.M. et al. (2009) Service life of butt joints of aluminium alloys AMg6 and D16 sheets made by consumable electrode welding (MIG Pulse). Mekhanika i Phisyka Rujnuvannya Bud. Materialiv i Konstruktsij, 8, 189-203 [in Ukrainian].

14. Knysh, V.V., Klochkov, I.N., Pashulya, M.P., Motrunich, S.I. (2014) Increase of fatigue resistance of sheet welded joints of aluminum alloys using high-frequency peening. Ibid., 5, 21-27.

15. Kirianov, D.V. (2007) Mathcad 14. St.-Petersburg, BKhVPeterburg [in Russian].

16. Tsumarev, Yu.A. (2010) Influence of asymmetry of one-sided butt welds on stress distribution in welded joint. Svarka i Diagnostika, 5, 24-27 [in Russian].

17. Lin, M.L., Eagar, T.W. (1985) Influence of arc pressure on weld pool geometry. Welding J., 6, 163-169.

18. Mashin, V.S., Pashulya, M.P. (2010) Features of consumable electrode pulsed-arc welding of aluminium alloys without application of forming backing elements. The Paton Welding J., 3, 43-49.

19. Rabkin, D.M., Ignatiev, V.G., Dovbishchenko, I.V. (1982) Arc welding of aluminium and its alloys. Moscow, Mashinostroenie [in Russian]. 


\title{
EFFECT OF TELLURIUM ON MICROSTRUCTURE OF LOW-ALLOY CAST IRON DEPOSITED BY ELECTROSLAG METHOD IN CURRENT-CARRYING MOLD
}

\author{
Yu.M. KUSKOV ${ }^{1}$, F.K. BIKTAGIROV ${ }^{1}$ and M.A. FESENKO ${ }^{2}$ \\ ${ }^{1}$ E.O. Paton Electric Welding Institute of the NAS of Ukraine \\ 11 Kazymyr Malevych Str., 03150, Kyiv, Ukraine. E-mail: office@paton.kiev.ua \\ ${ }^{2}$ National Technical University of Ukraine «Igor Sikorsky Kyiv Polytechnic Institute» \\ 37 Peremohy Prosp., 02056, Kyiv, Ukraine
}

\begin{abstract}
Cast iron is one of the main structural materials, having a number of valuable service properties, in particular, wear resistance. Improvement of this characteristic is usually achieved by changing the structure of cast iron due to introduction of expensive alloying elements into its composition. The experiments carried out showed the possibility of transforming gray low-alloy cast iron to chilled wear-resistant one, due to modification of the deposited metal by small portions of tellurium powder. Electroslag surfacing was carried out in a current-carrying mold with melting of filler in the form of chips of low-alloy cast iron in the slag layer and additionally introducing flux-cored wire with a charge, containing tellurium powder, into the slag pool. 6 Ref., 9 Figures.
\end{abstract}

Keyw ord s : electroslag surfacing, current-carrying mold, low-alloy cast iron chips, tellurium, metal structure

Tellurium belongs to metalloids and is applied in various industries, namely chemical, glass, semi-conductor, rubber, metallurgical, etc. In particular, tellurium is used in metallurgy to lower nitrogen absorption by liquid cast iron and steel. It effectively refines the grain in steel, lowers the porosity of castings from steel and cast iron [1]. Tellurium microadditives significantly improve the structure, mechanical properties and formability of cast iron and steel [2].

A special feature of this element, which can be used during performance of wear resistant surfacing, is the effect of small quantities of tellurium from 0.005 up to $0.1 \%$ on stabilization of carbides, for instance it is possible to produce chilled cast iron instead of gray cast iron during wear-resistant surfacing [3].

Interesting is the experience for manufacturing cast iron rolling rolls from unalloyed and medium-alloyed (2.0-4.5 \% Ni and 0.5-1.5 \% Cr) cast irons with addition of small quantities of tellurium filler to liquid metal, gained as far back as in 1950s [4]. It is found that it strongly slows down the graphitization and increases the depth of chilling. Adding $0.0001 \%$ tellurium is equivalent to lowering silicon content by $0.04 \%$, i.e. tellurium slows down graphitization 400 times stronger than silicon does. Therefore, in order to improve the quality of the roll chilled layer, additive of $0.0002-0.0006 \%$ tellurium is quite sufficient, that is regarded to be optimum for passivation of nonmetallic centers of graphitization in roll melts. On the other hand, excess of tellurium acts as a carbide-stabilizing factor. And while for rolls an increased quantity of carbides is undesirable in terms of their per-

(C) Yu.M. KUSKOV, F.K. BIKTAGIROV and M.A. FESENKO, 2019 formance, at deposition on the parts of relatively thin layers, having a carbide component in their structure, it is possible not only to significantly increase the wear resistance of cast iron, but also essentially improve the economic indices of surfacing.

This work is devoted to studying structure formation in metal produced by electroslag surfacing with low-alloy cast iron chips with addition of small quantities of tellurium.

In terms of technology, it is the most rational to solve such a task with application of a current-carrying mold (CCM) in surfacing [5]. Here, the open

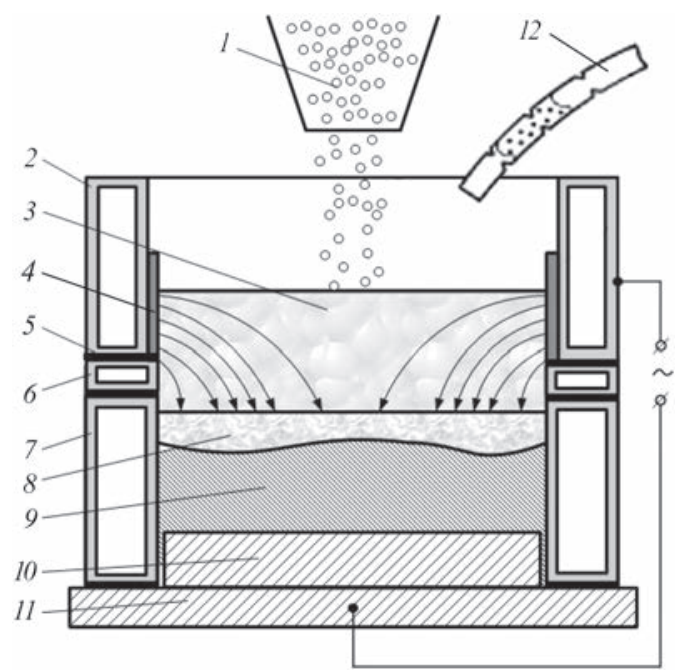

Figure 1. Schemes of electroslag surfacing in CCM with discrete filler (chips) with additional feeding of wire, containing tellurium powder charge, into the slag pool: 1 - discrete filler (chips); 2, 6, 7 - current-carrying, intermediate and forming sections of the mold, respectively; 3 - slag pool; 4 - protective lining; 5 - insulating gasket; 8 - metal pool; 9 - deposited metal; 10 - billet; 11 — tray; 12 - flux-cored wire with tellurium powder charge 


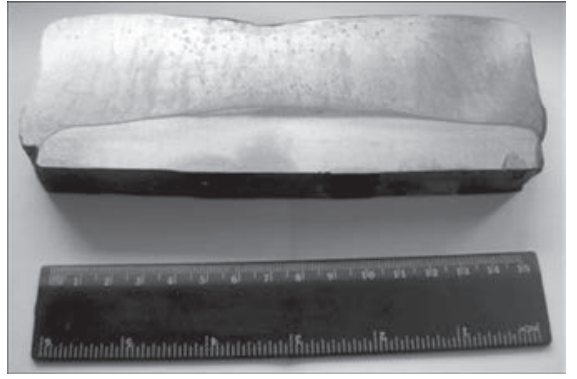

Figure 2. Macrosection of surfaced billet

mirror of the slag pool allows successfully combining addition of deposited metal chips and tellurium into the metal pool through the slag.

Surfacing with chips was performed on a steel billet of $170 \mathrm{~mm}$ diameter in CCM of $180 \mathrm{~mm}$ diameter. Vibrodosimeter was used as a device for chips feeding [6]. Considering the fineness of the tellurium powder, its pouring onto the slag pool surface could lead both to its nonuniform distribution in the metal pool and to greater loss during surfacing. Therefore, addition of tellurium powder into the slag pool was performed as follows. A tubular rod was formed from a steel strip of $0.5 \times 12 \mathrm{~mm}$ size, inside which the tellurium powder was placed. To avoid its pouring out or moving inside the rod, the rod was pinched approximately every $25 \mathrm{~mm}$. During surfacing two processes proceeded simultaneously: continuous feeding of the chips and periodic dipping of the rod end into the slag. The calculated value of the added tellurium was equal to $0.2 \%$ of that of the deposited cast iron. The surfacing scheme and longitudinal macrosection of the surfaced billet are shown in Figures 1 and 2, respectively.

Results of measurement of deposited metal Rockwell hardness $(H R C)$ are given in the macrosection sketch (Figure 3). Measurements of Brinnel hardness (HB) were additionally performed to asses the average hardness of the composite metal (matrix + inclusions).

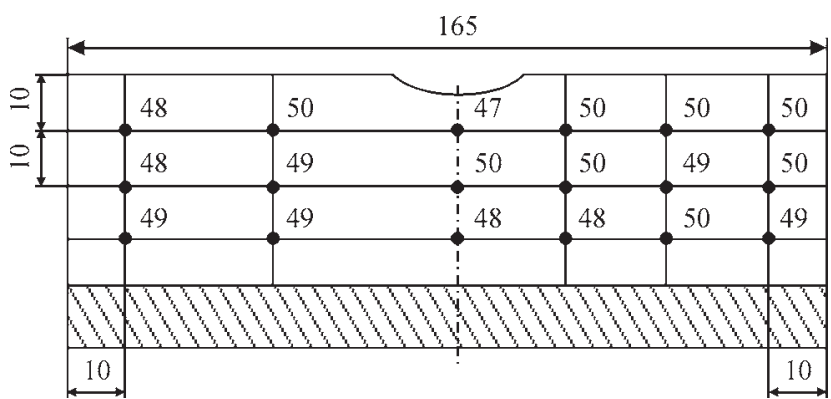

Figure 3. Sketch of a macrosection with hardness values (HRC) across the deposited layer section

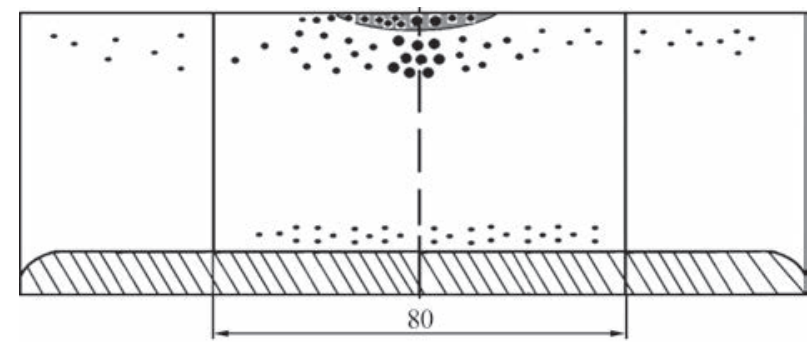

Figure 4. Sketch of a macrosection with inclusions located on its surface

Metallographic investigations were performed in optical microscope MMR-4, having an attachment, allowing taking photos of the studied zones of microsections (section No.3 - along the deposited layer axis; section No.1 - metal crystallized at the mold wall; section No.2 - metal located approximately in the middle of the distance between zones 1 and 3), by analogy with the zones of microhardness measurement (see Figure 3). Hardness meter PMT-3 was used for measurement of microhardness of the structural components.

Assessment of the deposited metal structure. According to the results of chemical analysis, residual tellurium content in the deposited metal is equal to $0.079-0.112 \%$. Deposited metal is dense, although shrinkage approximately $5 \mathrm{~mm}$ deep is present in the

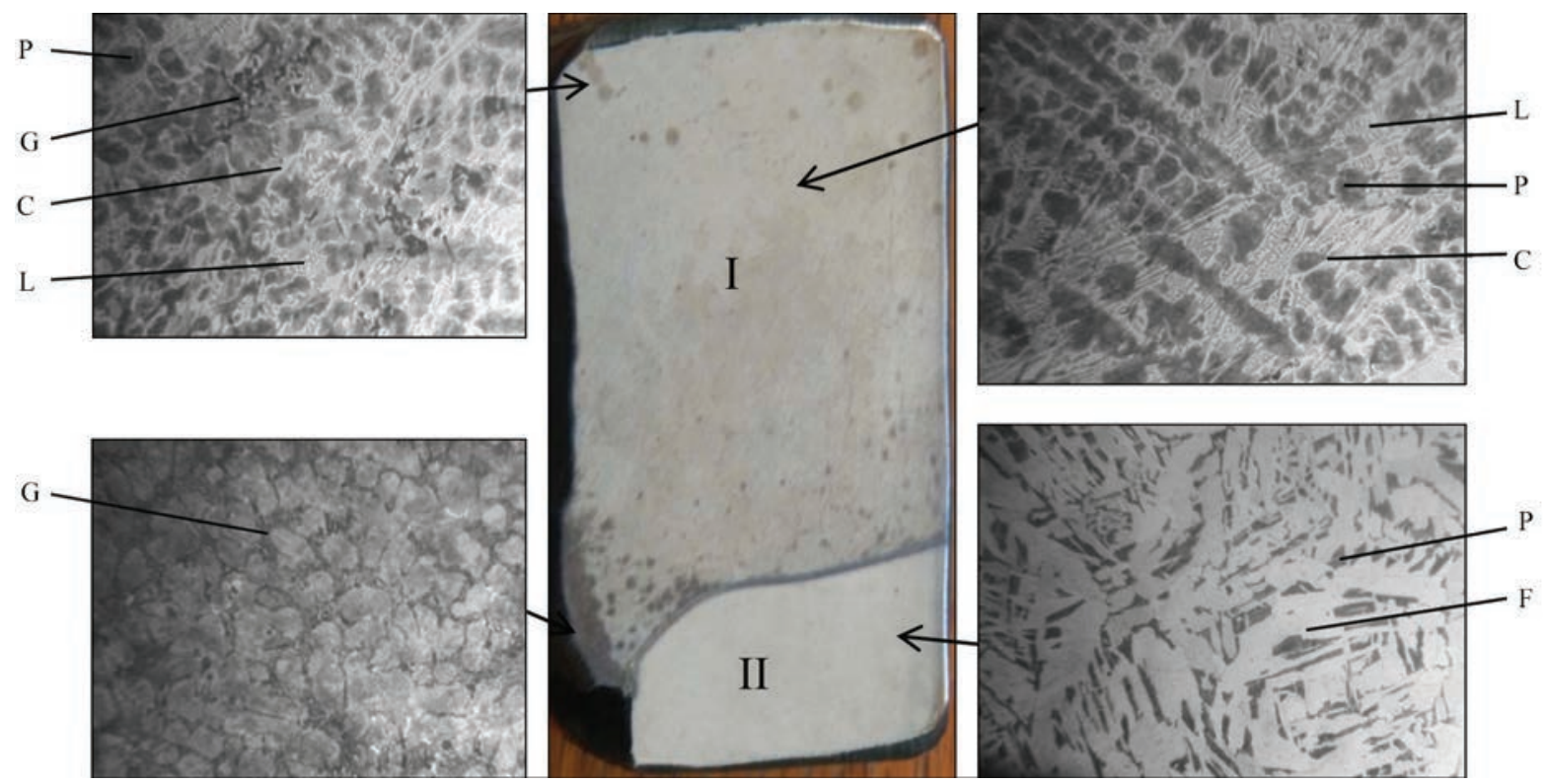

Figure 5. Microstructure $(\times 100)$ of deposited metal of microsection No.1: I — deposited metal; II — base metal 


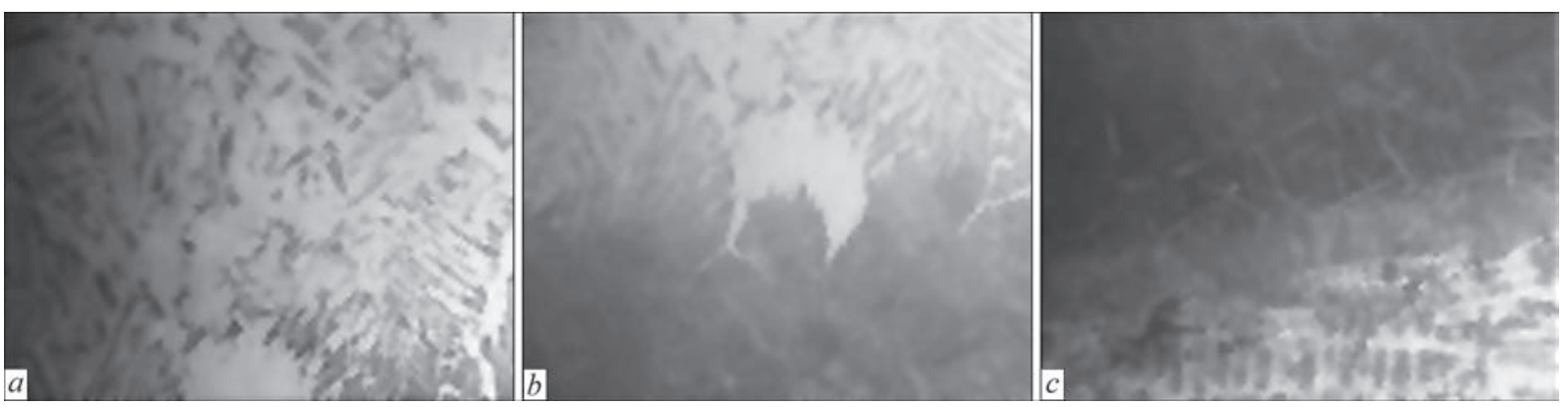

Figure 6. Microstructure $(\times 100)$ of fusion zone of microsection No.1 (for description of $a-c$ see the text)

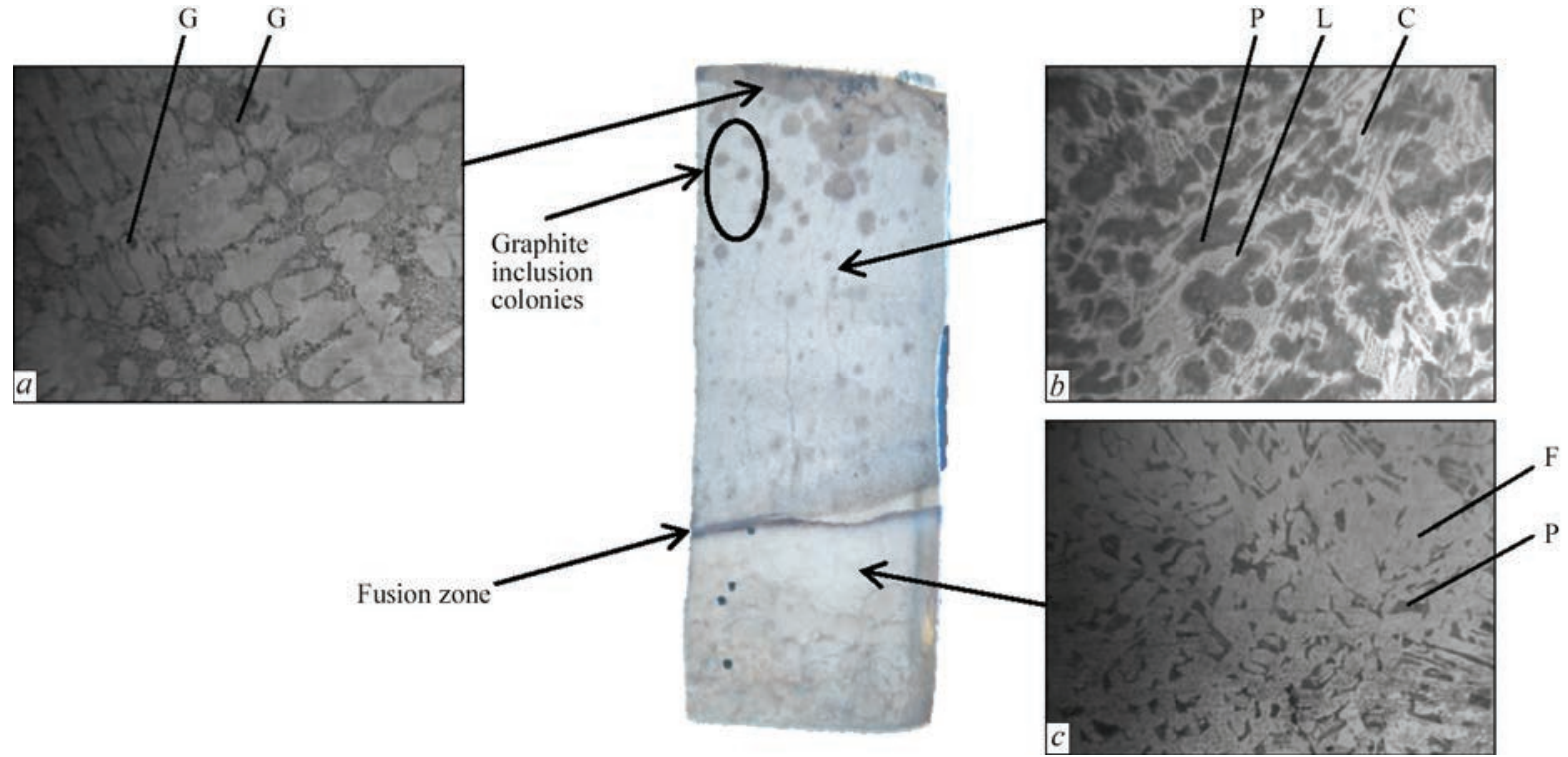

Figure 7. Microstructure $(\times 100)$ of deposited metal of microsection No.2

layer upper part along its axis. Nonuniformly distributed round-shaped inclusions of not more than 1-2 mm diameter are observed on the section surface (Figure 4). These inclusions are, mainly, located in the central zone of the section on length $L=80 \mathrm{~mm}$. Larger inclusions and their conglomerate are concentrated in the shrinkage cavity zone. Smaller-size inclusions are located at the fusion zone of base and deposited metals. In the part of the deposited layer, which was crystallized closer to mold walls $(L=40 \mathrm{~mm}$ ) inclusions are practically absent. Measurements of inclusion microhardness allowed identifying them as graphite precipitates with $H V 1-1.1-1.3 \mathrm{GPa}$.

The fusion zone is a line slanting at the edges towards the base metal (penetration is equal to approximately $5 \mathrm{~mm}$ ). Such a pattern of base metal penetration corresponds to distribution of current lines in the slag pool and nature of metal pool formation at surfacing in the CCM (see Figure 1).

Depending on penetration depth, the change of macrohardness $(H B)$ of the transition zone from the deposited to the base metal in sections $1-3$ is equal to: No.1 440-128; No.2 - 392-111; No.3 - 440-278.

Assessment of microstructure zones in microsections 1-3.
Sample No.1 (Figure 5). The main components of the deposited metal structure are cementite $(\mathrm{C})$, ledeburite (L) and pearlite (P). Rare inclusions of interdendritic graphite $(G)$ are found. Microhardness of structural components is characterized by the following values (GPa): $\mathrm{C}-4.8-6.45 ; \mathrm{L}-4.2-4.4$; P 3.1-3.2; G - 1.1-1.3. On the whole, presence of such a range of structural components corresponds to the structure of chilled wear-resistant cast iron.

The zone of metal fusion (Figure 6) is presented in the form of several transition layers: base metal $(a)-$ ferritic-pearlitic steel $(c)$, a narrow band $(\delta=1-2 \mathrm{~mm})$ of metal of a composition produced as a result of mix-

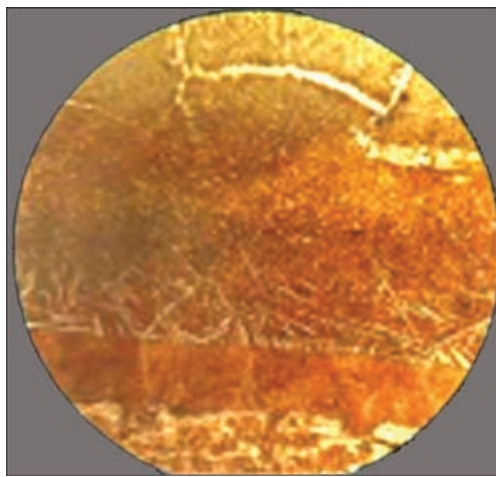

Figure 8. Microstructure $(\times 30)$ of fusion zone of microsection No.2 


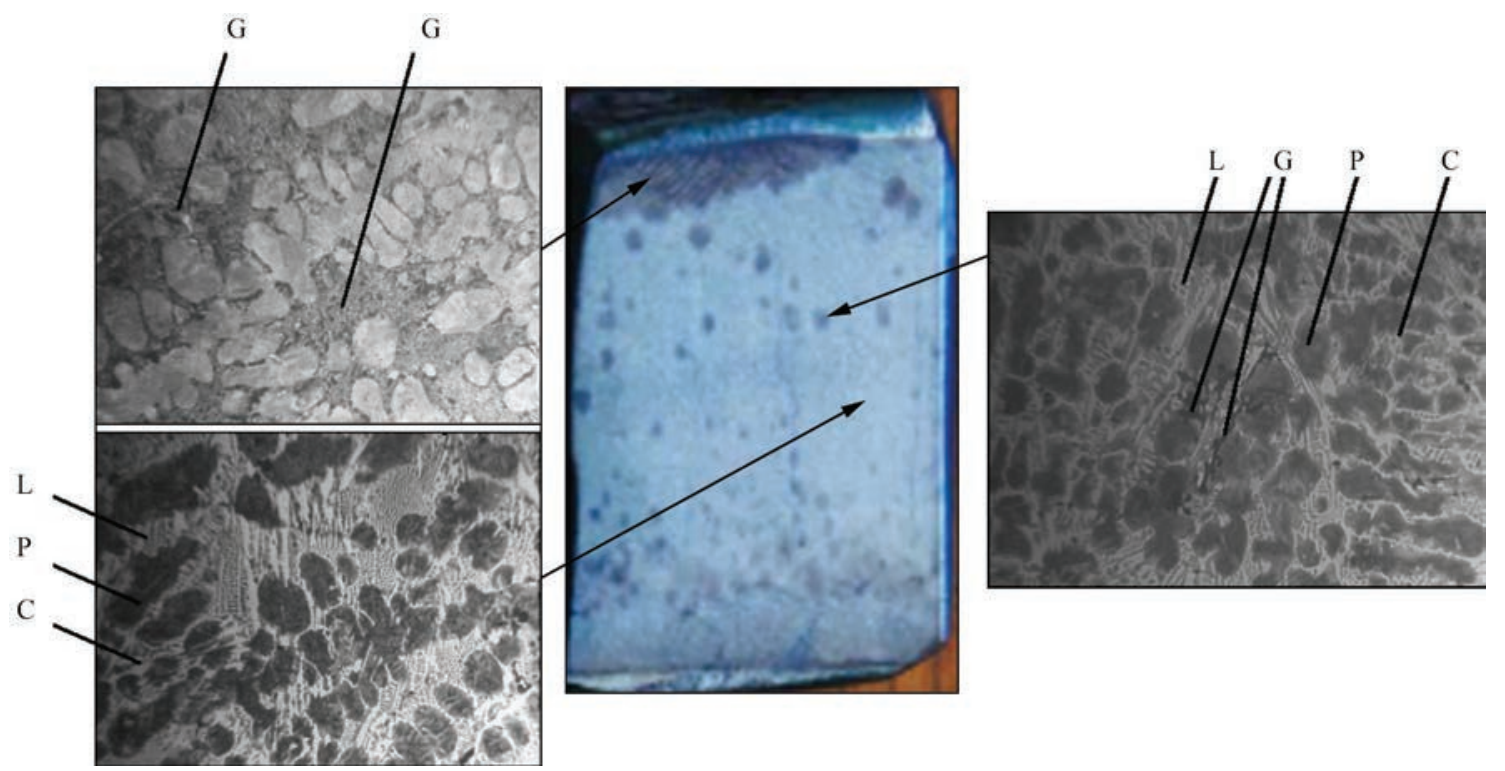

Figure 9. Microstructure $(\times 100)$ of deposited metal of microsection No.3

ing of the deposited and base metal $(b)$ - a layer with a small quantity of characteristic martensite or Widmanstatten needles - a layer of deposited cast iron.

Sample No. 2 (Figure 7). Structure of this part of the deposited metal largely corresponds to that of sample No.1.The difference consists in that there is a large number of graphite inclusions, particularly in the upper part of the layer. If we exclude the graphite inclusion colonies from consideration, such a structure also corresponds to that of chilled cast iron.

Metal fusion zone (Figure 8) also consists of several layers, but layer boundaries are clearer, that is attributable to smaller penetration of base metal.

Sample No. 3. Deposited metal of this sample has the most complex structure, formed as a result of some features of the applied technique of ESS in CCM. As one can see from Figure 1, the discrete surfacing material (chips in our case) is fed on the slag pool surface in the vicinity of its vertical axis (in the mold center). In the case, if the filler feed speed does not correspond to the accepted electric surfacing mode, or in other words to pool thermal conditions, the following situation is in place. On the one hand, not the total volume of the fed filler has enough time to melt completely, on the other, the forming column of unmelted or incompletely melted filler prevents uniform distribution of tellurium particles and its interaction with liquid metal in its entire volume.

These are exactly the reasons for structural nonuniformity across the deposited layer cross-section, obtained during surfacing. More over, in this experiment, the last portions of chips not only did not melt completely, but concentrated in the narrow surface zone of the shrinkage cavity. As a result, in the area where this accumulation occurred, the metal structure consists of platelike graphite, cementite, ledeburite and pearlite. Here, both in the accumulation zone and in the presence of individual coarse inclusions, graphite is distributed in the form of highly ramified branches located in interdendritic space. As a result, a structure of mottled cast iron $(\mathrm{G}+\mathrm{P}+\mathrm{C}+\mathrm{L})$ is observed in those areas where graphite is present in sufficiently large quantity. In areas with its lower content, the structure corresponds to chilled cast iron $(\mathrm{P}+\mathrm{C}+\mathrm{L})$.

Thus, performed research proved the possibility of producing wear-resistant cast iron in electroslag surfacing in CCM, by modifying by tellurium the liquid metal of the deposited filler in the form of chips of low-alloyed cast iron. However, to achieve a uniform interaction of tellurium with the entire volume of liquid metal, it is necessary to provide during surfacing the correspondence between mass velocity and dimensions of the fed filler to electric modes of ESS process.

1. Kindyakov, P.S., Korshunov, B.G., Fedorov, P.I., Kislyakov, I.P. (1976) Chemistry and technology of rare and scattered elements. Pt 3. Moscow, Vysshaya Shkola [in Russian].

2. (1985) Properties of elements: Refer Book. Ed. by M.E. Dritsa. Moscow, Metallurgiya [in Russian].

3. Houdremont, E. (1966) Special steels. Vol. 3. Moscow, Metallurgiya [in Russian].

4. Krivosheev, A.E. (1957) Cast rolls. Moscow, Metallurgizdat [in Russian].

5. Kuskov, Yu.M., Gordan, G.N., Bogajchuk, I.L., Kajda, T.V. (2015) Electroslag surfacing using discrete materials of different methods of manufacture. The Paton Welding J., 5-6, 30-33.

6. Shchupak, G.B., Us, V.I., Kuskov, Yu.M. et al. (1993) Dosing system of filler materials in electroslag technology. Problemy Spets. Elektrometallurgii, 1, 29-31 [in Russian]. 


\title{
DRIVES OF MECHANISMS OF AUTOMATIC MACHINES FOR ORBITAL TIG WELDING OF METAL PIPELINE BUTT JOINTS IN NPP POWER UNITS
}

\author{
N.M. MAKHLIN and V.Yu. BURYAK \\ SE «SEC of Welding and Control in the Field of Nuclear Energy of Ukraine \\ of E.O.Paton Electric Welding Institute of the NAS of Ukraine» \\ 11 Kazymyr Malevych Str., 03150, Kyiv, Ukraine. E-mail: electro@paton.kiev.ua
}

\begin{abstract}
Electric drives are integral devices in any welding installation for arc and plasma welding. Since a number of specific requirements are made to the accuracy and reliability of the actuating mechanisms in modern automatic machines for orbital welding of position butt joints of pipelines in NPP units, these requirements are also imposed on their driving mechanisms, that required development of the latter. The schemes of unified reversible DC drives of actuating mechanisms in modern automatic machines for orbital welding of position butt joints in NPP pipelines are described. A transistor drive with feedback from an optical speed sensor, characterized by high reliability, ability to accurately preset (program) the rotation speed of the motor shaft, absence of mechanical switching contacts for starting or stopping, or for reversing, as well as a device for high-precision high-speed automatic arc voltage control was designed. The results of industrial operation of some automatic machines for orbital welding designed at the Scientific and Engineering Center of Welding and Control in the Field of Nuclear Energy (SEC WCNE), are given, which use the described reversing drives and the device for automatic arc voltage control. The aim of this, paper is to present the results of the work carried out at the SEC WCNE in the direction of designing components of automatic machines for orbital welding of position butts in thin-walled pipelines from austenitic, pearlitic and carbon steels and nonferrous metal alloys (except for aluminium and its alloys). 12 Ref., 8 Figures.
\end{abstract}

Keywords : orbital arc welding, nonconsumable electrode, inert gases, drive, direct current electric motor, optoelectric speed sensor, transistor regulator

Improvement of automatic machines for orbital welding (GTAW) of position butt joints of pipelines in NPP power units is directly related to increase of operating reliability of actuating mechanisms, in particular, electric drives [1, 2]. It was shown [3] that the controlled dc drives of mechanisms of such automatic machines have several advantages compared to electric drives of asynchronous ac motors. Here, it is rational to use drives with negative feedback by the rotation frequency of motor output shaft.

According to the research conducted at SEC WCNE, allowing for the features of operation of automatic machines for GTAW, in particular, when the welding head with the actuating mechanisms and control system with drive controllers can be removed to a considerable distance from each other and can be in different rooms (that is often the case in nuclear engineering), the most stable, accurate, reliable and independent on external disturbances for systems with negative feedback by rotation frequency of motor output shaft, are the incremental optoelectric sensors of rotation speed (encoders), generating a strictly constant number of output square-wave information pulses (constant pulse sequence) per one revolution of the motor shaft (Figure 1,a). At present both small-sized dc motors (gear motors) with two shaft outputs, and optoelectric sensors of rotation speed of motor output shaft (encoders) are widely avaliable in the market of Ukraine at a quite acceptable cost. For instance, encoder 0.5.2420.1211.0128 (0125) can be used as

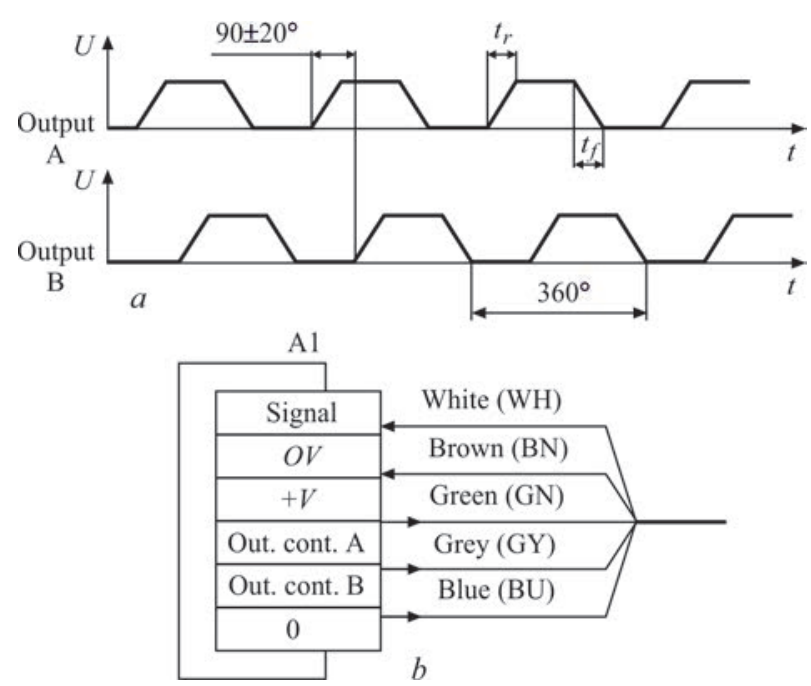

Figure 1. Optoelectric sensor of the speed of shaft rotation of motor (encoder) 05.2420.1211.0128 (0125) of «Kübler» Company: $a$ - pulse sequences at information outputs A and $\mathrm{B} ; b-$ connection diagram 


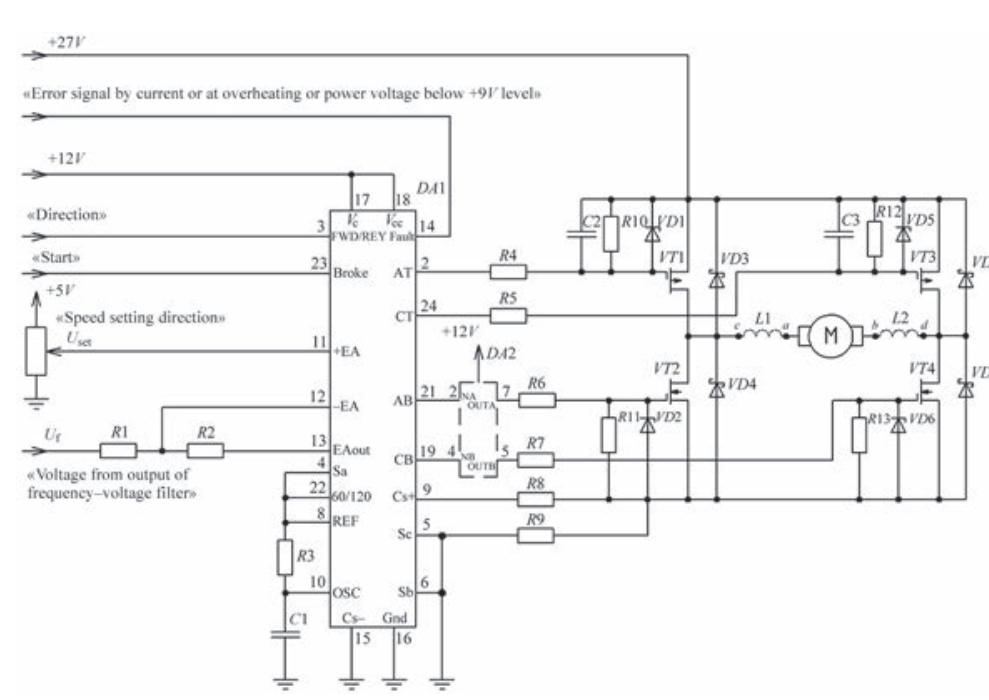

Figure 2. Simplified block-diagram of a unified drive of the mechanisms in automatic machines for GTAW of position butts of cylindrical metal pipelines

such an optoelectric sensor, the connection diagram of which is given in Figure 1, $b$. It is developed and manufactured by Kübler Company [4].

One of the features of this encoder is availability of two output channels in it - channel A and channel $\mathrm{B}$, in which the pulse sequences are similar by amplitude, load capacity and repetition frequency, but are shifted by phase by $(90 \pm 20)^{\circ}$ (Figure $1, a$ ) that significantly widens the area of this encoder application and simplifies the repairability of the drives, in which such encoders are used. All the communications with the encoder are carried out through a coaxial or axial cable from multicolored insulated cores.

Analysis of various published sources, in particular [5-7], and accumulated experience of designing the electric drives, as well as the conclusions following from work [3], give every reason to believe that it is the most rational to apply for construction of electric drives of actuating mechanisms in automatic machines for GTAW the transistorized pulse-width modulators (as in the case of sensorless drives of welding machines), where the basic circuit solution is the bridge circuit with powerful field transistors with an insulated gate (MOSFET). The main feature of the proposed engineering solution consists in that variation of the type and selection of the respective electric characteristics of the bridge transistors allows, if required, achieving maximum values of electric drive power (right up to $500 \mathrm{~W}$ ), practically without changing either the structure, or, mainly, the nominal values of its components, that enables unification of the drives designed for various-purpose automatic machines for GTAW.

Figure 2 gives a simplified diagram of a unified drive of the mechanisms of GTAW automatic machines.

The power part of the drive is an H-bridge formed by powerful field transistors with an insulated gate
MOSFET VT1-VT4. In the basic variant of the drive MOSFET with P-type channel IRF4905 are used as «upper» transistors $V T 1$ and $V T 3$, operating in the mode of transistor switches, and MOSFET with N-type channel IRF3205Z are used as «lower» transistors VT2 and VT4, functioning in the mode of pulse-width modulation (PWM). In the case, if the motor armature inductance is low (that is characteristic for low power dc motors), inductances (with an infinite or large magnetic gap) can be connected in series with the armature: $L 1$ between points $c$ and $a$ and $L 2-$ between points $d$ and $b$. If it is necessary to ensure functioning of higher power drive, then in order to control «lower» transistors $V T 2$ and VT4, operating in PWM mode, a two-channel driver DA2 can be added to the drive scheme, for instance, of IXDN604SIA type, developed and manufactured by IXYS Company.

For control of power transistor H-bridge, we propose the available in Ukraine specialized microcircuit MC33035DWG developed and manufactured by ON Semiconductor Company as the main element in the considered drive. It is a multichannel microcontroller to control the dc motors, which is designed for surface mounting, allowing performance of PWM and ensuring protection of the controlled H-bridge from current overloads, or its overheating, or protection from inadmissible lowering of the level of power supply to the microcircuit proper. Here, the speed of motor shaft rotation is determined by average values of voltage applied to it, and regulation of the number of motor shaft revolutions and stabilization of this number per a unit of time are achieved by changing the duty cycle of power pulses of the drains of the respective «lower» transistors of H-bridge.

Arrival of START signal (low logic level «log. $0 »)$ to microcontroller BRAKE input (pin 23 of microcircuit $D A 1)$, results in switching on of power transistor VT1 in open transistor switch mode and of power transistor VT 4 - in PWM mode. As a result, the motor shaft rotates with the set speed and in the set working direction. At reversal «high» logic level («unit» level) arrives to input 3 of microcircuit $D A 1$ that leads to switching off power transistors VT1 and VT4 and switching on power transistor VT3 in open transistor switch mode and of power transistor VT2 - in PWM mode.

Stop realization at manual or automatic feeding of «Stop» signal is performed at arrival of «high» logic level («unit» level) to «Brake» input of the microcontroller (pin 23 of microcircuit DA1), resulting in automatic switching off of power transistors VT1 and VT3 and practically simultaneous switching on of power transistors VT2 and VT4, which in this case 
will automatically go from PWM mode into the mode of permanently open transistor switches, that ensures effective dynamic braking of the motor.

Figure 3 shows an oscillogram, illustrating «acceleration» (i.e. rising of voltage and current of the drive in time) of fully loaded drives of actuating mechanisms in automatic machines for GTAW; and Figure 4 gives an oscillogram illustrating «braking» of these drives. The given oscillograms show that the longest «acceleration» time (allowing for the inertia of the mechanisms of automatic machines for GTAW) of approximately $80 \%$ of the largest working value of voltage at the motor armature (largest working value of armature current) does not exceed $20 \mathrm{~ms}$, and the longest time of «braking» under the same conditions is not more than $25 \mathrm{~ms}$.

The preset (programmed) signal (voltage) of setting the speed is adjustable in the range from 0 up to $+5 \mathrm{VDC}$. It is formed outside the drive main part, being subjected to filtration of the high-frequency components, and comes to the inverting input of microcontroller error amplifier (pin 11 of microcircuit $D A 1)$. A signal (voltage), the average value of which is directly proportional to the frequency of pulse sequence at the output of one of the encoder channels, is applied to the inverting input of this error amplifier (pin 12 of microcircuit $D A 1$ ) via resistor $R 1$. This signal is formed using «frequency/voltage» integrated converter and $2^{\text {nd }}$ order filter. Output voltage of error amplifier affects the duty cycle of PWM pulses, the frequency of which is determined by time-setting chain $R 3 C 1$. In the proposed drive PWM frequency is equal to approximately $25 \mathrm{kHz}$ and, thus, on the one hand, it goes beyond the audible sound range, and causes slight ripple of motor armature current, and on the other hand, it ensures an acceptable level of dynamic losses in power transistors of H-bridge.

Operating in the mode of permanently open transistor switch «upper» power transistor VT1 (here the «upper» power transistor VT3 is switched off) is switched on by applying to the gate of this power transistor via resistor $R 6$ the voltage from AT output of microcontroller DA1 (pin 2 of microcircuit DA1), and operating in the mode of permanently open transistor switch «upper» power transistor VT3 (here «upper» power transistor VT1 is switched off and is in the condition of permanently closed transistor switch) is switched on by applying the voltage from CT output of microcontroller DA1 (pin 24 of microcircuit DA1) to the gate of this power transistor via resistor $R 6$. The gates of power transistors VT1 and VT3 are protected by $R C D$-chains: the gate of power transistor VT1 by chain $R 10 C 2 V D 1$, and gate of power transistor $V T 3$ - by chain R12C3VD5. During the entire cycle of operation of «upper» power transistor VT1 the «lower» power transistor VT4 operates «in pair» with

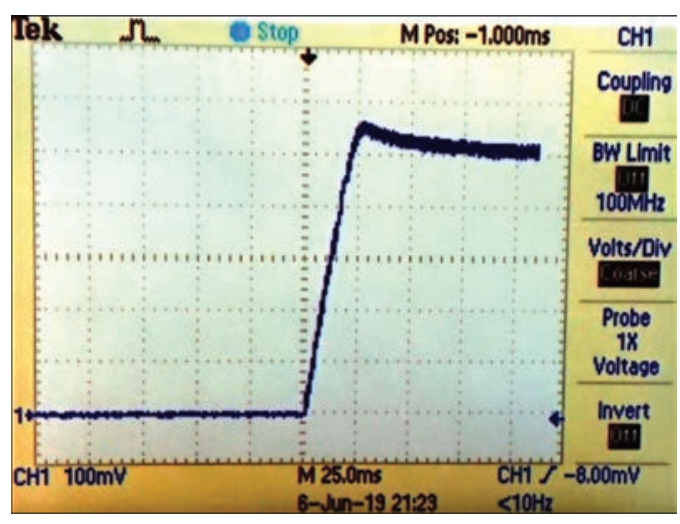

Figure 3. Oscillogram of «acceleration» of the drive of mechanisms of nonconsumable electrode rotation and oscillation in automatic machines for GTAW of position butt joints of metal pipelines

it in PWM mode, which is controlled via resistor $R 7$ by pulsed voltage from CB output of microcontroller $D A 1$ (pin 19 of microcircuit DA1). When «upper» power transistor VT3 is in the switched-on condition, «lower» power transistor VT2 operates «in pair» with it in PWM mode, which is controlled via resistor $R 6$ by pulsed voltage from $A B$ output of microcontroller $D A 1$ (pin 21 of microcircuit DA1). The gates of power transistors $V T 2$ and $V T 4$ are protected by $R D$-chains: gate of power transistor VT2 - by chain R11VD2, gate of power transistor VT4 - by chain R13VD6.

During functioning of the proposed drive, current limitation is ensured by voltage on divider $R 8, R 9$, the signal from which (via resistor $R 8$ ) comes to input $\mathrm{Cs}^{+}$ of the microcontroller (pin 9 of microcircuit DA1).

The described reversing drive was used as a unified assembly in automatic machines ADTs 627 U3.1, ADTs 625 U3.1, ADTs 626 U3.1, ADTs 628 UKhL4, ADTs 629 UKhL4 and ADTs 630 UKhL4 for GTAW of position butt joints of metal pipelines [8, 9]. In automatic machines ADTs 627 U3.1, ADTs 625 U3.1 and ADTs 626 U3.1 for GTAW, designed predominantly for welding by the methods of autopressing or sequential penetration, this drive was applied to ensure functioning of the mechanism of rotation (ro-

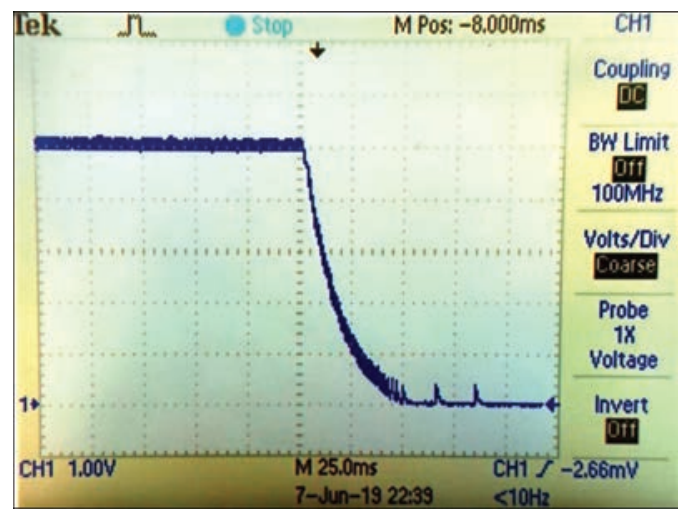

Figure 4. Oscillogram of «braking» of the drive of mechanisms of nonconsumable electrode rotation and oscillation in automatic machines for GTAW of position butt joints in metal pipelines 


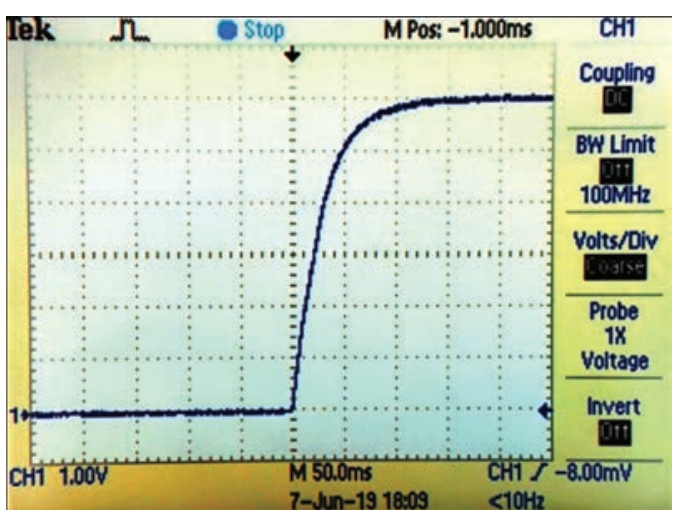

Figure 5. Oscillogram of «acceleration» of the drive of filler wire feed mechanism in automatic machines for GTAW of position butt joints of metal pipelines

tator) of the welding head faceplate around the pipes being welded. In automatic machines ADTs 628 UKhL4, ADTs 629 UKhL4 and ADTs 630 UKhL4 the described reversing drive is designed for driving the faceplate rotator, nonconsumable electrode oscillator and filler wire feed mechanism. In all the models of the above-mentioned automatic machines, the available in Ukraine gear motors $2657 \mathrm{~W} 024$ CR 30/1 of Faull Haber Company and encoders 05.2420.1211.0128 (0125) of Kübler Company are used in faceplate rotators, and nonconsumable electrode oscillators of their welding heads. The filler wire feed mechanism of automatic machines ADTs 628 UKhL4, ADTs 629 UKhL4 and ADTs 630 UKhL4 for GTAW is fitted with the available in Ukraine dc motor DCM 502070-1000 of higher power $\left(P_{\max }=\right.$ $=120 \mathrm{~kW}$ ) with built-in optoelectric sensor of shaft rotation speed (encoder), at the information output of which a pulse sequence with pulse repetition rate of $1000 \mathrm{p} / \mathrm{rev}$ is formed. This device is developed and manufactured by Leadshine Technology Co., Ltd. The nominal voltage of this motor is equal to $30.3 \mathrm{~V}$, nominal value of armature current is $3.94 \mathrm{~A}$, nominal frequency of shaft rotation is $2900 \mathrm{rpm}$. Proceeding from the specification of motor DCM 502070-1000,

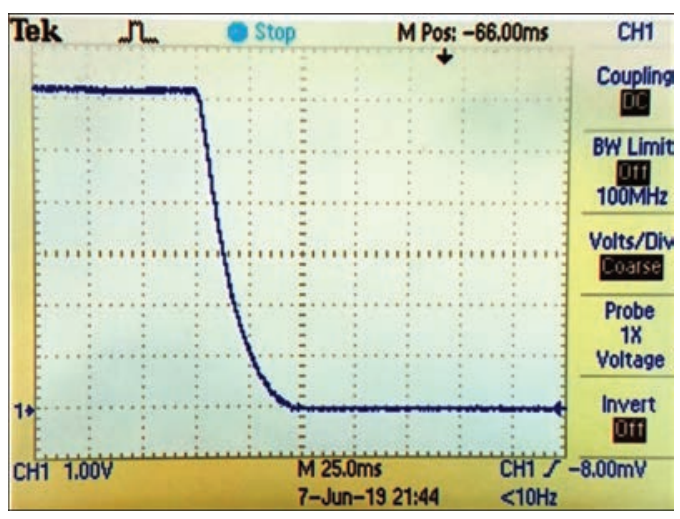

Figure 6. Oscillogram of «braking» of the drive of filler wire feed mechanism in automatic machines for GTAW of position butt joints of metal pipelines the circuit of the above drive was taken as a base, but with slight modification: supply voltage of $\mathrm{H}$-bridge was selected equal to $+34 \mathrm{VDC}$, and driver DA2 was added to the circuit of control of «lower» power transistors of H-bridge, nominals of the components of 2nd order filter, to which the output of «frequency/ voltage» converter is loaded, were corrected, as well as nominals of resistors $R 8, R 9$ (Figure 2).

Figures 5 and 6 give oscillograms illustrating the «acceleration» and «braking», respectively, at fully loaded drive of filler wire feed mechanism of automatic machines ADTs 628 UKhL4, ADTs 629 UKhL4 and ADTs 630 UKhL4 for GTAW. The given oscillograms are indicative of the fact that the time of «acceleration» of this drive (allowing for the inertia of the filler wire feed mechanism) does not exceed $45 \mathrm{~ms}$, and the «braking» time $-50 \mathrm{~ms}$.

During orbital welding of butt joints of pipelines in NPP power units, one of the most important characteristics of welded joint quality is the admissible irregularity of weld penetration depth, depending on spatial position of the nonconsumable electrode at the set welding speed $[2,10]$. It is known that in order to achieve the required quality of the welded joint in these cases, it is necessary to simultaneously stabilize also the welding speed (speed of movement of welding head with the torch along the position butt trajectory) and welding current and voltage (arc length). And while the welding speed stabilization is ensured using the described drive, and welding current stabilization is due to «vertical» («bayonet») output volt-ampere characteristics of welding current source, arc voltage stabilization is performed either using mechanical devices for arc length stabilization (ALS), or using devices for automatic regulation of arc voltage (ARAV). The operating algorithm of ALS and ARAV devices, their design principles and technical requirements to them are described in detail in works $[2,5,10,11]$. Mechanical device for ALS is used in automatic machine ADTs 627.U3.1 for GTAW of position butt joints of metal pipelines with nominal outer diameter from 7 up to $24 \mathrm{~mm}$. In all the other above-mentioned models of automatic machines for GTAW of position butt joints of metal pipelines (with nominal outer diameter from 18 up to $219 \mathrm{~mm}$ ) a unified ARAV device is used, the simplified scheme of which is given in Figure 7.

The main element of ARAV device is a powerful operational amplifier $D A 2$, the output of which is connected to ARAV motor armature via limiting resistor $R$. This motor rotates, depending on the error signal, between the set and actual instantaneous values of arc voltage. In the differential amplifier of error, included into the structure of microcircuit $D A 2$, its output voltage is directly proportional to the difference of 
arc voltages at direct (pin 1 of microcircuit $D A 2$ ) and inverting (pin 2 of microcircuit DA2) inputs. Operating points of drain characteristics of output power transistors of microcircuit DA2 are determined by the value and sign of output voltage of the above amplifier. Activation of microcircuit $D A 2$ is performed by logical levels using digital microcircuit $D D 1$ and optotransistor VT1. Here, if phototransistor of optocouple VT1 is open, microcircuit DA2 is «dormant». Transition (activation) of microcircuit $D A 2$ from «dormant» into working (active) state can take place only in the case, when phototransistor of optocouple VT1 is completely closed. Current limitation through output power transistors of microcircuit $D A 2$ is determined by nominal resistance of resistor $R 10$. At the moment, when voltage levels at error amplifier inputs (pins 1 and 2 of microcircuit DA2) become equal to each other, the voltage at this amplifier output and at the output of power transistors of microcircuit $D A 2$ will become practically equal to zero and motor $\mathrm{M}$ will stop its rotation.

Signal for setting arc voltage $U_{\text {a.set }}$ comes from the outside through two-sided analog switch (interconnected pins 6 and 10 of microcircuit $D A 1$ ) is filtered by T-shaped filter $R 5, R 8, C 1$ and applied to direct input of differential amplifier of error of microcircuit $D A 2$.

The signal proportional to actual current value of arc voltage $U_{\mathrm{a}}$, is formed with the accuracy not worse than $1 \%$ at the output of voltage sensor B1 developed at SEC WCNE (type DN — 100C) [12], from where it is fed to the inverting input of differential amplifier of error of microcircuit $D A 2$ via another bilateral analog switch (interconnected pins 14 and 15 of microcircuit $D A 1)$ and resistor $R 6$.

As the possibility of ADJUSTMENT operation, when the welding current and arc voltage are absent, is envisaged in automatic machines ADTs 627 U3.1, ADTs 625 U3.1, ADTs 626 U3.1, ADTs 628 UKhL4, ADTs 629 UKhL4 and ADTs 630 UKhL4 for GTAW of position butts joints of metal pipelines, the proposed ARAV device contains resistive dividers $R 1, R 2$ and $R 3, R 4$. Signals from these dividers are used for simulation of arc voltage, and they come to inverting input of differential amplifier of error of microcircuit $D A 2$ via the respective bilateral analog switches (interconnected pins 11 and 7, 3 and 2, respectively, of microcircuit DA1) and resistor $R 6$.

In ARAV device, readily available in Ukraine microcircuit OPA547T, developed and produced by «Texas Instruments» Company, can be applied as a powerful specialized microcircuit with bipolar power supply DA2, and, for instance, microcircuit DG411DY, developed and produced by VISHAY Company, can be used as bilateral analog switches DA1,

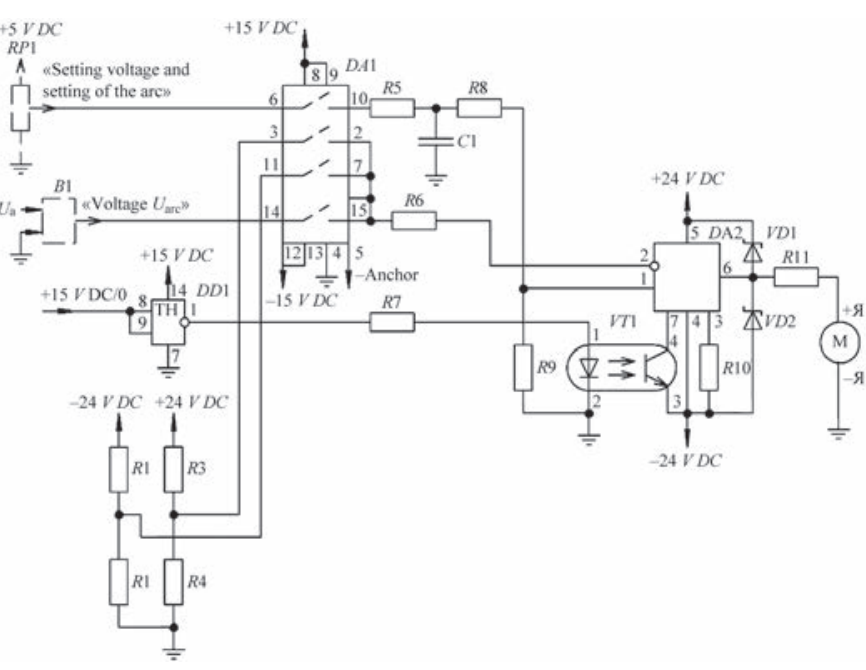

Figure 7. Simplified block-diagram of a unified ARAV device in automatic machines for GTAW of position butt joints of metal pipelines

microcircuit HEF4093BT, developed and produced by NXP Company can be applied as digital microcircuit DD1, and, for instance, gear motor $1524 \mathrm{~T} 024$ SR 16/7 3.71:1, developed and produced by the same Faull Haber Company can be used as low-power dc motor. Figure 8 shows the voltage oscillogram at the inputs of differential amplifier of error (for the case, when the difference between voltage at direct input and voltage at inverting input of this amplifier does not exceed $\pm 0.15 \mathrm{~V}$ ), according to which the total time of «acceleration» of ARAV mechanism does not exceed $25 \mathrm{~ms}$, and total «braking» time $-60 \mathrm{~ms}$.

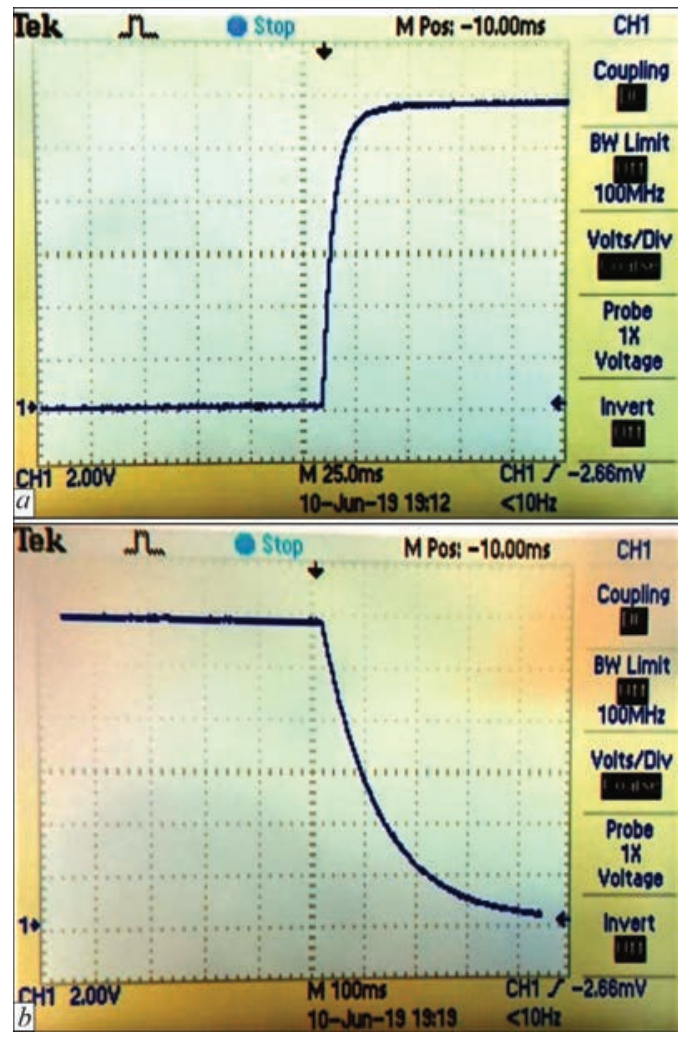

Figure 8. Oscillogram of «acceleration» $(a)$ and «braking» $(b)$ of ARAV device mechanism in automatic machines for GTAW of position butt joints of metal pipelines 
Automatic machines ADTs 627 U3,1, ADTs 625 U3.1, ADTs 626 U3.1 for GTAW of position butt joints of metal pipelines, fitted with the above drives, not only successfully passed comprehensive technological and operational tests at PWI and SEC WCNE, but also pilot production trials at SD «Atomenergomash», SD «DB «Atomprylad» of SC «NNEGC «Energoatom», as well as TISER Ltd. Test samples of automatic machines ADTs 627 U3.1 with welding heads ADTs 627.03.00.000 and ADTs 627.03.00.00001 have been in operation since 2010, and up to now. Results of pilot production trials are positive. At present SEC WCNE is finishing technological comprehensive and operational tests of automatic machines ADTs 628 UKhL4, ADTs 629 UKhL4 and ADTs 630 UKhL4 for GTAW of position butt joints of metal pipelines with nonconsumable electrode oscillations and mechanized filler wire feed.

\section{Conclusions}

1. Application of negative feedback by the speed of dc motor shaft rotation organized using the respective sensor (optoelectric encoder), significantly improves the static and dynamic characteristics of the drives of actuating mechanisms in automatic machines for GTAW of position butt joints of cylindrical metal pipelines (compared to sensorless drives), significantly widens the range of drive adjustment (not less than two times), improves the stability of their operation and provides the required accuracy of setting the speed of rotation of actuating mechanisms motor shafts in the above-mentioned automatic machines for GTAW.

2. It is experimentally established that the time up to complete acceleration and braking of gear motors of such mechanisms is not more than 20 and $25 \mathrm{~ms}$ (for the drive of filler wire feed mechanism it is 45 and $50 \mathrm{~ms}$, respectively), that enables functioning of GTAW automatic machines in the modes of steppulse welding (at not more than $2 \mathrm{~Hz}$ frequency) and modulated current welding with the ratio of $I_{\text {pul }} / I_{\mathrm{p}}=$ $=4 / 1$ (where $I_{\text {pul }}$ is the largest value of welding current in the pulse, and $I_{\mathrm{p}}$ is the largest value of welding current in the pause) and up to $4 \mathrm{~Hz}$ frequency.

3. The described unified reversible drive and ARAV device do not have any electromechanical switching elements, that improves the reliability of this drive and device and enables controlling switching on/off of this drive and device using logic signals in all the possible operating modes of GTAW automatic machines.

4. The ARAV device presented in this work is also unified, designed by a relatively simple electric cir- cuit, is characterized by high reliability and ensures maintaining a stable set value of arc voltage with the accuracy not worse than that of the best foreign samples of ARAV devices.

5. The developed and described reversible drive and ARAV device can be effectively used in any other units (in particular, in automatic machines and complexes) for nonconsumable electrode welding in inert gases or their mixtures, if motors or gear motors with two shaft outputs (for instance such a capability is envisaged for dc motors of DPR series) are applied in the drives of mechanisms of these units. Here, not only optoelectric sensors, but also those of other types can be used as sensors of the speed of motor shaft rotation, for instance tachogenerators or induction sensors, based on Hall effect.

In conclusion, the authors express their sincere gratitude to engineers D.S. Olianenko and V.E. Vodolazskiy for valuable assistance in fulfillment, documenting and preparing this work for publication.

1. Poloskov, S.I., Bukarov, V.A., Ishchenko, Yu.S. (2000) Influence of variations of parameters of argon-arc welding of pipe position butt joints on quality of welded joints. In: Proc. of All-Russian Sci.-Techn. Conf. on Welding and Related Technologies. MPEI, 22-25 [in Russian].

2. (1986) Equipment for arc welding: Refer. book. Ed. by V.V. Smirnov. Leningrad, Energoatomizdat [in Russian].

3. Lankin, Yu.N., Semikin, V.F., Sushy, L.F. (2010) Control of sensorless DC drives of welding machines. The Paton Welding J., 3, 24-29.

4. (2019) Product list by «Kübler». URL: http:www.kuebler. com.

5. Gladkov, E.A. (2006) Control of processes and equipment in welding: Manual for students of higher education institutions. Moscow, Akademiya [in Russian].

6. Maniktala, S. (2008) Pulse power sources from A to Z. Kiev, MK-Press; St.- Petersburg, KORONA-VEK [in Russian].

7. Gotlib, I.M. (2002) Power sources. Inverters, converters, linear and pulse stabilizers. Moscow, Postmarket [in Russian].

8. Makhlin, N.M., Korotynsky, A.E., Bogdanovsky, V.A. et al. (2011) Single- and multioperator systems for automatic welding of position butt joints of nuclear power plant piping. The Paton Welding J., 11, 28-36.

9. Makhlin, N.M., Korotynsky, A.E., Svyrydenko, A.O. (2013) Hardware-software complexes for automatic welding of position butt joints of nuclear power plants piping. Nauka ta Innovatsii, 9(6), 31-45 [in Ukrainian].

10. Bukarov, V.A. (2002) Technology of automatic shielded-gas arc welding. In: Welding in nuclear industry and power engineering: Transact. of NIKIMT. Moscow, Izdat. AT2002, 1, 149-210 [in Russian].

11. (1986) Automation of welding processes. Ed. by V.K. Lebedev, V.P. Chernysh. Kiev, Vyshcha Shkola [in Russian].

12. Korotynsky, A.E., Makhlin, N.M., Buryak, V.G., Kunkin, D.D. (2005) Universal sensor of electric parameters of welding. The Paton Welding J., 3, 49-50. 


\section{Calendar of September ${ }^{*}$}

SEPTEMBER 1, 1939 Beginning of the Second World War. Preparation to it significantly effected application of electric welding in production of all types of arms. Germany in order to circumvent peace agreement started using welded joints in the defense industry. Series of technologies, such a underwater welding, received a large development in this time. During the first years of the war volume of welding engineering in America increased more than three times due to manual electric arc welding and submerged arc welding.

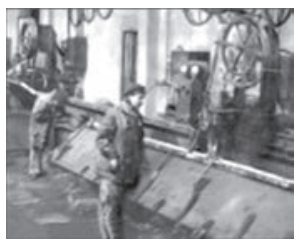

SEPTEMBER 2, 1939 «K-53», Soviet cruising diesel-electric submarine of the World War II period was set afloat. A series of novelties such as all-welded light body was used in construction of vessels. New project assumed increase of tonnage and autonomy. Basements for auxiliary and main mechanisms were made using welding. 13 ballast systems were constructed, part of which were fuel ones. Light and strong casing and erection were formed from $6 \mathrm{~mm}$ ship steel using welding.

SEPTEMBER 3, $2001 \quad$ I.M. Savich died (1927-2001). He was a representative of the Paton school. Scientific fundamentals of underwater welding and cutting were developed under his leadership. He investigated the peculiarities of arcing under conditions of high hydrostatic pressure and conditions for providing its stability at various depths, behavior of molten metal and mechanism of weld formation, peculiarities of metal to gas interaction. He participated in a series of original materials and unique equipment.
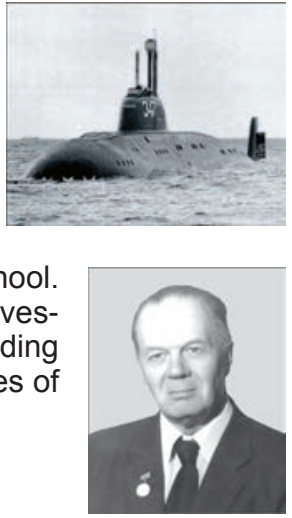

SEPTEMBER 4, 1907 Birthday of K.V. Lyubavsky (1907-1984), a well-known researcher in the field of metallurgy of welding processes, author of many consumables and technologies of arc welding. Its largest achievement in science is related with development $\mathrm{CO}_{2}$ welding. K.V. Lyubavsky became a laureate of State and Lenin Prize.

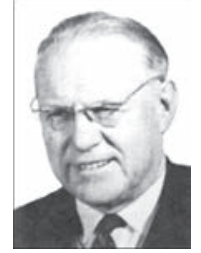

SEPTEMBER 5, 1945 American submarine of «Salmon SS-183» class made its last patrolling Submarines of this class, constructed by Porpoises Company, has new all-welded structure. A the same time, main part of engineers, employed by US government insisted on application of riveted structure of the body. As a result, «Salmon SS-183» submarines proved the relevance of application of welding in manufacture of vessel body. Thanks to this «Salmon SS-183» submarines became operational in US Navy and successfully participated in sea battles of the Second World War.

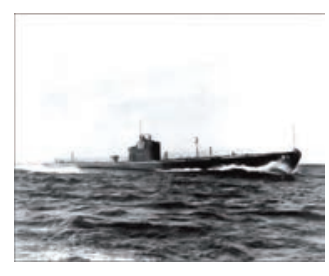

SEPTEMBER 6, 1938 Birthday of V.M. Kislitsyn (1938-2017), representative of the Paton school. Several types of water electrolytic generators, which found wide application in flame treatment of steel, copper and its alloys, precious metals, glass and other materials of thickness from tens of micrometers to several millimeters was developed with his participation for the first time in the Soviet Union.

SEPTEMBER 7, 1997 First flight of F-22 Raptor, American multipurpose fifth generation fighter aircraft, designed by Lockheed Martin, Boeing and General Dynamics Companies. New fighter aircraft was made using novel developments, including state-of-the-art avionics, new engines with digital control as well as low-observability for radars. Unique electron-beam welding unit was used in aircraft development. Electron-beam welding process allowed getting multifunctional complex in permanent form in planer design. This transfer significantly reduced the need in fastening elements, decreased structure weight and simplified assembly and cut its price.

SEPTEMBER 8, 1941 Nazi-German armed forces stated military blockade of Leningrad. Welders played a particular role in city defense. The first in the world underwater pipeline for pumping of oil products was proposed in 1942 in blockaded Leningrad. Pipeline was constructed for 43 days, length was $30 \mathrm{~km}, 21$ of them were laid on the bottom of Ladoga Lake at 1-13 m depth. Adjustment and welding of «branches» continued till June 14, 1942. Assembly of 200 meter branch pipeline was carried out on offshore construction site, and then they were joined and laid on the Ladoga Lake bottom by divers. Efficiency of pipeline (besides, it was called «Artery of life») reached $350 \mathrm{t}$ of fuel

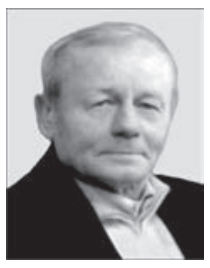
a day. There were different types of fuel, namely petrol, ligroin, diesel fuel. The pipeline was active for 20 months, during which 40 thou t of fuel was pumped through it.

\footnotetext{
*The material was prepared by the Steel Work Company (Krivoy Rog, Ukraine) with the participation of the editorial board of the Journal. The Calendar is published every month, starting from the issue of «The Paton Welding Journal» No.1, 2019.
} 
SEPTEMBER 9, 2013 Las Vegas High Roller amusement ride of $168 \mathrm{~m}$ was opened in the USA. The observation wheel is the fantastic fulfillment of achievements of machine-building and design as well as world record-holder in height. New amusement ride is equipped with 28 cabins of 6 meters diameter, each of which can include up to 40 people. External rim of «High Roller» wheel was welded from two tubular steel beam of inch thickness, then they were joined in groups of four on four beams forming rim section. Each of these elements then were joined and as a result an external wheel rim was obtained. Supporting structures were designed and constructed in the same way in order to carry tremendous load of the wheel.

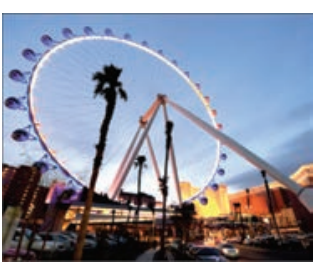

SEPTEMBER 10, 1957 Plasma cutter was patented. Plasma cutting was invented in 1954 in a laboratory of Linde department of Union Carbide Company. Young scientist Robert Gage found that TIG arc passed through small diameter nozzle significantly rises its intensity and temperature. Passing through this focused arc sufficiently large gas flow, he discovered that such arc can be used for metal cutting. Arc temperature, reaching more than $24000 \mathrm{~K}$, melts metal and intensive air flow blows out molten metal for cutting. Since gas in arc was in overheated state, called plasma, this process was named plasma cutting.

SEPTEMBER 11, 1938 Birthday of A.S. Zubchenko (11.09.1938-27.06.2017), a well-known scientist in the field of

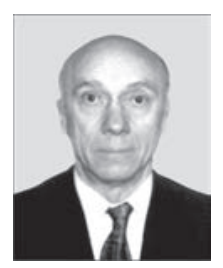
weldability, brittleness nature and development of technological high-chromium corrosion-resistant steels and consumables for their welding. For many years he was a head of large research organization, TsNIITmash, Moscow.

SEPTEMBER 12, 1935 American submarine «USS Pike (SS-173)» was set afloat. After commencing the design of «P» type vessels in 1933 the American submarine fleet started development of a new line of submarines, which improving from series to series resulted firstly in military series «Gato» and ended in 1951 by vessels of «tang» type. In comparison with vessels of type «C» increments of tonnage made $140 \mathrm{t}$ that, as a result, lead to $1310 \mathrm{t}$ tonnage. They were $8 \mathrm{~m}$ longer that made $92 \mathrm{~m}$ of length. Speed increased to 19 knots. Welded bodies of «Pike» vessels

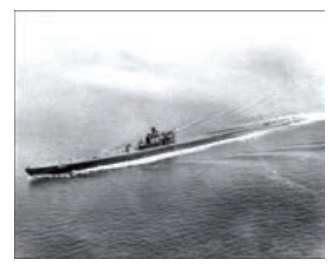
allowed their submergence to large depth and provide reliable protection from depth bombs.

SEPTEMBER 13, 1972 The patent was applied for improvement of electron beam welding by D.A. Stor. Back in November 1957 the French Committee on Nuclear Energy made first public disclosure of information on process developed by D.A. Stor, namely, on electron beam welding method, which uses a focused flow of electrons as a power source in vacuum. Regardless the complexity of joint development using such a method, EBW became frequently used in production of different types of critical products and mechanisms. It promoted high quality of weld metal and series of other technological advantages.
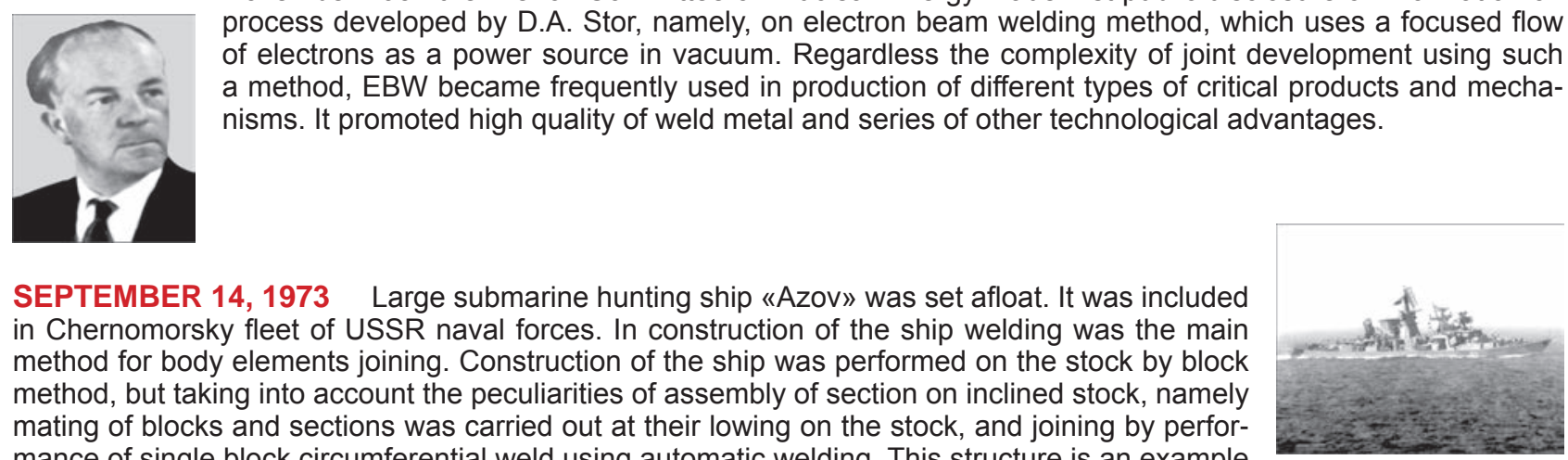

SEPTEMBER 14, 1973 Large submarine hunting ship «Azov» was set afloat. It was included in Chernomorsky fleet of USSR naval forces. In construction of the ship welding was the main method for body elements joining. Construction of the ship was performed on the stock by block method, but taking into account the peculiarities of assembly of section on inclined stock, namely mating of blocks and sections was carried out at their lowing on the stock, and joining by performance of single block circumferential weld using automatic welding. This structure is an example of reasonable application of equipment in manufacture of composite structure.

SEPTEMBER 15, 2014 Huge welding installation was developed at NASA. Vertical assembly platform is a single 170 meter welding aggregate, which was called "Vertical Assembly Center» and located inside the NASA assembly center based in New Orleans. This huge welding installation is designed for welding of lift launch vehicle tank. This development allows successful welding of parts of perspective super heavy - lift launch vehicles that are planned to be used for the most different purposes among which Mars flights.

SEPTEMBER 16, 1937 A sculpture of $25 \mathrm{~m}$ height and around $75 \mathrm{t}$ weight «Worker and Kolkhoz Woman» for Soviet Pavilion at the International Paris Exhibition was composed using electric welding at Pilot Plant TsNIITmash. Sheets of stainless steel were joined by spot welding. The sculpture was a symbol of Soviet age. The author is Vera Mukhina, conception and idea of architecture Boris lofan. 
SEPTEMBER 17, 1951 Monograph of N.N. Rykalin «Calculations of thermal processes in welding» was published. It considers the processes of heat distribution in metal heating by arc and gas flame, effect of nature of heat propagation on processes melting the electrodes and base metal as well as welding thermal cycle and structural transformations of metal.

SEPTEMBER 18, 1952 E.O. Paton Electric Welding Institute developed A-314 apparatus for electroslag welding. Electroslag welding of blast-furnace jacket at «Zaporozhstal» Plant and assembly of erection joints of E.O. Paton all-welded bridge in Kyiv was for the first time in the world practice performed using this apparatus.

SEPTEMBER 19, 1935 K.E. Tsiolkovsky (1857-1935) died in Kaluga. In 1935 scientific-technical group of Tsiolkovsky working at «Dirizhablestroy» combine near Moscow started construction of a prototype of the first all-metal airship with a shell from corrugated sheets of stainless steel of $0.1 \mathrm{~mm}$ thickness, which were joined with the help of electric welding. Soon the representative of K.E. Tsiolkovsky in «Dirizhablestroy» Ya.A. Rappoport pushed ahead an idea of buying electric welding machine for spot welding and roller contact welding of sheet metal. Works of Konstantin Tsiolkovsky attracted attention to welding technology for manufacture of flying vehicles.

SEPTEMBER 20, 1948 The first flight of Mi-1, the first Soviet multi-purpose commercial helicopter designed by M.L. Mil DB. The central part of fuselage of the helicopter is welded frame of steel tubes, to which a cabin framing is attached with fixed to it duralumin skin. In the front part of fuselage there is glass cabin. From the end of the central part of the fuselage there is all-metal tail boom with transmission beam and intermediate gearbox. In 1954 the inter-government agreement was signed on production in Poland of Mi- 1 and spare parts to it. In total 1683 helicopters of various modifications were manufactured in Poland.
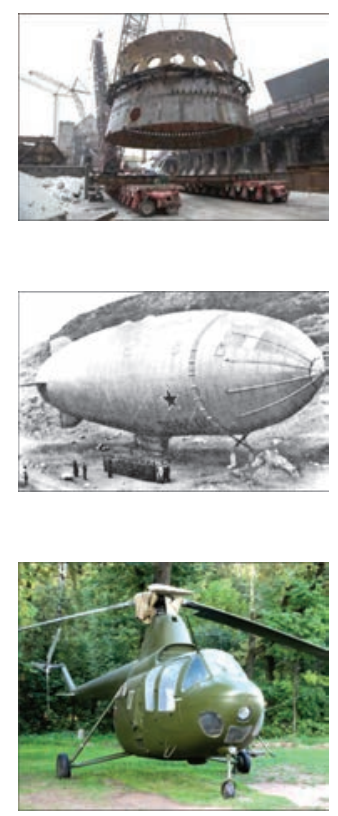

SEPTEMBER 21, 1919 Birthday of D.M. Kushnerev (1919-2002), a well-known scientist in the field of metallurgy of arc processes of welding, representative of the Paton school. His name is related with development of ceramic fluxes and organization of their commercial production. Application of such fluxes in many respects determines high quality of weld metal in automatic submerged-arc welding.
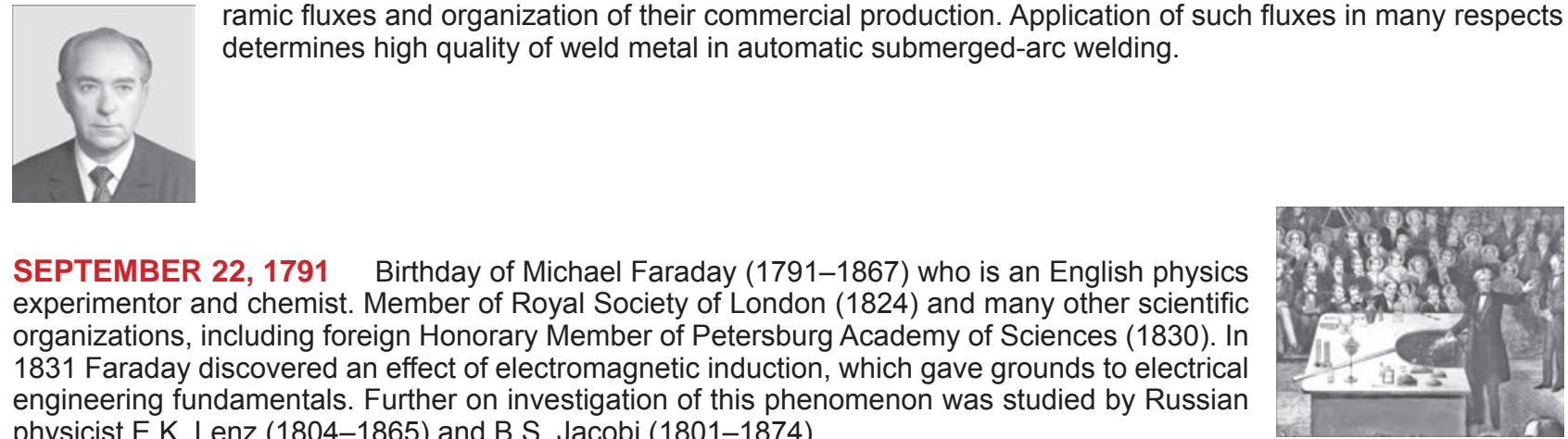

SEPTEMBER 22, 1791 Birthday of Michael Faraday (1791-1867) who is an English physics experimentor and chemist. Member of Royal Society of London (1824) and many other scientific organizations, including foreign Honorary Member of Petersburg Academy of Sciences (1830). In 1831 Faraday discovered an effect of electromagnetic induction, which gave grounds to electrical engineering fundamentals. Further on investigation of this phenomenon was studied by Russian physicist E.K. Lenz (1804-1865) and B.S. Jacobi (1801-1874).

SEPTEMBERS 23, 1969 For the first time in world practice the specialists of the E.O. Paton Electric Welding Institute carried out semi-automatic welding by composite weld of high-pressure steel pipeline at $10 \mathrm{~m}$ depth on the bottom of the Dniper River in Dnepropetrovsk region.

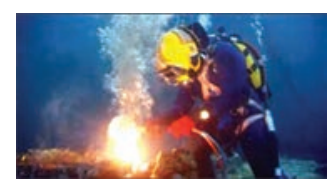

SEPTEMBER 24, 1975 Legendary AN-2 airplane transported 250 million passenger. The airplane has a series of qualities, which made it so popular, namely simplicity, reliability, possibility of operation on small flight strips. In order to simplify airplane repair under the field conditions a fuselage structure was made of steel tubes joined by welding and skin was linen. An-2 was manufactured in USSR and Poland and is still produced in PRC. In total 18 thou machines were constructed. It was recorded in the Guinness Book of World Records as a single airplane, which has been manufactured already for 60 years.

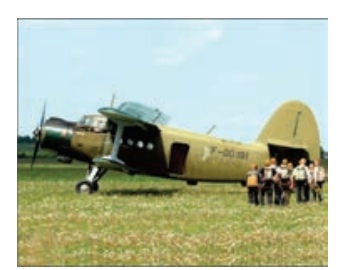


SEPTEMBER 25, 1990 Under the leadership of K.A. Yushchenko (prominent scientist, academician, representative of the Paton school) till September 1990 there was developed the scientific fundamentals of cryogenic materials science, created corresponding materials and processes of welding, which found application in manufacture of special equipment. Around 50 new grades of steels, welding wires and fluxes, developed under his leadership are used in cryogenic machine-building. They were realized in Buran, Tokamak-7, Tokamak-15 projects, space imitators and MHD-generators.

SEPTEMBER 26, 1938 Day of signature of Acceptance Certificate of Kirov cruiser, the Soviet light artillery cruiser of project 26 . The cruiser played an important role during defense of Leningrad. Electric welding, which just started to be implemented in the shipbuilding, was used in ship construction in limited scopes. The main problem which appeared was small tonnage. It was assumed, if possible, to use welding and aluminum alloys and, thus, to the maximum lighten the structures and mechanisms. The initial value of standard tonnage in $6500 \mathrm{t}$ was obviously underestimated. By initiative of V.P. Vologdin in construction of such type of ships up to $20 \%$ of all metal used in vessel body construction was welded.

SEPTEMBER 27, 1908 The first specimen of Ford Model T was built at Pickett Plant. It was also knows as "Tin Lizzie», the car was manufactured by Ford Motor Company from 1908 till 1927. It was first in the world car being manufactured by million series. Henry Ford in opinion of many people "put America on wheels», making a new passenger car comparatively available for middle class Americans. It was possible thanks to such innovations as application of conveyor instead of individual manual assembly as well as implementation of a series of new technologies for joining the parts and assemblies of car. In particular, resistance and autogenous welding were used in conveyor manufacture.

SEPTEMBER 28, 1931 Designing of three turret medium Soviet tank T-28 was started. It was developed by the engineers of Tank Tractor Design Bureau VOAO under the general leadership of S.A. Ginsburg. Tank hull is of a box form, rivet-welded or welded in models after 1940. The hull was assembled of rolled butt welded amour plates of 13-30 mm thickness. Frames of engine, primary gear, fan and gearbox were welded to the bottom of hull along the engine compartment.

SEPTEMBER 29, 1940 Birthday of L.M. Lobanov, prominent scientist, academician, representative of the Paton school. His works dedicated to methods of optical modelling, holography, electron speckle-interferometry and stereography for evaluation of stressed state and quality control of welded joints in the structures of metallic, composite and polymer materials received wide recognition. Developed methodological approaches and devices have high accuracy and information content. His works allowed forming new scientific direction, namely deformation-free welding of structures.

SEPTEMBER 30, 1964 American engineer Gaspar Kazlauskas, a staff member of North American Aviation Company got a task to develop a welding apparatus for pipe welding. As a result he patented his own invention - orbital welding head. Application of this device is related with wide use of tubular structures in modern industry.

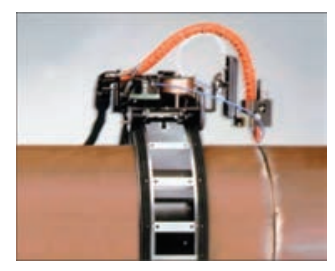

